Maria Paula Ferreira

\title{
Assistência à Saúde nos Departamentos Regionais de Saúde: um exercício metodológico sobre eficiência e acesso aos serviços de saúde
}

Tese apresentada à Faculdade de Medicina da Universidade de São Paulo para obtenção do título de doutor em Ciências

Área de concentração: Medicina Preventiva Orientador: Prof ${ }^{\mathrm{a}} \mathrm{Dr}^{\mathrm{a}}$ Ana Luiza d'Ávila Viana 
Para meu pai, José Apparecido

(in memorian) 


\section{Agradecimentos}

Os meus agradecimentos à prof ${ }^{\mathrm{a}}$ Ana Luiza d'Ávila Viana, pela orientação e apoio durante todo o processo de trabalho. Aos professores Paulo Eduardo Mangeon Elians, Amélia Cohn e Paulo de Martino Jannuzzi, pelas valiosas sugestões dadas ao trabalho durante o exame de qualificação. À Fundação Seade, na pessoa da dra. Felícia Reicher Madeira, pelo apoio e cessão dos dados da Pesquisa de Condições de Vida. À Nádia Pinheiro Dini, por sua amizade, apoio e principalmente paciência. Aos meus colegas de trabalho da Gemet, em especial Elaine, Ana Lúcia, Mitti, Marcelo e Gustavo, pela disponibilidade e interesse nas discussões sobre o trabalho. À Icléia, Tânia e Vania, pela editoração e revisão do texto, o que propiciou à tese um ganho em qualidade. Por fim, à Iramaia Luvizotto Colaiacovo, que, ao permitir a utilização dos dados sobre gastos em saúde realizados pelo tesouro estadual, contribuiu para o enriquecimento do trabalho. 


\section{Sumário}





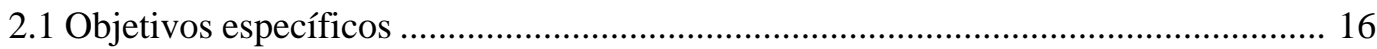

3. Métodos e referencial teórico …............................................................................... 17

3.1 Acesso aos serviços de saúde............................................................................ 17

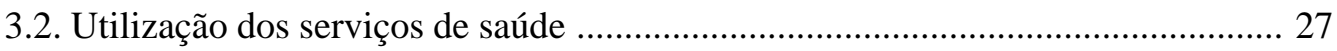

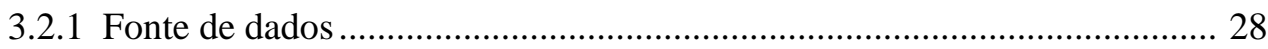

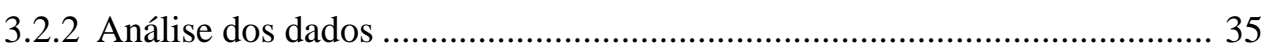

3.2.2.1 Modelo - Condição de utilização de serviços de saúde .................. 41

3.2.2.2 Modelo - Tipo de serviço utilizado ................................................. 45

3.2.3 Variáveis utilizadas no estudo ................................................................. 48

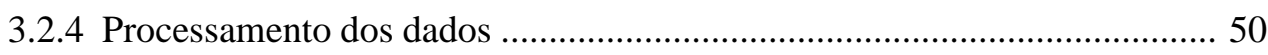

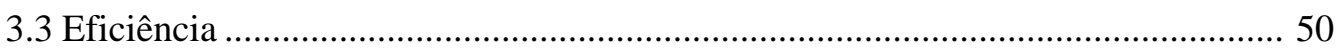

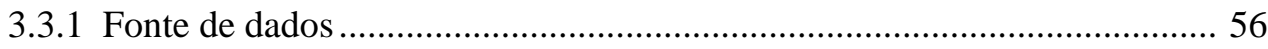

3.3.2 O modelo de eficiência técnica ................................................................ 60

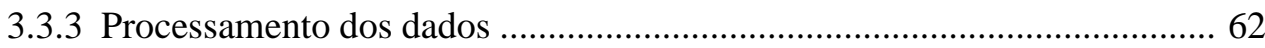

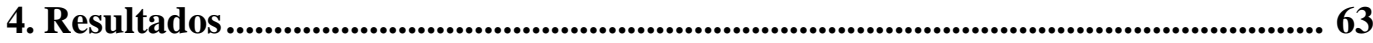

4.1 Procura de serviços de saúde ............................................................................... 69

4.1.1 Tipo de estabelecimento procurado ....................................................... 72

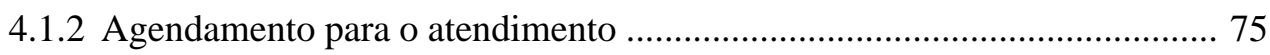

4.1.3 Posse de planos ou convênios médicos .................................................. 77

4.2 Padrão de utilização dos serviços de saúde ........................................................ 79

4.3. Padrão de utilização do Sistema Único de Saúde - SUS ........................................ 89

4.4 Eficiência na utilização dos serviços de saúde ....................................................... 93

5. Discussão .................................................................................................................................. 101

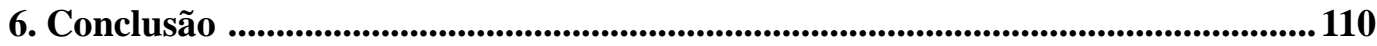

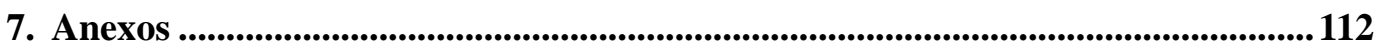

Anexo 1 - Departamentos Regionais de Saúde ........................................................113

Anexo 2 - Distribuição da amostra de Pesquisa de Condições de Vida - PCV nos Departamentos Regionais de Saúde - DRS ....................................... 120

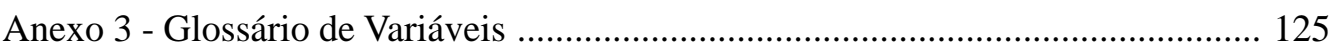

Anexo 4 - Medidas de ajuste dos modelos de regressão logística



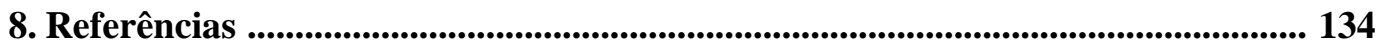

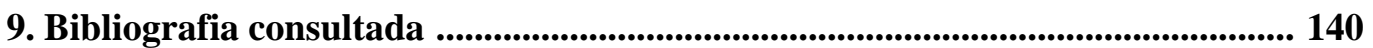




\section{Listas de figuras, gráficos, tabelas}

\section{Lista de Figuras}

Figura 1 - Possíveis Áreas para o Conceito de Acessibilidade ....................................... 19

Figura 2 - Diagrama da estrutura dos dados em um modelo de três níveis ..................... 37

Figura 3 - Modelo empírico de eficiência ..................................................................... 93

\section{Lista de Gráficos}

Gráfico 1 - Pessoas que utilizaram serviços de saúde nos últimos 30 dias, segundo faixa etária. Estado de São Paulo. 2006.

Gráfico 2 - Exemplo da relação entre despesas totais em saúde (input) e produção ambulatorial (output) pressuposta nos modelos CCR e BCC

Gráfico 3 - Razão entre o total da produção ambulatorial de média e alta complexidades e o total da produção ambulatorial de média e alta complexidades entre os residentes no DRS, segundo Departamento Regional de Saúde. Estado de São Paulo. 2008.

Gráfico 4 - Índices de envelhecimento e de feminilidade, segundo Departamentos Regionais de Saúde. Estado de São Paulo. 2006.

Gráfico 5 - Distribuição dos municípios segundo o Índice Paulista de Responsabilidade Social - IPRS, por Departamento Regional de Saúde - DRS. Estado de São Paulo. 2006.

Gráfico 6 - Intervalo de Confiança de 95\% para o porcentual de pessoas de 15 anos e mais que utilizaram serviços de saúde nos últimos 30 dias, segundo Departamentos Regionais de Saúde - DRS. Estado de São Paulo. 2006

Gráfico 7 - Intervalo de Confiança de 95\% para o porcentual de pessoas de 15 anos e mais que utilizaram SUS, segundo Departamentos Regionais de Saúde - DRS. Estado de São Paulo. 2006

Gráfico 8 - Intervalo de Confiança de 95\% para proporção de beneficiários de planos e convênios médicos, segundo Departamentos Regionais de Saúde - DRS. Estado de São Paulo. 2006

Gráfico 9 - Intervalo de Confiança de 95\% para a taxa de utilização do SUS entre os beneficiários de planos e convênios médicos, segundo Departamentos Regionais de Saúde - DRS. Estado de São Paulo. 2006.

Gráfico 10 - Intervalo de Confiança de 95\% para a taxa de utilização do SUS entre os beneficiários de planos e convênios médicos, segundo tipo de estabelecimento procurado. Estado de São Paulo. 2006

Gráfico 11 - Razão de vantagem para condição de utilização dos serviços de saúde, segundo faixa etária e escolaridade. Estado de São Paulo. 2006 .. 84

Gráfico 12 - Razões de vantagem para condição de utilização dos serviços de saúde, segundo porcentual de beneficiários de planos e convênios médicos no DRS e porcentual de população cadastrada no PSF no DRS. Estado de São Paulo. 2006

Gráfico 13 - Dispersão entre o porcentual de beneficiários de planos e convênios médicos no DRS e porcentual de população cadastrada no PSF no DRS. Estado de São Paulo. 2006.

Gráfico 14 - Dispersão entre o porcentual de pessoas que utilizaram serviços de saúde e o número de médicos por mil habitantes no DRS. Estado de São Paulo. 2006 


\section{Lista de Mapa}

Mapa 1 - Departamentos Regionais de Saúde segundo eficiência puramente técnica e utilização do SUS. Estado de São Paulo. 2006.

\section{Lista de Quadro}

Quadro 1 - Variáveis utilizadas no estudo

\section{Lista de Tabelas}

Tabela 1 - Distribuição da população, por coeficiente de variação e taxa de urbanização, segundo Departamento Regional de Saúde.

Estado de São Paulo. 2006

Tabela 2 - Porcentual de beneficiários de planos e convênios de saúde, erro padrão e intervalo de confiança, por fonte de dados, segundo Departamento Regional de Saúde. Estado de São Paulo. 2006

Tabela 3 - Tamanho das amostras utilizadas na construção dos modelos de regressão logística multiníveis. Estado de São Paulo. 2006

Tabela 4 - Produção ambulatorial, número de internações, segundo Departamento Regional de Saúde - DRS. Estado de São Paulo. 2006

Tabela 5 - Despesas em saúde, leitos SUS e médicos por mil habitantes, segundo Departamento Regional de Saúde - DRS. Estado de São Paulo. 2006.

Tabela 6 - Matriz de correlação de Pearson entre inputs e outputs para o modelo de eficiência

Tabela 7 - Componentes do modelo de análise envoltória de dados - DEA, segundo Departamentos Regionais de Saúde. Estado de São Paulo. 2006

Tabela 8 - $\quad$ Número de municípios e população, segundo Departamentos Regionais de Saúde - DRS. Estado de São Paulo. 2006.

Tabela 9 - Distribuição da população de 15 anos e mais, por faixa etária, segundo Departamentos Regionais de Saúde - DRS. Estado de São Paulo. 2006

Tabela 10 - Distribuição das pessoas de 15 anos e mais que utilizaram serviços de saúde nos últimos 30 dias, segundo tipo de estabelecimento procurado e situação de pagamento. Estado de São Paulo. 2006.

Tabela 11- Proporção das pessoas de 15 anos e mais que utilizaram posto ou centro de saúde do SUS nos últimos 30 dias, segundo Departamentos Regionais de Saúde - DRS. Estado de São Paulo. 2006

Tabela 12 - Proporção das pessoas de 15 anos e mais que utilizaram serviços de saúde nos últimos 30 dias e que realizaram agendamento, segundo tipo de estabelecimento procurado e situação de pagamento. Estado de São Paulo. 2006

Tabela 13 - Distribuição das pessoas de 15 anos e mais e proporção que utilizaram serviços de saúde, segundo variáveis explicativas individuais. Estado de São Paulo. 2006

Tabelas 14 - Estimativas referentes à parte fixa dos modelos de regressão logística com efeitos mistos para condição de utilização de serviços de saúde. Estado de São Paulo. 2006

Tabelas 15 - Estimativas referentes à parte fixa do modelo de regressão logística com efeitos mistos para tipo de serviço de saúde utilizado. Estado de São Paulo. 2006

Tabela 16 - Valor mediano da probabilidade marginal de utilização do SUS entre pessoas de 15 anos e mais dado o modelo de regressão logística de efeitos mistos, segundo Departamentos Regionais de Saúde. Estado de São Paulo. 2006 
Tabela 17 - Eficiência técnica e puramente técnica, segundo Departamentos Regionais de Saúde - DRS’s. Estado de São Paulo. 2006

Tabela 18 - População, despesa per capita em saúde, participação de procedimentos de média e alta complexidades no total dos procedimentos ambulatoriais, número de procedimentos ambulatoriais e internações, segundo Departamentos Regionais de Saúde. Estado de São Paulo. 2006

Tabela 19 - Proporção da população que utilizou serviços de saúde e que utilizou o Sistema Único de Saúde nos últimos 30 dias, segundo grupos de DRS.

Estado de São Paulo. 2006 98

Tabela 20 - População, despesa per capita em saúde, participação dos gastos estaduais no total das despesas em saúde, participação dos procedimentos de média e alta complexidades no total dos procedimentos ambulatoriais e internações por mil habitantes, segundo grupos de DRS.

Estado de São Paulo. 2006 
Ferreira MP. Assistência à Saúde nos Departamentos Regionais de Saúde: um exercício metodológico sobre eficiência e acesso aos serviços de saúde. São Paulo; 2009. [Tese de doutorado - Faculdade de Medicina da Universidade de São Paulo].

Objetivos. Avaliar as condições do acesso aos serviços de saúde da população residente no Estado de São Paulo, e da eficiência na utilização dos recursos para a produção ambulatorial e hospitalar do SUS, segundo os Departamentos Regionais de Saúde DRS. Métodos. O estudo baseou-se em dois parâmetros. O primeiro foi a utilização de dados já existentes, ou seja, as informações disponíveis sobre o tema em bancos de dados públicos: tanto registros administrativos como pesquisas domiciliares. O segundo parâmetro foi o emprego de métodos quantitativos que permitissem a inferência sobre as condições do acesso e eficiência para os Departamentos Regionais de Saúde do Estado de São Paulo. Para a análise do acesso aos serviços de saúde utilizaram-se modelos de regressão logística com efeitos mistos e a análise de eficiência foi realizada a partir da aplicação da técnica de Análise Envoltória de Dados - DEA. Resultados. No Estado de São Paulo, a heterogeneidade das condições econômicas, sociais e demográficas existentes nas diferentes regiões do Estado não se reflete na condição de procura e utilização dos serviços de saúde, mas no grau de dependência de suas populações ao Sistema Único de Saúde. O PSF é um fator que aumenta a probabilidade de utilização dos serviços de saúde, particularmente do SUS, pela população e, a condição de posse do plano de saúde não é garantia para o atendimento. Entre os departamentos eficientes encontram-se tanto aqueles que agregam municípios produtores de serviços de saúde de média e alta complexidade, quanto os DRS's caracterizados pela produção ambulatorial em atenção básica, em especial programas específicos na área da atenção básica. Conclusões. Os resultados obtidos mostram um Estado de São Paulo menos desigual quanto ao acesso aos serviços de saúde, quando se consideram os resultados de estudos sobre utilização de serviços de saúde realizados a partir das bases de dados da PNAD para os anos 1998 e 2003. A ação do SUS mostra-se de acordo como a diretriz de equidade prevista na Lei Orgânica da Saúde. A eficiência na produção de saúde é observada em diferentes contextos relacionados aos SUS, dado que ocorre tanto nos departamentos em que o setor privado é um simples coadjuvante quanto naqueles em que o setor privado é responsável por importante segmento do setor saúde.

Descritores: Avaliação em Saúde. Acesso. Eficiência. Utilização dos Serviços de Saúde. 


\section{SUMMARY}

Ferreira MP. Health Assistance in the Health Regional Departments: a methodological exercise about efficiency and access to the health services. São Paulo; 2009. [Tese de doutorado - Faculdade de Medicina da Universidade de São Paulo].

Objectives. To evaluate the conditions of access to the health services of population living in São Paulo State, and evaluate the efficiency in the use of resources to the production of Sistema Único de Saúde - SUS, according to the Health Regional Departments - HRD. Method. The study was based on two parameters. The first one was the use of pre existing data, that is, accessible information about this issue in public data warehouse: administrative registers and also housing surveys. The second parameter was the use of quantitative methods which would permit the inference about conditions of access and efficiency to the Health Regional Departments of São Paulo State. To the analysis of access to the health services was used logistic regression models with mixed effects and the efficiency analysis was done applying the Data Envelopment Analysis - DEA. Results. In São Paulo State, the heterogeneity of economical, social and demographic conditions that exist in the different regions does not reflect in the condition of search and use of health services but does reflect in the dependency level of São Paulo population of SUS. The PSF is a factor that increases the probability of population use of health services, specially SUS, and having a health plan is not a guarantee of attendance. Among the efficient departments are that ones which gather cities that are producers of medium and high complexity health services and the HRD that produce basic attention, in special, specific programs in the basic attention field. Conclusion. Results show a less uneven São Paulo State in respect to access to the health services when considering results of studies about the use of health services done with 1998 and 2003 PNAD data warehouse. SUS action is accordingly with the equality guideline expected in the Organic Health Law. The efficiency in the health production is observed in a variety of context related to SUS, what occurs not only in the departments where the private sector is a simple auxiliary but also in the ones where the private sector is the responsible for an important segment of health sector.

Descriptors: Evaluation in Health. Access. Efficiency. Use of Health Services. 


\section{INTRODUÇÃO}

No

Brasil, nas décadas de 1980 e especialmente 1990, ocorreram importantes transformações econômicas, sociais e políticas, com mudanças da ação do Estado nas políticas econômicas e sociais e nos perfis epidemiológicos e demográficos da população. ${ }^{1}$ No âmbito das políticas sociais, destacam-se os processos de descentralização da execução das políticas, o crescimento do controle das ações e gastos públicos e a expansão das políticas sociais focalizadas vis à vis a redução dos recursos disponíveis. Ferlie et al. (1999) analisaram o processo de reformas vivido pela organização e administração dos serviços públicos ingleses na década de 1980, classificando-o a partir de quatro diretrizes: impulso para a eficiência (que consiste em transpor para o setor público os mesmos padrões de eficiência utilizados no setor privado); maior controle financeiro (desenvolvimento de sistemas de controle de custos e de monitoramento); downsizing e descentralização (processo de terceirização dos serviços); e busca pela excelência, segundo os padrões do setor privado.

Nesse contexto, de redução de recursos disponíveis e mudança do perfil epidemiológico e demográfico da população, foi criado o sistema nacional de saúde -

\footnotetext{
${ }^{1}$ Quanto às mudanças no perfil demográfico e epidemiológico, observa-se ao longo das décadas de 1990 e 2000 o processo de envelhecimento populacional, ou seja, a maior participação relativa de pessoas mais idosas - 60 anos e mais - na população em detrimento dos mais jovens - menores de 14 anos, além do aumento das doenças crônicas e degenerativas e da diminuição das infecto-contagiosas (FUNDAÇÃO SEADE, 2005).
} 
Sistema Único de Saúde (SUS) -, com o objetivo de atender o principio de universalidade na cobertura e no atendimento estabelecido pela Constituição Federal de $1988 .{ }^{2}$

A busca pela eficiência na área das políticas sociais e, principalmente, o controle das ações e de gastos geraram a necessidade de constante monitoramento e avaliação do desempenho e dos resultados alcançados pela ação pública, com a devida periodicidade e qualidade.

Deve-se destacar, ainda, que as agências financiadoras internacionais, como Banco Mundial e Banco Interamericano de Desenvolvimento - BID, recomendam nos termos de referências dos projetos o módulo referente a avaliação e monitoramento. No sítio do Banco Mundial, no documento que descreve o ciclo de um projeto a ser financiado - Project Cycle -, a etapa da avaliação é considerada como uma das seis fases que compõem o projeto. Sua execução é prevista para ocorrer após a finalização do projeto, sendo realizada por um grupo de avaliadores independentes do banco, que irão verificar se os objetivos do projeto foram alcançados (BANCO MUNDIAL, 2006). Para o BID, o componente de avaliação de um projeto faz parte de suas políticas operativas generales, denominando-se avaliação ex post das operações, e tem por objetivo verificar se foram alcançados os objetivos do projeto, bem como a eficiência com que isso ocorreu (BID, 2009). ${ }^{3}$

\footnotetext{
${ }^{2}$ A partir da Lei Orgânica da Saúde (Lei 8.080/90) - que estabeleceu as atribuições e competências de cada nível de governo no âmbito do SUS - coube aos Estados a responsabilidade pela promoção da descentralização dos serviços e ações de saúde, com a prestação do apoio técnico e financeiro aos municípios. Entre suas atribuições estão, principalmente, acompanhamento, controle e avaliação das redes hierarquizadas do SUS, bem como a gestão dos sistemas públicos de alta complexidade, de referência regional e estadual. Os municípios tornaram-se responsáveis pelo gerenciamento e execução dos serviços públicos de saúde locais.

${ }^{3}$ Os endereços eletrônicos do Banco Mundial e BID são respectivamente <http://web.worldbank.org> e $<$ http://www.iadb.org $>$.
} 
Ala-Harja e Helgason (2000), ao analisarem o papel da avaliação de programas nas reformas do setor público ocorridas em países da Organização para a Cooperação e o Desenvolvimento Econômico - OCDE, afirmam que, a partir dos anos 1980, as atividades relacionadas à avaliação foram estimuladas por governos predominantemente conservadores, na tentativa de equacionar a questão das políticas públicas em face das limitações fiscais. Assim, as atividades de avaliação constituíam uma ferramenta para a racionalização dos recursos orçamentários e uma justificativa para reformulação das políticas públicas. Porém, desde então, a avaliação é utilizada para o fortalecimento da legitimidade do setor público, pois possibilita uma "prestação de contas” das ações governamentais. Os autores citam ainda, como uma nova vertente nessa área, a metaavaliação, em que se avalia a própria avaliação.

Para Thoenig (2000), as atividades de avaliação, apesar de estarem mais presentes em países onde as reformas do setor público foram mais amplas, não são necessariamente características de certo tipo de Estado ou cultura administrativa. Para o autor pode-se entender avaliação “como uma atividade que é relativamente limitada no seu alcance, focaliza problemas claramente definidos, emprega uma linguagem que os formuladores de políticas conseguem compreender, utiliza dados disponíveis mesmo que eles não sejam perfeitos e descreve um estado de coisas mais do que o analisa” (THOENIG p. 60, 2000).

No setor de saúde, os estudos de avaliação de programas e serviços de saúde tiveram início nos anos 1990 (HARTZ, 1997), contribuindo para o incremento da discussão sobre o tema avaliação no Brasil, que vai além do papel da avaliação como ferramenta 
de caráter técnico a ser utilizada para legitimar as políticas governamentais num cenário de cortes e restrições orçamentárias. Nesse debate encontram-se a ampliação dos direitos civis advindos da Constituição de 1988, a criação do Sistema Único de Saúde - SUS e a crescente importância da política de saúde, que colocam constantemente na agenda pública as questões sobre a qualidade dos serviços prestados (FURTADO, 2008). Devese destacar que Ala-Harja e Helgason (2000) mencionam esse novo papel da avaliação para o setor público em geral.

Ainda na ótica do uso das avaliações para a legitimação de cortes de gastos e reformas estruturais na área da saúde, Viacava et al. (2004, apud HURST, 2004) destacam que a avaliação pode se tornar um instrumento na busca da eficiência técnica do atendimento ao “consumidor” e não mais ao “usuário”, no entanto ela em si é desejável, pois uma questão importante é ter como perspectiva o fato de que o processo de avaliação pode auxiliar a impulsionar mudanças de comportamentos que impliquem melhores resultados.

Nessa linha, Felisberto (2004) e Hartz (2002) argumentam que a busca por mudanças de comportamentos que acarretem melhores resultados passa pela institucionalização da avaliação na rotina dos serviços de saúde, com a inclusão de ações de avaliação e monitoramento como suporte no planejamento e na gestão da atenção básica. Para os autores, ao se utilizarem, nos diversos níveis do sistema de saúde, as informações produzidas rotineiramente com caráter avaliativo e de monitoramento, é possível mudar comportamentos para serem atingidos melhores resultados. Uma medida nesse sentido é a disponibilização pelo Ministério da Saúde, 
em meio eletrônico e também em consulta pública na Internet, de diversos sistemas de informações que permitem acompanhar o desempenho do Sistema Único de Saúde SUS. $^{4}$

Quanto à abordagem das avaliações realizadas no Brasil, destaca-se o que Worthen et al. (2004), denominam de avaliação centrada nos objetivos, ou seja, cujo interesse do estudo é verificar em que medida as metas e os objetivos predeterminados foram alcançados. Novaes (2000) afirma que as principais questões que orientam as avaliações referem-se aos impactos causados pelas ações previamente planejadas, ou seja, estabelecem-se relações de casualidade entre ações planejadas e/ou executadas e os resultados alcançados (ou as alterações observadas ao final da intervenção).

Worthen et al. (2004), partindo do pressuposto de que a avaliação pode ser realizada em diferentes fases do desenvolvimento de um programa e que, dependendo da fase, o mesmo modelo de avaliação pode ser classificado de diversas maneiras, propõem outras cinco classificações para os modelos de avaliação: centrada na administração, em que se pretende identificar as necessidades de informações dos gestores responsáveis pela tomada de decisão; centrada no consumidor, em que se propõe fornecer informações para consumidores referentes a escolhas de diferentes produtos, serviços e outros bens; centrada em especialistas, que consiste na utilização de profissionais especializados que fazem uso de seu conhecimento para julgar a qualidade de qualquer atividade que esteja sendo avaliada; centradas no adversário, que consiste em oferecer um exame

\footnotetext{
${ }^{4}$ Entre as informações produzidas pelo sistema de saúde estão o Sistema de Informação Ambulatorial SIA/SUS, o Sistema de Informações Hospitalares - SIH/SUS, o Sistema de Informação da Atenção Básica - Siab, o Cadastro Nacional de Estabelecimentos de Saúde - CNES, o Sistema de Informação sobre Orçamentos Públicos em Saúde - Siops, entre outros.
} 
equilibrado de questões controvertidas ouvindo todos os lados; centrada no participante, que pretende compreender e retratar as características de uma determinada atividade, respondendo à necessidade de informação de determinado público.

Segundo Worthen et al. (2004) essas categorias têm alguma correspondência com a forma como House (1983) classificou as dimensões da avaliação: entre utilitarista e intuicionista-plurarista. Na ótica da avaliação utilitarista busca-se identificar o fator que beneficia a maioria do grupo afetado por determinado programa ou ação, enquanto na de cunho intuicionista-plurarista tenta-se identificar o impacto das ações ou programas no indivíduo. As avaliações utilitaristas são usualmente empregadas em programas sociais de grande porte relativos às áreas da assistência social, saúde e educação. Entre estas avaliações incluem-se aquelas centradas nos objetivos e na administração e, entre as intuicionistas-pluraristas encontra-se a avaliação focada no participante. Furtado (2006) afirma que as avaliações voltadas para os objetivos e a administração são utilitaristas porque se caracterizam pela importância dada à efetiva utilização da avaliação pelos atores encarregados de tomar decisões.

Já as metodologias utilizadas nos estudos de avaliações seguem, na maioria dos casos, aquelas desenvolvidas nos Estados Unidos para avaliação de programas (WORTHEN et al., 2004; ROSSI et al. 2004; BAKER, 2000). Apesar da crescente participação dos métodos qualitativos, principalmente nos anos 2000, ainda observa-se a importância dos métodos quantitativos, principalmente nas avaliações de programas governamentais. No entanto, independentemente do método de pesquisa utilizado, o enfoque da avaliação continua a ser predominantemente os objetivos, pois a simples 
utilização de métodos qualitativos, como por exemplo entrevistas, grupos focais e outros, não estabelece por si só o enfoque na avaliação. ${ }^{5}$

No sentido de contribuir para o debate em relação aos estudos de avaliação na área da saúde e partindo do pressuposto de que o objetivo da avaliação é fornecer conhecimento utilizável (ROSSI 2004 apud CRONBACH, 1980), realizou-se um exercício metodológico referente à avaliação de determinados aspectos do sistema de saúde do Estado de São Paulo sob uma ótica regional, uma vez que, em um cenário de planejamento regional da atenção à saúde, tal como o estabelecido pelo Pacto pela Saúde $^{6}$ (BRASIL, 2006), a avaliação das diversas ações que configuram a política de saúde, tais como sua formulação, implantação e decisões tomadas, torna-se elemento central na agenda do gestor estadual.

A opção pela análise regional deveu-se ao cenário propiciado pelas diretrizes do Pacto pela Saúde (BRASIL, 2006), que, a partir de 2006, iniciou um novo momento da regionalização do SUS, com a definição das responsabilidades de cada nível de gestão e a criação dos Colegiados de Gestão Regional (HEIMANN et al., 2007),

\footnotetext{
${ }^{5}$ Entre os estudos de avaliação realizados nos últimos anos que utilizam métodos qualitativos e quantitativos com a adoção de desenhos quase-experimentais estão: a pesquisa de Avaliação de Impacto do Bolsa-Família, realizada pelo Ministério do Desenvolvimento Social - MDS e atualmente em sua segunda tomada de campo; a pesquisa de avaliação do Programa de Expansão e Consolidação da Saúde da Família - PROESF, realizada pelo Consórcio Medicina/USP, em 2005 e 2006; e a pesquisa sobre o Impacto da Linha 4 do Metrô de São Paulo sobre as condições de vida da população ali residente, realizada pela Fundação Seade e Companhia do Metrô de São Paulo, com prazo de término para 2010; além de outros com o objetivo específico de avaliação.

${ }^{6}$ O Pacto pela Saúde foi estabelecido a partir da definição de prioridades articuladas e integradas entre os gestores do SUS, nos níveis municipal, estadual e federal, tendo entre seus componentes o Pacto pela Vida, o Pacto em Defesa do SUS e o Pacto de Gestão do SUS. Os autores envolvidos em sua elaboração foram o Ministério da Saúde e representantes dos gestores estaduais e municipais - Conselho Nacional de Secretários Estaduais de Saúde (CONASS) e Conselho Nacional de Secretários Municipais de Saúde (CONASEMS).
} 
fazendo com que a regionalização passe a ter um caráter mais político do que técnico (VIANA et al., 2008).

O Pacto pela Saúde estabelece novos instrumentos para a regionalização e reafirma os existentes: Plano Diretor de Regionalização - PDR; Plano Diretor de Investimento - PDI; e Programação Pactuada Integrada - PPI. Foram criadas as regiões e macrorregiões de saúde. As primeiras respondem pela suficiência na atenção básica, por parte das ações de média e alta complexidades e ações básicas de vigilância em saúde. Já as macrorregiões agregam as regiões e organizam as ações de média e alta complexidades na atenção à saúde. Para São Paulo, têm-se 64 regiões de saúde e 17 macrorregiões de saúde denominadas de Departamentos Regionais de Saúde - DRS.

Nesse contexto de descentralização do sistema de saúde por meio de uma ótica regional, torna-se relevante o desenvolvimento de instrumentos de avaliação que permitam a realização de análises regionalizadas a partir de informações já existentes, produzidas e disponibilizadas rotineiramente pelas instituições gestoras do sistema de saúde, ou por outros órgãos públicos, além de se considerar tanto o setor público quanto o privado na área da saúde.

O desenvolvimento desse tipo de análise é especialmente importante para o Estado de São Paulo, dado seu porte populacional, suas características econômicas, bem como o tamanho e a complexidade do setor saúde no Estado, que constitui o mais complexo sistema de saúde do Brasil, englobando o maior mercado consumidor de serviços suplementares e equipamentos de saúde, com grande concentração de investimentos 
na área de ciência e tecnologia. Isso faz com que o sistema de saúde de São Paulo seja característico do mix público-privado (VIANA et al., 2008).

Dois aspectos do sistema de saúde foram selecionados para a análise: as condições do acesso aos serviços de saúde; e a eficiência na utilização dos recursos na produção ambulatorial e hospitalar do SUS.

No paradigma proposto por Viacava et al. para avaliação do sistema de saúde o componente acesso, como analisado no presente estudo, pode ser considerado como um dos fatores elencados pelos autores como responsáveis pelo desempenho do sistema de saúde, sendo expresso por eles como a capacidade das pessoas em obter os serviços necessários no lugar e momento certo (VIACAVA et al. p. 721), 2000). Os demais componentes são: aceitabilidade, o respeito ao direito das pessoas, a continuidade na prestação dos serviços e a adequabilidade dos serviços prestados em termos do conhecimento técnico-cientifico existente, a segurança do sistema em evitar ou minimizar os riscos aos seus usuários; sua efetividade; e eficiência definida pelos autores como relação entre o produto da intervenção de saúde e os recursos utilizados (VIACAVA et al. p. 721).

A eficiência tal como medida no presente estudo pode ser entendida pelo que Donabedian (1992) denomina eficiência de produção, ou seja, a produção de serviços de forma mais eficiente. Apesar de não considerar a eficiência de produção em sua definição de qualidade ${ }^{7}$ Donabedian (1992) reconhece a importância central dessa

\footnotetext{
${ }^{7}$ Donabedian (1990) denomina os sete pilares da qualidade dos serviços de saúde como: eficácia, eficiência, efetividade, otimização, aceitabilidade, legitimidade e equidade, sendo que por eficiência entende-se eficiência clínica (a medida do custo com o qual uma dada melhora nas condições de saúde são alcançadas). Nesse enfoque. os dados desejáveis para avaliação de uma determinada ação referemse ao contexto (ou condições estruturais) em que se insere a ação, aos processos que definem e influenciam as ações e ao resultado da ação.
} 
medida na organização dos sistemas de saúde, uma vez que o aumento da eficiência de produção permite a manutenção da qualidade dos serviços a custos menores. Esse conceito pode ser definido, ainda, como eficiência técnica, já que para Shiell et al. (2005) a eficiência técnica refere-se a maximização dos resultados dado certas quantidades de recursos, ou ao contrário, como manter os resultados no nível atual minimizando os recursos.

No âmbito do acesso foram caracterizadas as diferenças regionais em relação à proporção da população que utiliza serviços de saúde e identificados os fatores que dificultam a utilização de tais serviços. Para o caso específico do SUS, averiguou-se também a diretriz referente à equidade, ou seja, o SUS está de fato atendendo aos indivíduos segundo suas necessidades de saúde, independentemente de atributos pessoais, culturais e socioeconômicos.

Para a eficiência técnica estimou-se, por meio de programação linear, uma razão de eficiência técnica para cada Departamento Regional de Saúde - DRS, referente à relação entre o total de sua produção ambulatorial e hospitalar e os recursos despendidos para alcançar tal nível de produção, sendo que nesse caso apenas serão consideradas as informações referentes ao SUS. Assim, matematicamente essa razão pode ser expressa como: E=Produção/Recursos.

Metodologicamente, o estudo baseou-se em dois parâmetros: a utilização de dados já existentes, ou seja, as informações disponíveis sobre o tema em bancos de dados públicos (tanto registros administrativos como pesquisas domiciliares); e o emprego de 
métodos quantitativos que permitissem a inferência sobre as condições do acesso e eficiência para os Departamentos Regionais de Saúde do Estado de São Paulo.

A opção por dados existentes baseou-se no fato de que já estavam disponíveis fontes de informações confiáveis, padronizadas, com série histórica e a abrangência geográfica necessária. Como afirmam Whorthen et al (2004), nem toda pergunta deve ser respondida por meio de coleta de informações originais, devendo-se apenas selecionar o dado adequado ao seu problema, sem cometer o "erro tipo III”, que consiste em responder a pergunta errada.

Assim, todos os dados utilizados, de natureza amostral e registros administrativos, estão disponíveis na Internet. Os dados amostrais são provenientes da Pesquisa de Condições de Vida - PCV, que consiste em levantamento por amostra de domicílios realizada na área urbana no Estado de São Paulo pela Fundação Seade em 2006. Os registros administrativos referem-se a informações sobre a produção ambulatorial, hospitalar, número de leitos e outros dados disponíveis para consulta pública no sítio do Departamento de Informática do SUS - Datasus. (BRASIL, 2005). ${ }^{8}$

A utilização da Pesquisa de Condições de Vida justifica-se na medida em que, os inquéritos domiciliares são importantes ferramentas para o planejamento e avaliação de serviços de saúde, podendo-se citar entre suas vantagens: a possibilidade da identificação da população que não tem acesso ao sistema de saúde (LEBRÃO et al., 1991); a facilidade em atingir usuários de diferentes instituições prestadoras de serviços (CARVALHEIRO, 1981); além da superação das limitações que dados de fontes

\footnotetext{
${ }^{8}$ http://www.datasus.gob.br.
} 
secundárias apresentam, em especial a que se refere à seleção de casos de maior gravidade, em estudos de morbidade (CESAR, 1997). ${ }^{9}$

Os métodos quantitativos foram utilizados com dois objetivos. Na avaliação do acesso aos serviços de saúde utilizaram-se modelos estatísticos que possibilitassem a realização de análise regional. Devido ao caráter amostral das informações sobre utilização dos serviços de saúde, cuja fonte de dados é a PCV, tornou-se necessária a incorporação na análise de modelos estatísticos que possibilitassem inferir com maior precisão os resultados da pesquisa amostral para domínios distintos dos originalmente contemplados no delineamento da amostra. Além disso, por meio dessas ferramentas, é possível combinar informações amostrais e as provenientes de registros administrativos, ou seja, dados individuais com dados ecológicos (referentes a municípios, DRS e outros). No presente caso, a análise regional das condições do acesso aos serviços de saúde foi realizada por meio de modelos estatísticos com efeitos mistos (ou modelos multiniveis) (RABE-HESKETH; SKRONDAL, 2008).

Já para a avaliação da eficiência usou-se um modelo matemático que permitisse estabelecer de forma empírica a relação de eficiência entre recursos e produção ambulatorial e hospitalar e, portanto, classificar as regionais de saúde a partir dessa relação. Para tanto, utilizou-se a Análise por Envoltória de Dados (Data Envelopment Analysis - DEA) desenvolvida por Charnes, Cooper e Rhodes em 1978, que tem sido

\footnotetext{
${ }^{9}$ No Brasil, para a avaliação do acesso aos serviços de saúde, utiliza-se usualmente o questionário específico sobre o tema aplicado a cada cinco anos pela Pesquisa Nacional por Amostra de Domicílios (PNAD), realizada anualmente pelo Instituto Brasileiro de Geografia e Estatística (IBGE). Entre os estudos sobre acesso e utilização dos serviços de saúde realizados a partir dessa pesquisa, estão Travassos et al. (2004), Pinheiro et al. (2002), Sawyer et al. (2002) e Barata (2008).
} 
empregada na avaliação de programas e projetos de órgãos governamentais, organizações não-governamentais e, mais recentemente, em empresas do setor privado.

Na área da saúde um exemplo do uso da DEA é o estudo feito por Marinho (2003), no qual foram avaliados os serviços ambulatoriais e hospitalares referentes a 1998, nos municípios do Estado do Rio de Janeiro. O autor analisou a eficiência da prestação de serviços de saúde em 74 municípios do Estado do Rio de Janeiro que definiram as unidades tomadoras de decisão - DMUs que constam do modelo da DEA. Com base nesses dados, a rede de serviços de saúde daquele Estado foi representada como um sistema de entradas e de saídas que transforma capacidade de atendimento, materializada em recursos materiais e financeiros, em serviços típicos do atendimento hospitalar e ambulatorial, além de um indicador de qualidade (MARINHO, 2003).

Em estudo publicado em 2009, Marinho et al. comparam, por meio da DEA, os sistemas de saúde do Brasil e dos países da OCDE. A eficiência na provisão de serviços de saúde é estimada com base na esperança de vida ao nascer para homens e para mulheres, no índice de sobrevivência infantil, nos anos de vida recuperados para doenças transmissíveis, nos anos de vida recuperados para doenças não-transmissíveis, nos anos de vida recuperados para causas externas, no tamanho da população e na área geográfica.

Faria et al. (2008) apresentam uma análise da relação existente entre os gastos públicos com educação e saúde realizados em diversos municípios fluminenses e os indicadores de condições de vida da população, no final dos anos 1990 por meio da 
técnica de Análise Envoltória de Dados. Gonçalves et al. (2008) realizaram uma análise dos hospitais públicos das capitais brasileiras por meio do modelo DEA.

Ressalte-se, porém, que essa técnica, apesar de ter sido desenvolvida para avaliar a eficiência em escolas, pressupõe condições que normalmente estão presentes em linhas de produção de fábricas e não em municípios ou agregados de municípios, já que uma das principais suposições para o bom desempenho da DEA é a homogeneidade entre as unidades que compõem o estudo em relação às variáveis do modelo. Suposição muito difícil de ser satisfeita quando se comparam municípios ou agregados de municípios em relação ao sistema de saúde.

Outro fator importante na aplicação dessa técnica refere-se às variáveis que compõem a razão de eficiência. Os recursos devem efetivamente implicar alterações nos resultados. Por exemplo, se a variável escolhida para representar o resultado de um determinado programa ou política na área de saúde for esperança de vida ao nascer da população de um conjunto de municípios, tem-se por principio a dificuldade em quantificar as ações que possibilitariam o aumento nesse indicador, dado que a esperança de vida é afetada por um conjunto de fatores que expressam tanto as políticas atuais quanto as passadas.

Nesse sentido, na análise sobre eficiência ora apresentada, os resultados obtidos devem ser considerados mediante as implicações metodológicas decorrentes da aplicação da DEA na unidade de análise constituída pelos Departamentos Regionais de Saúde. 
Assim, o presente estudo avalia, segundo a ótica regional, as condições do acesso aos serviços de saúde da população residente no Estado de São Paulo - considerandose os setores público e privado - e a eficiência na utilização dos recursos para a produção ambulatorial e hospitalar do SUS. Os resultados apresentados são discutidos analiticamente e segundo as implicações metodológicas decorrentes das ferramentas quantitativas utilizadas no estudo. 


\title{
2. OBJETIVOS
}

\begin{abstract}
1 valiar as condições do acesso aos serviços de saúde da população residente no Estado de São Paulo e a eficiência na utilização dos recursos para a produção ambulatorial e hospitalar do SUS, segundo os Departamentos Regionais de Saúde DRS.
\end{abstract}

\subsection{Objetivos Específicos}

- Avaliar as condições de acesso aos serviços de saúde da população residente no Estado de São Paulo, por meio da utilização dos serviços de saúde nos 17 DRS.

- Identificar as características socioeconômicas e demográficas dos usuários do SUS, segundo os 17 DRS.

- Calcular a probabilidade de um indivíduo utilizar o SUS dado suas características individuais (socioeconômicas e demográficas) e do seu local de residência (DRS).

- Construir um modelo de eficiência técnica por meio de Análise Envoltória de Dados, para os 17 Departamentos Regionais de Saúde. 


\section{MÉTODOS E REFERENCIAL TEÓRICO}

\subsection{Acesso aos serviços de saúde}

A procura por atendimento de saúde é influenciada por fatores relacionados com autopercepção de problemas de saúde ou diagnósticos preexistentes, que podem motivar o indivíduo a buscar assistência à saúde, condições sociais da população, tais como características sociodemográficas, culturais e capacidade de consumo, e formas de organização do sistema de saúde, referentes à cobertura e disponibilidade dos serviços de saúde. Assim, enquanto as condições sociais expressam as características da população demandante dos serviços, os aspectos do sistema de saúde relacionam-se à oferta de serviços, uma vez que a forma de organização desse sistema - tais como oferta de serviços e equipamentos, recursos humanos, distribuição no território e forma do financiamento - pode facilitar ou dificultar o acesso da população a esses serviços.

Essa multiplicidade de fatores torna multidimensional o conceito de acesso aos serviços de saúde. Para Travassos e Castro (p. 218, 2008), acesso é “o fator que intermedeia a relação entre a procura e a entrada no serviço. Refere-se às características da oferta de serviços de saúde que facilitam ou obstruem a sua utilização por potenciais usuários e exprime a capacidade da oferta de produzir serviços e de responder às necessidades da população”. 
Essa definição aproxima-se daquela a proposta por Donabedian (1973), que adota a terminologia acessibilidade para identificar a dimensão da oferta dos serviços de saúde capaz de responder às necessidades dos indivíduos. Segundo esse autor citado por Frenk (1992), acessibilidade é algo além da simples disponibilidade de recursos em um dado tempo ou lugar, mas inclui as características dos recursos que facilitam ou não o uso dos serviços por potenciais usuários.

Para o autor, os fatores que facilitam ou não a acessibilidade são de dois tipos: sócio-organizacionais e geográficos. Os primeiros referem-se a todas as características da oferta, como, por exemplo, políticas de saúde que selecionam as pessoas em função de raça/cor, sexo e condição social. As características individuais dos usuários - como atributos pessoais, condições socioeconômicas e aspectos demográficos - estão expressas nos fatores sócio-organizacionais que expressam a característica da oferta que intervém na relação entre usuários e serviços de saúde. Já o fator geográfico refere-se ao custo de locomoção dos usuários até os serviços de saúde, o tempo de viagem, ou seja, corresponde à acessibilidade física aos serviços.

Frenk (1992) adota essa mesma abordagem para classificar a acessibilidade em três tipos: domínio restrito, domínio intermediário e domínio amplo. O primeiro referese ao processo da procura por serviços de saúde até a sua utilização, ou seja, a entrada nos serviços. Nesse nível, os fatores que influenciam a acessibilidade são aqueles que podem facilitar ou dificultar a utilização dos serviços. Já no domínio intermediário, além do contato inicial, tem-se a continuidade do cuidado e, no domínio amplo, considera-se ainda o desejo de obtenção de cuidados de saúde e, nesse caso, a dimensão 
acessibilidade deve contemplar as crenças sobre saúde, o nível de confiança no sistema de saúde, etc. (Figura 1).

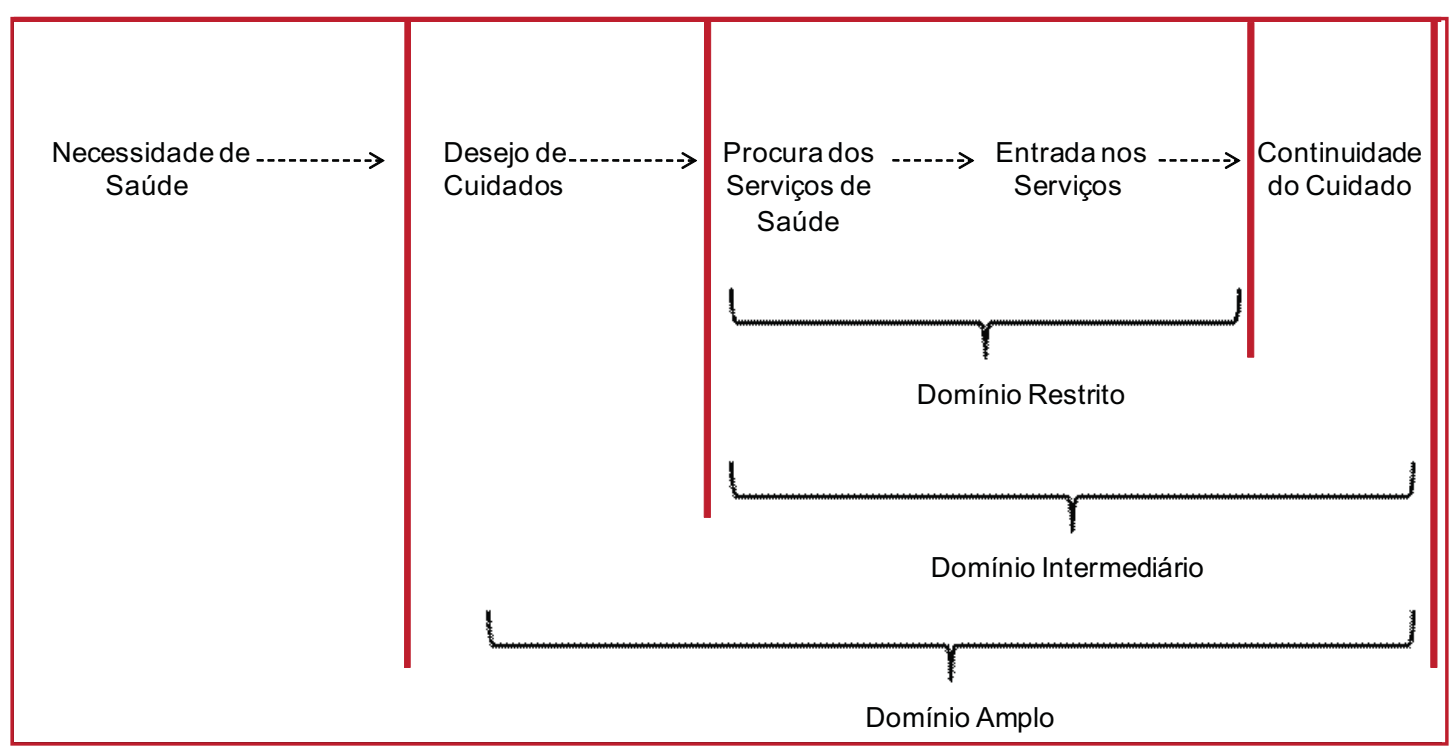

Figura 1 - Possíveis Áreas para o Conceito de Acessibilidade FONTE: Traduzido e adaptado de Frenk, 1992.

A partir dessa classificação, Frenk (1992) sugere que o termo acessibilidade seja atribuído ao processo de buscar e receber cuidados, enquanto o termo acesso seja utilizado para descrever a habilidade de potenciais usuários do sistema de saúde em buscar e obter cuidados. Para o autor, o acesso compreende a dimensão da acessibilidade definida por ele como domínio restrito. Como sinônimo de acesso, Frenk também utiliza a expressão poder de utilização, que tem caráter complementar ao termo barreiras de acesso, que dificultam tanto a procura quanto a utilização dos serviços.

Assim, em um sistema de saúde organizado e voltado para a população, as barreiras deveriam estar na esfera individual e o poder na esfera do sistema. Por exemplo, para atingir populações residentes em locais de difícil acesso físico, o sistema de saúde 
deveria ter mecanismos que provessem as pessoas de atendimento médico básico, tais como acesso a agentes de saúde.

O autor classifica as barreiras em três tipos: ecológicas ou geográficas, financeiras e organizacionais. As primeiras referem-se, por exemplo, às distâncias e ao tempo de viagem que os potenciais usuários estão sujeitos para a utilização dos serviços de saúde. As barreiras financeiras estão relacionadas aos custos financeiros dos serviços de saúde, enquanto as organizacionais expressam a própria forma de organização do sistema de saúde, como possibilidade de agendamento de consultas, tempo de espera para ser atendido em ambulatório, tempo de espera para realização de exames, etc.

Para Oliveira et al. (2004), igualmente importante é a noção dos espaços de relações, ou seja, a distância física pode ser um fator que impossibilita a utilização de serviços de saúde para pessoas que não possuem formas de custear os meios de transportes, por outro lado, para os que detêm tais meios, a mera distância física pode não constituir uma barreira.

Thiede e McIntryre (2008) tratam o acesso aos serviços de saúde como a oportunidade para o uso desses serviços. Assim, a utilização dos serviços de saúde por um indivíduo é resultante da relação entre a capacidade do indivíduo de aproveitar os recursos disponíveis no sistema de saúde e os próprios recursos oferecidos pelo sistema. A utilização dos serviços de saúde ocorrerá quando a capacidade do indivíduo em aproveitar a oportunidade propiciada pelo sistema de saúde for suficiente para a realização dessa ação - utilização dos serviços de saúde. Fatores observáveis facilitam 
ou dificultam a realização dessa ação, ou seja, interferem na relação entre indivíduos e sistema de saúde.

Esse enfoque aproxima-se da noção de vulnerabilidade social proposta por Kaztman (1999) para os estudos sobre pobreza. Segundo o autor, as condições de vida das pessoas e famílias expressam sua maior ou menor capacidade de controlar as forças que afetam o seu bem-estar, isto é, a posse ou o controle dos recursos requeridos para o aproveitamento das oportunidades, que são propiciadas pelo Estado, sociedade e mercado.

Se os recursos forem insuficientes para que as oportunidades sejam aproveitadas, a família estará em situação de vulnerabilidade social. Por recursos entendem-se todos os bens tangíveis ou não, que são controlados pela família e pessoa, como, por exemplo, os ativos (ou capital ${ }^{1}$ ) mobilizados com o objetivo de facilitar o acesso aos canais de mobilidade e integração social. Nesse sentido, a vulnerabilidade é uma noção multidimensional, pois afeta indivíduos, grupos e comunidades, em planos distintos de seu bem-estar, em diferentes formas e intensidades.

Para Thiede e McIntryre (2008), as dimensões que conformam o acesso aos serviços de saúde são: disponibilidade, que representa tanto a existência de serviços de saúde específicos quanto as facilidades incorporadas a esses serviços, tais como, consulta com pré-agendamento, horário de funcionamento dos serviços de saúde, distância dos equipamentos de saúde e os usuários; capacidade de pagamento, referente à relação

\footnotetext{
${ }^{1}$ Kaztman (1999) utiliza os termos ativo e capital como sinônimos.
} 
entre os custos diretos e indiretos dos serviços utilizados e a capacidade de pagamento do usuário; e aceitabilidade, relacionada a fatores sociais e culturais.

Perpassando essas dimensões, para os autores, o nível de informação dos indivíduos a respeitos do sistema de saúde, dos serviços e das doenças constitui o elemento que media e possibilita as escolhas em termos da utilização dos serviços de saúde. Isto porque, a partir da apropriação das informações sobre o sistema de saúde e a percepção de sua própria condição de saúde tornam-se perceptíveis ao usuário as barreiras existentes para a utilização dos serviços. Segundo Thiede (2005), em uma sociedade democrática o debate da equidade em saúde deveria estar centrado no processo de propiciar às pessoas os instrumentos necessários para que possam fazer suas escolhas em relação à utilização dos serviços de saúde, e ao mesmo tempo, tornar possível tais escolhas.

Travassos e Castro (2008) consideram essas dimensões e suas inter-relações barreiras de acesso, tais como descritas por Frenk (1992). A dimensão disponibilidade é tida como a mais importante, uma vez que a presença física de equipamentos, serviços e recursos humanos é indispensável para que ocorra a utilização dos serviços de saúde.

Para Godard e Smith (2001), a formulação precisa da noção de acesso depende do contexto no qual a análise está sendo realizada. Assim, enquanto o conceito de acesso, nos Estados Unidos, é freqüentemente operacionalizado como a condição de posse de seguro ou plano de saúde, na Europa, onde o sistema de saúde é em geral universal, poderia ser entendido como a possibilidade de se conseguir certos tipos de serviços com um determinado nível de qualidade. 
Mesmo nos sistemas com cobertura universal, pode haver uma considerável variação no custo pessoal para a utilização dos serviços que, em tese, inviabilizaria o acesso. Entre os fatores relacionados a esse "custo pessoal” estão: o tempo de espera para o atendimento; atitude do corpo clínico; resultados obtidos após a utilização dos serviços. Além disso, os sistemas universais podem variar substantivamente entre grupos de indivíduos pertencentes à mesma população, decorrentes de diferenças culturais (GODARD e SMITH, 2001).

Ao analisarem a equidade no acesso aos serviços de saúde, Godard e Smith (2001) consideraram como dimensões que conformam o acesso: a disponibilidade, em que determinados serviços de saúde podem não estar disponíveis para determinados grupos populacionais, ou os profissionais de saúde podem tender a oferecer tratamentos distintos a pacientes com as mesmas necessidades de saúde, porém de grupos populacionais diferentes; a qualidade, que pode variar entre os serviços oferecidos para pacientes pertencentes a segmentos sociais ou étnicos distintos; os custos dos serviços, que podem variar entre populações distintas, e a informação, dado que o grau de conhecimento sobre os serviços de saúde pode facilitar ou dificultar o acesso de grupos populacionais a certos serviços de saúde.

Assim, para os autores, a equidade no acesso ocorre no momento em que pessoas com iguais necessidades de saúde têm acesso aos mesmos recursos, ou seja, disponibilidade de serviços iguais para pacientes com necessidades iguais. ${ }^{2}$ Nessa

\footnotetext{
${ }^{2}$ Como necessidade de saúde, os autores definem a existência de algum tipo específico de ocorrência clínica (e possivelmente social).
} 
mesma linha, no Brasil, o Conselho Nacional de Saúde estabeleceu que: “A construção da equidade na área da saúde consiste, basicamente, em investir na oferta de serviços para grupos populacionais com acesso e utilização insuficientes, entre outros mecanismos, sem reprimir a demanda de serviços necessários a segmentos e grupos que já têm o acesso garantido” (BRASIL, 2003, p16).

Andersen e Newman (1973) propuseram um modelo comportamental para explicar o acesso por meio da utilização dos serviços de saúde, baseado nas características do sistema de saúde, em fatores individuais e nas necessidades de saúde. Nesse contexto, o acesso corresponde ao processo de entrada nos serviços até os cuidados subsequentes, o que, pela definição de Frenk (1992), estaria no domínio intermediário (ou restrito, se fosse considerado apenas a utilização dos serviços de saúde) da acessibilidade. Segundo Frenk (1992), uma das críticas a esse modelo corresponde ao fato de ser muito difícil distinguir um estudo de uso de serviços daquele referente a acesso aos serviços de saúde.

Aday e Andersen (1974) definiram três dimensões como determinantes da utilização dos serviços de saúde: as politicas de saúde, as características do sistema de saúde e as características da população que a tornam mais ou menos propensa a utilizar um serviço de saúde.

As políticas de saúde tanto influenciam a forma de organização dos serviços de saúde em seus diferentes níveis de complexidade, as normas de financiamento do sistema de saúde, a participação dos setores público e privado, a composição tecnológica do sistema de saúde e a formação e gestão dos recursos humanos, quanto possibilitam 
alterar as características da população demandante dos serviços de saúde, as quais podem ser explicadas por: os fatores predisponentes, fatores capacitantes e necessidade de saúde.

Os fatores predisponentes referem-se às características individuais, como sexo, idade, religião, hábitos culturais e valores pessoais, e não dependem da necessidade de saúde, mas podem afetar a procura por serviços de saúde. Os fatores capacitantes relacionam-se tanto às características individuais quanto ao contexto externo, devendose estar presentes para que a utilização dos serviços de saúde se realize. Entre esses fatores, encontra-se a o nível de renda do indivíduo, pois, em uma sociedade capitalista em que a saúde também é um bem de consumo, a renda dos indivíduos, em tese, lhes propiciará maior probabilidade de utilização dos serviços de saúde. Da mesma forma, os mais escolarizados poderão ter maior facilidade para a obtenção das informações necessárias para utilizar os serviços de saúde. Já as necessidades de saúde constituem o estado de saúde dos indivíduos, tanto do ponto de vista da percepção quanto do diagnóstico de profissionais da saúde.

Andersen (1995), ao fazer a revisão desse modelo, classificou o acesso em quatro categorias: acesso potencial, que corresponde à disponibilidade dos serviços de saúde e está relacionado aos fatores capacitantes; acesso realizado, referente ao uso dos serviços de saúde; acesso efetivo, que inclui o processo de cuidado de saúde, ou seja, abrange a utilização dos serviços de saúde que alcançam seu objetivo - melhorar as condições de saúde; e acesso eficiente, que compreende a relação entre as alterações nas condições de saúde da população e o volume dos serviços prestados. 
Para Andersen (1995), a equidade ocorre quando os únicos fatores que explicam a utilização dos serviços de saúde são as características demográficas e as necessidades de saúde, ou seja, o uso dos serviços de saúde deve estar associado a idade, sexo e necessidade de saúde das pessoas.

Esse modelo, segundo Travassos e Castro (2008), está baseado em uma estrutura hierarquizada em dois grandes componentes: o sistema de saúde e o contexto externo em que esse sistema está inserido. A associação entre esses dois componentes produz o padrão de utilização dos serviços de saúde de uma localidade. Para esses autores, os fatores capacitantes não se restringem às características da população demandante dos serviços de saúde, mas se referem também ao sistema de saúde, como, por exemplo, o tipo de serviços de saúde disponível em determinadas regiões.

Apesar da discordância em termos da terminologia - acesso ou acessibilidade -, o acesso é considerado, pela maioria dos autores, uma dimensão do sistema de saúde associada à oferta, enquanto o termo acessibilidade é, em geral, utilizado por autores que enfocam essa dimensão como um fator de ajuste entre a oferta e a demanda, no caso a população. O termo acesso é usualmente empregado para o processo de entrada inicial nos serviços de saúde. Em geral, também há uma concordância entre os autores sobre as variáveis que interferem no acesso aos serviços de saúde, além de se considerar a utilização dos serviços de saúde uma medida de acesso (TRAVASSOS e MARTINS, 2004).

Na perspectiva do que Andersen denomina de acesso realizado e Frenk (1992) de acesso restrito ou poder de utilização, o presente estudo caracteriza o acesso como 
utilização dos serviços de saúde pela população residente em áreas urbanas no Estado de São Paulo.

Para tanto, serão analisados os dados da Pesquisa de Condições de Vida - PCV, realizada pela Fundação Seade no Estado de São Paulo em 2006, e registros administrativos produzidos pelo Ministério da Saúde e Fundação Seade.

No sentido de evitar possíveis distorções nos resultados, dado os diferentes fatores que determinam a procura e a utilização dos serviços de saúde entre crianças e adolescentes menores de 14 anos e os demais membros da população, esse primeiro contingente foi excluído da análise. De forma análoga, em trabalho publicado em 2006, Travassos et al. analisaram a desigualdade na utilização dos serviços de saúde no Brasil separadamente para a faixa etária de 0 a 9 anos e 10 anos e mais.

Assim, o universo de análise corresponde as pessoas de 15 anos e mais residentes em áreas urbanas do Estado de São Paulo, em 2006, que representavam aproximadamente 97\% da população nessa faixa etária no Estado, nesse ano.

\subsection{Utilização dos serviços de saúde}

Considerou-se tendo utilizado serviços de saúde a pessoa que, no período de referência de 30 dias, procurou estabelecimento de saúde e foi atendida no mesmo dia, incluindo-se consultas pré-agendadas. A categoria Utilizou nos últimos 30 dias referese às pessoas que procuraram serviços de saúde e foram atendidas no mesmo dia. Já a categoria Não utilizou nos últimos 30 dias corresponde aos indivíduos que não 
procuraram serviços de saúde nos últimos 30 dias, ou que procuraram, mas não foram atendidos no mesmo dia. Os estabelecimentos considerados foram: pronto-socorro, hospital, clínica ou consultório médico, posto ou centro de saúde, laboratório ou centro de diagnóstico e outros tipos (exceto clínica ou consultório odontológico).

Para o tipo de serviço utilizado - Sistema Único de Saúde - SUS e planos ou convênios médicos - foram consideradas, no primeiro caso, as pessoas que declararam ter utilizado serviços gratuitos de saúde e, no segundo, aquelas que usuram serviços pré-pagos.

O período de 30 dias para investigação da procura e utilização dos serviços de saúde é o adotado pela PCV, sendo que em inquéritos domiciliares desse tipo também é empregado o período de 15 dias (VIACAVA, 2002).

\subsubsection{Fonte de dados}

A Pesquisa de Condições de Vida - PCV, realizada em 2006 pela Fundação Seade no Estado de São Paulo, consiste em um levantamento por amostragem de domicílios (FUNDAÇÃO SEADE, 2006). Esse tipo de fonte de informações - inquérito domiciliar - é considerado o mais adequado para o estudo da influência das condições sociais no acesso e utilização dos serviços de saúde (TRAVASSOS e CASTRO, 2008; CÉSAR e TANAKA, 1996).

A PCV tem como principal objetivo captar e produzir informações que permitam avaliar as condições socioeconômicas e de vida da população paulista, por meio de diferentes recortes analíticos: saúde, renda, habitação, educação, emprego e acesso a programas sociais. 
Entre os temas investigados pela pesquisa estão:

- características demográficas dos moradores do domicílio - sexo, idade, estado conjugal, posição na família e no domicílio, raça/cor, local de nascimento, etc.;

- características físicas do domicílio e entorno - acesso a serviços públicos de infraestrutura urbana, características físicas da moradia, formas de apropriação da moradia;

- renda e patrimônio familiar - rendimento familiar, posse de bens imóveis, duráveis e financeiros, além de programas de transferência de renda e outras formas de auxílios - monetários ou não-monetários;

- educação, participação e acesso à Internet - nível de escolaridade dos membros do domicílio, condição de frequência à escola, participação associativa e acesso à Internet;

- inserção no mercado de trabalho e rendimentos - condição de atividade, forma de inserção no mercado de trabalho, rendimentos provenientes do trabalho e aposentadorias, etc.;

- saúde: perguntas referentes a posse de convênio ou plano de saúde (médico ou odontológico), procura por serviços de saúde nos 30 dias anteriores à pesquisa, condições do atendimento, ocorrência de problema de saúde, além de um conjunto de perguntas sobre saúde reprodutiva para as moradoras de 14 anos ou mais. 
As informações foram coletadas para todos os membros do domicílio, porém o informante foi o responsável pelo domicílio ou seu cônjuge, com exceção das questões referentes a mercado de trabalho, para as quais todas as pessoas de dez anos e mais foram entrevistadas.

Investigaram-se apenas os domicílios de áreas urbanas e rurais de extensão urbana, com exceção dos localizados na Região Administrativa de Registro e no Município de São Paulo, onde também foram pesquisados aqueles situados na zona rural.

A amostra da pesquisa englobou foi de 20.000 domicílios, distribuídos em seis domínios no Estado de São Paulo: Região Metropolitana de São Paulo (5.200 domicílios), Região Metropolitana da Baixada Santista (3.000 domicílios), Região Administrativa de Campinas (3.800 domicílios), Região Administrativa de Sorocaba (1.600 domicílios), Região Administrativa de São José dos Campos (1.600 domicílios), Região Administrativa de Registro (1.600 domicílios), Aglomerado Noroeste (1.600 domicílios) - composto pelas Regiões Administrativas de São José do Rio Preto, Barretos, Araçatuba, Presidente Prudente e Marília - e Aglomerado Central-Norte (1.600 domicílios) - formado pelas regiões de Franca, Ribeirão Preto, Central e Bauru.

Trata-se de uma amostra estratificada por conglomerados em dois estágios, com o setor censitário como a unidade de primeiro estágio e o domicílio particular permanente como a de segundo.

Os estratos foram definidos segundo o Índice Paulista de Vulnerabilidade Social IPVS. O estrato 1, que engloba $80 \%$ dos domicílios da amostra, é formado pelos setores censitários classificados no grupo 1 (nenhuma vulnerabilidade), grupo 2 (vulnerabilidade 
muito baixa) e grupo 3 (vulnerabilidade baixa), enquanto o estrato 2 corresponde aos setores censitários pertencentes aos grupos 4 (vulnerabilidade média), 5 (vulnerabilidade alta) e 6 (vulnerabilidade muito alta).

Apesar de a amostra da PCV não ter sido planejada para representar os 17 Departamentos Regionais de Saúde - DRS do Estado de São Paulo, é possível segmentá-la segundo essa regionalização. No entanto, devem-se considerar a falta de precisão e os possíveis vieses que podem ocorrer nos resultados a serem obtidos. Assim, para verificar as possíveis limitações analíticas decorrentes dessa regionalização a partir da base de dados da Pesquisa de Condições de Vida, foram calculados os coeficientes de variação da estimativa do total da população de 15 anos e mais para os 17 DRS. Também comparou-se a distribuição da população estimada pela PCV nos DRS com a observada (Tabela 1).

Na estimativa do total da população-alvo da pesquisa, foram observados coeficientes de variação acima de $20 \%$ para os DRS pertencentes aos domínios amostrais Aglomerado Noroeste e Aglomerado Centro-Norte, devido ao menor tamanho da amostra para essas regiões quando desagregada do respectivo domínio amostral. No entanto, com exceção dos DRS de Barretos (44,2\%), São João da Boa Vista (40,9\%), Presidente Prudente (39,0\%) e Franca (31,6\%), para os demais os coeficientes permaneceram abaixo de $30 \% .^{3}$

\footnotetext{
${ }^{3}$ O coeficiente de variação consiste na razão entre o erro padrão da estimativa e seu valor esperado (média). No presente caso, é a razão entre o erro padrão da estimativa do total populacional e essa estimativa. Coeficientes de variação elevados indicam maiores erros amostrais.
} 
A distribuição da população de cada DRS, em relação ao total do Estado, obtida por meio da PCV, mantém-se muito próxima a daquela calculada a partir da projeção populacional. Estão sobre-representados, na amostra, os departamentos de São José do Rio Preto e São João da Boa Vista. Por outro lado, o DRS de Campinas é subrepresentado.

Tabela 1 - Distribuição da população, por coeficiente de variação e taxa de urbanização, segundo Departamento Regional de Saúde. Estado de São Paulo. 2006

\begin{tabular}{|c|c|c|c|c|c|c|}
\hline \multirow{2}{*}{$\begin{array}{l}\text { Departamento Regional } \\
\text { de Saúde - DRS }\end{array}$} & \multicolumn{3}{|c|}{$\begin{array}{c}\text { Pesquisa de Condições de Vida - } \\
\text { PCV }\end{array}$} & \multicolumn{2}{|c|}{$\begin{array}{l}\text { População } \\
\text { projetada }^{(1)}\end{array}$} & \multirow{2}{*}{$\begin{array}{c}\text { Taxa de } \\
\text { urbanização } \\
2000(\%)\end{array}$} \\
\hline & $\begin{array}{l}\text { Coeficiente } \\
\text { de variação } \\
(\%)\end{array}$ & $\begin{array}{c}\text { Estimativa } \\
\text { da população } \\
\text { amostrada }\end{array}$ & $\%$ & $\begin{array}{c}\text { População } \\
\text { urbana }\end{array}$ & $\%$ & \\
\hline Total & - & 38819229 & 100,0 & 38445519 & 100,0 & - \\
\hline DRS 01 - Grande São Paulo & 2,0 & 19297533 & 49,7 & 19268059 & 50,1 & 95,8 \\
\hline DRS 02 - Araçatuba & 22,9 & 669685 & 1,7 & 633626 & 1,6 & 91,1 \\
\hline DRS 03 - Araraquara & 25,8 & 810302 & 2,1 & 831020 & 2,2 & 92,6 \\
\hline DRS 04 - Baixada Santista & 6,2 & 1639624 & 4,2 & 1615187 & 4,2 & 99,6 \\
\hline DRS 05 - Barretos & 34,2 & 356812 & 0,9 & 374031 & 1,0 & 92,1 \\
\hline DRS 06 - Bauru & 21,2 & 1517007 & 3,9 & 1455553 & 3,8 & 90,7 \\
\hline DRS 07 - Campinas & 10,1 & 3293341 & 8,5 & 3554398 & 9,2 & 93,9 \\
\hline DRS 08 - Franca & 28,4 & 532259 & 1,4 & 603607 & 1,6 & 93,8 \\
\hline DRS 09 - Marília & 21,1 & 834675 & 2,2 & 949967 & 2,5 & 88,8 \\
\hline DRS 10 - Piracicaba & 23,1 & 1302676 & 3,4 & 1280533 & 3,3 & 93,4 \\
\hline DRS 11 - Presidente Prudente & 34,0 & 503990 & 1,3 & 610117 & 1,6 & 85,5 \\
\hline DRS 12 - Registro & 7,1 & 234911 & 0,6 & 283053 & 0,7 & 65,9 \\
\hline DRS 13 - Ribeirão Preto & 19,2 & 1196566 & 3,1 & 1191542 & 3,1 & 96,0 \\
\hline DRS 14 - São João da Boa Vista & 32,9 & 1050514 & 2,7 & 679694 & 1,8 & 87,3 \\
\hline DRS 15 - São José do Rio Preto & 18,2 & 1568226 & 4,0 & 1268655 & 3,3 & 88,9 \\
\hline DRS 16 - Sorocaba & 7,9 & 1937270 & 5,0 & 1809407 & 4,7 & 83,1 \\
\hline DRS 17 - Taubaté & 4,7 & 2073836 & 5,3 & 2037519 & 5,3 & 93,0 \\
\hline
\end{tabular}

FONTE: Fundação Seade. Pesquisa de Condições de Vida - PCV. Elaboração do autor.

(1) Projeções populacionais para $1^{\circ}$ de julho de 2006, corrigidas pela taxa de urbanização obtida por meio do Censo Demográfico 2000. Foi utilizada a taxa de urbanização referente a 2000, pois não são calculadas projeções populacionais para a população urbana. As projeções populacionais foram produzidas pela Fundação Seade e estão disponíveis no sitio <www.seade.gov.br>. Para os DRS’s da Grande São Paulo e Registro considerou-se a população total projetada 
Esses resultados indicam que, embora seja possível analisar separadamente os 17 DRS por meio da amostra, a precisão das estimativas obtidas será muito distinta. Por outro lado, não foram observados vieses causados por essa segmentação da amostra, já que a distribuição da população que compõe o universo de estudo da PCV aproxima-se bastante daquela observada na projeção populacional.

Da Fundação Seade também foram utilizadas as informações sobre o total de médicos registrados no Conselho Regional de Medicina - CRM/SP, em dezembro de 2006, segundo município de residência, e projeções populacionais.

Ainda foram incluídos dados disponíveis para consulta pública no sitio do Datasus (http://www.datasus.gov.br), tais como o porcentual da população do município cadastrada no Programa Saúde da Família - PSF, em 2006, e o total de beneficiários de convênio e plano de assistência médica em dezembro de 2006, segundo local de residência, exclusive os beneficiários de planos exclusivamente odontológicos.

As informações sobre beneficiários estão disponíveis no Sistema de Informações de Beneficiários - SIB, em que as operadoras de planos privados de saúde enviam, mensalmente, os dados de vínculos de beneficiários aos planos, incluindo a movimentação de adesões, alterações e cancelamentos desses vínculos, com atualização trimestral. Um beneficiário pode possuir mais de um plano e, assim, constar no sistema tantas vezes quantos forem os vínculos que possuir com planos privados de assistência à saúde.

Quanto ao município de residência do beneficiário, as informações estão sujeitas a erros, pois a operadora pode, indevidamente, informar para a ANS o endereço da empresa contratante de plano coletivo, em vez daquele referente à residência do beneficiário. 
Isso pode provocar erro na consulta realizada, devido à possibilidade de aumento da quantidade de beneficiários no local de sede da empresa contratante em detrimento do local de moradia do beneficiário.

Para avaliar a qualidade dessa informação, realizou-se uma comparação entre as proporções de beneficiários de planos e convênios médicos obtidas por meio dessa

Tabela 2 - Porcentual de beneficiários de planos e convênios de saúde, erro padrão e intervalo de confiança, por fonte de dados, segundo Departamento Regional de Saúde. Estado de São Paulo. 2006

\begin{tabular}{|c|c|c|c|c|c|}
\hline \multirow{3}{*}{$\begin{array}{l}\text { Departamento Regional } \\
\text { de Saúde - DRS }\end{array}$} & \multicolumn{4}{|c|}{ Pesquisa de Condições de Vida - PCV } & \multirow{3}{*}{$\begin{array}{c}\text { ANS } \\
\text { Beneficiários } \\
\text { de planos e } \\
\text { convênios } \\
\text { de saúde }\end{array}$} \\
\hline & \multirow{2}{*}{$\begin{array}{l}\text { Pessoas que } \\
\text { declararam } \\
\text { possuir planos } \\
\text { ou convênios } \\
\text { de saúde }\end{array}$} & \multirow{2}{*}{$\begin{array}{l}\text { Erro padrão } \\
\text { do porcentual } \\
\text { de beneficiá- } \\
\text { rios de planos } \\
\text { e convênios } \\
\text { de saúde }\end{array}$} & \multicolumn{2}{|c|}{$\begin{array}{c}\text { Intervalo de Confiança } \\
\text { de } 95 \%\end{array}$} & \\
\hline & & & $\begin{array}{l}\text { Valor } \\
\text { mínimo }\end{array}$ & $\begin{array}{l}\text { Valor } \\
\text { máximo }\end{array}$ & \\
\hline DRS 01 - Grande São Paulo & 36,7 & 1,4 & 4,0 & 39,5 & 48,0 \\
\hline DRS 02 - Araçatuba & 24,2 & 4,5 & 15,4 & 32,9 & 13,8 \\
\hline DRS 03 - Araraquara & 27,0 & 7,9 & 11,5 & 42,6 & 30,7 \\
\hline DRS 04 - Baixada Santista & 38,4 & 2,4 & 33,8 & 43,1 & 36,0 \\
\hline DRS 05 - Barretos & 32,6 & 7,4 & 18,0 & 47,2 & 23,4 \\
\hline DRS 06 - Bauru & 30,2 & 6,0 & 18,5 & 41,9 & 18,0 \\
\hline DRS 07 - Campinas & 39,9 & 2,1 & 35,8 & 44,1 & 39,4 \\
\hline DRS 08 - Franca & 26,4 & 5,0 & 16,6 & 36,2 & 28,0 \\
\hline DRS 09 - Marília & 16,2 & 2,9 & 10,5 & 21,9 & 12,3 \\
\hline DRS 10 - Piracicaba & 35,2 & 5,1 & 25,2 & 45,3 & 34,1 \\
\hline DRS 11 - Presidente Prudente & 20,6 & 4,4 & 11,9 & 29,3 & 17,0 \\
\hline DRS 12 - Registro & 16,1 & 1,6 & 12,9 & 19,3 & 7,9 \\
\hline DRS 13 - Ribeirão Preto & 37,6 & 4,8 & 28,1 & 47,0 & 33,4 \\
\hline DRS 14 - São João da Boa Vista & 21,4 & 7,4 & 6,8 & 35,9 & 28,6 \\
\hline DRS 15 - São José do Rio Preto & 32,7 & 3,5 & 25,8 & 39,5 & 23,2 \\
\hline DRS 16 - Sorocaba & 34,2 & 2,0 & 30,3 & 38,0 & 23,6 \\
\hline DRS 17 - Taubaté & 32,0 & 2,8 & 26,6 & 37,4 & 28,9 \\
\hline
\end{tabular}

FONTE: Fundação Seade. Pesquisa de Condições de Vida - PCV. ANS/SIB. Sistema de Informações de Beneficiários. Elaboração do autor. 
fonte de dados e pela Pesquisa de Condições de Vida. Os resultados mostraram maior presença relativa de beneficiários no DRS da Grande São Paulo, segundo os dados da ANS, o que pode indicar possíveis erros de preenchimento sobre o município de residência do beneficiário. As maiores discrepâncias ocorreram nos DRS de Bauru, Araçatuba, Sorocaba, São José do Rio Preto, Barretos e Registros, onde as proporções calculadas com os dados da ANS são muito menores daquelas obtidas pela PCV, e em São João da Boa Vista, onde se observa o contrário. No entanto, a correlação linear entre as estatísticas - obtidas pelas duas fontes de dados nos 17 DRS - corresponde a 0,77, indicando consistência entre as duas fontes de informação.

\subsubsection{Análise dos dados}

Os dados foram analisados por meio de análise univariada, em que foram construídos intervalos de confiança de 95\% para as proporções de interesse, e por modelos de regressão logística com efeitos aleatórios (ou mistos), que permitem estudar de forma multivariada os fatores que influenciam a utilização dos serviços de saúde.

Na análise univariada, para cada uma das variáveis selecionadas no estudo, para o total do Estado e em cada um dos DRS, foram calculadas estimativas dos parâmetros populacionais de interesse (proporções).

Para cada departamento regional de saúde, as estimativas das proporções foram obtidas por meio do estimador dado pela expressão (1), pois, no caso de amostragem por conglomerados com tamanhos desiguais, a proporção (ou a média amostral) é um estimador do tipo razão (KISH, 1965).

$$
r=\frac{y}{x}=\frac{1}{x} \sum_{i=1}^{a} y_{i}=\frac{\sum_{i=1}^{a} w_{i} y_{i}}{\sum_{i=1}^{a} w_{i} b_{i}}
$$


onde: $a$ corresponde ao número de setores censitários (UPA) na amostra no DRS; $x=\sum_{i=1}^{a} w_{i} b_{i}$ refere-se à estimativa da população de interesse obtida na amostra; $b_{i}$ é o tamanho do $a$-ésimo setor censitário; $w_{i}$ é o fator de expansão da amostra; e $y_{i}$ corresponde ao valor da variável de interesse do elemento i no domínio, que, no caso em que $Y$ é variável dicotômica, assume os valores 0 ou 1 se o elemento possui ou não a característica em estudo.

A variância de $r$ foi estimada pelo Método de Linearização de Taylor, tal que $\operatorname{var}(r)=\frac{1}{x^{2}}\left[\operatorname{var}(y)+r^{2} \operatorname{var}(x)-2 r \operatorname{cov}(x, y)\right](\mathrm{KISH}, 1965)$.

No cálculo das variâncias não foi utilizada a correção para população finita (1- f), onde $f$ é a fração amostral, sendo que, no caso da amostra da Pesquisa de Condições de Vida, essa correção é aproximadamente um.

O fator de expansão da amostra $w_{i}$ corresponde ao inverso da fração amostral, mais um fator de correção para a não resposta no setor censitário.

Os intervalos de confiança são expressos como:

$$
\left(r_{i} \pm 1,96 \sqrt{\operatorname{var}\left(r_{i}\right)}\right)
$$

Dois modelos de regressão logística com efeitos aleatórios foram construídos. No primeiro, a variável dependente corresponde à própria condição de utilização dos serviços de saúde, ou seja, $Y=1$, se a pessoa utilizou serviços de saúde nos 30 dias anteriores à entrevista, e $Y=0$, se a pessoa não utilizou serviços de saúde nos 30 dias anteriores à entrevista. No segundo, analisou-se o tipo de serviço utilizado - gratuito ou pré-pago, sendo que a variável dependente pode ser escrita como $Y^{r}=1$, se a pessoa utilizou serviços de sáude do SUS, e $Y^{r}=0$ se a pessoa utilizou convênio ou plano de saúde. 
É justificada a adoção de uma análise multinível, pois pode-se supor que a população em estudo está distribuída em estrutura hierarquizada. No presente caso, os indivíduos residem em setores censitários localizados nos DRS, ou seja, o conjunto de informações a ser estudado distribui-se em três níveis: indivíduo, setor censitário e DRS (Figura 2).

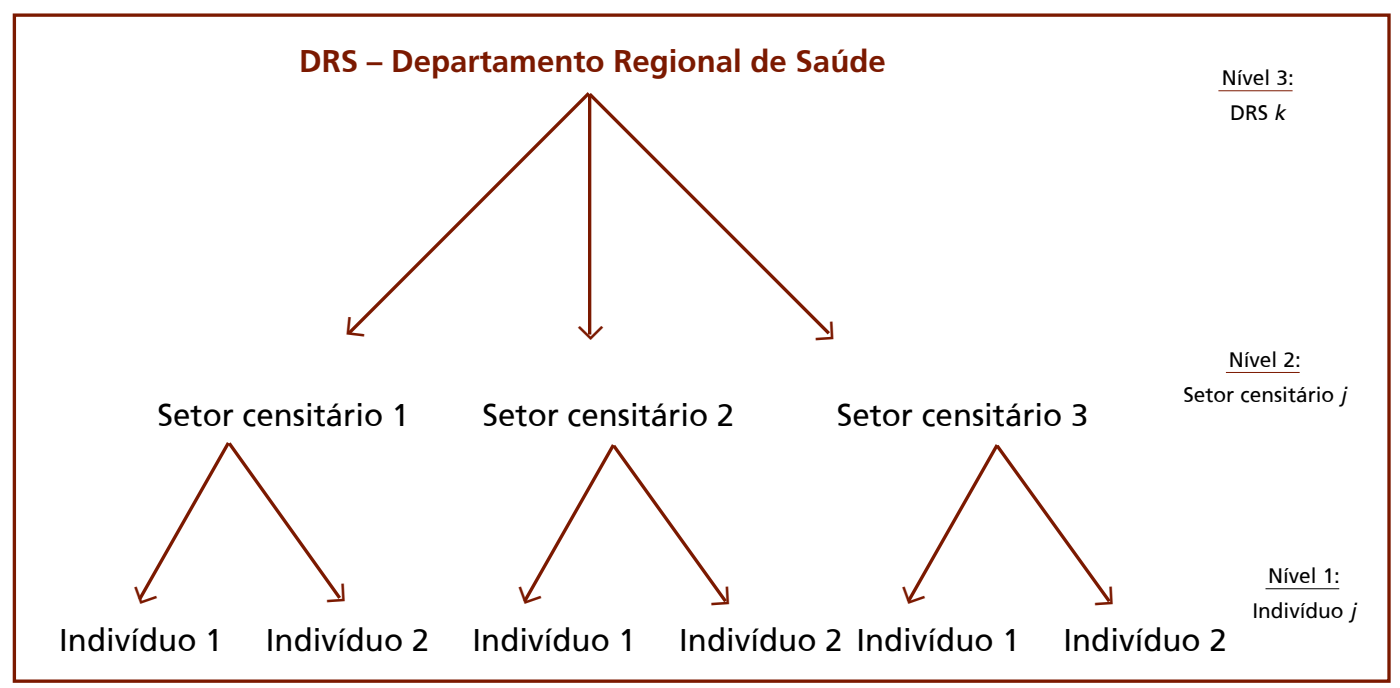

Figura 2 - Diagrama da estrutura dos dados em um modelo de três níveis FONTE: Adaptado de Rabe-Hesketh e Skrondal (2008).

A partir de Andersen (1995), os fatores associados à utilização dos serviços de saúde foram classificados em predisponentes e capacitantes. Entre os primeiros estão o sexo e a idade do indivíduo, uma vez que a demanda por serviços de saúde segundo gênero e grupos etários é diferenciada, independentemente das características do sistema de saúde. Esse diferencial pode ser observado no Gráfico 1, no qual constatam-se taxas de utilização mais elevadas na faixa etária de 0 a 14 anos (38,6\%), com declínio acentuado na de 15 a 19 anos (23, 4\%) e elevação progressiva nos grupos etários subsequentes, atingindo a maior proporção na faixa de 60 anos e mais $(41,7 \%)$. 
Gráfico 1 - Pessoas que utilizaram serviços de saúde nos últimos 30 dias, segundo faixa etária. Estado de São Paulo. 2006

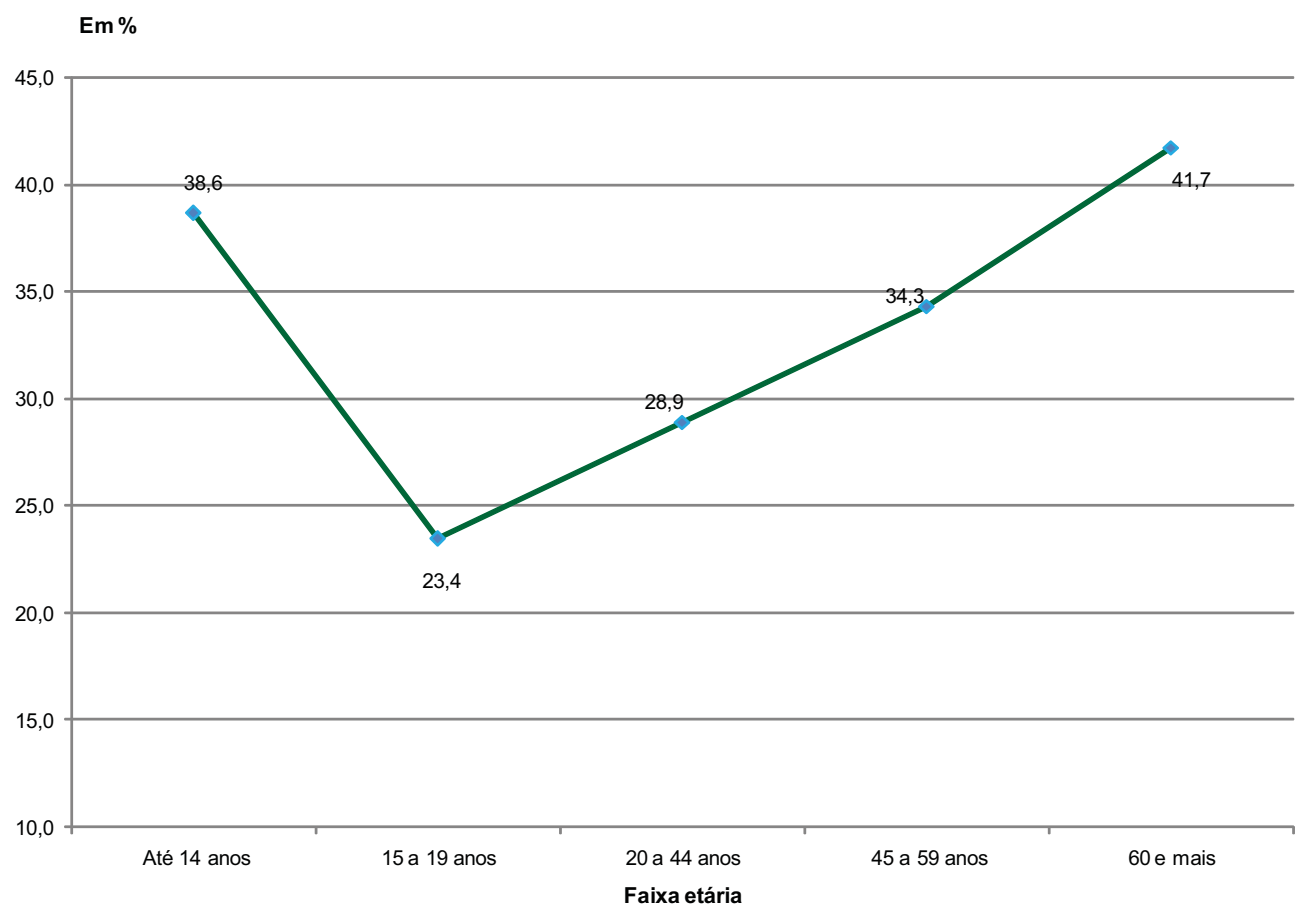

FONTE: Fundação Seade. Pesquisa de Condições de Vida - PCV. Elaboração do autor.

NOTA: As faixas etárias foram definidas segundo o ciclo de vida dos indivíduos e sua associação com a utilização dos serviços de saúde.

Já os fatores capacitantes podem ser classificados em três níveis: individual, de vizinhança (setor censitário) e DRS. No primeiro encontram-se os elementos que possibilitam ou dificultam o acesso do indivíduo aos serviços de saúde, tais como sua capacidade de pagamento dos serviços e seu grau de informação a respeito dos serviços existentes. Os indicadores que expressam essa dimensão são a renda familiar per capita, a condição de posse de plano ou convênio médico e o nível de escolaridade.

O nível de vizinhança (setor censitário) engloba as condições socioeconômicas da comunidade, bairro ou vizinhança, dado que a segregação espacial existente nos centros urbanos paulistas, ao mesmo tempo em que é resultado da desigualdade social, contribui decisivamente para a permanência desses padrões. Assim, o local de moradia pode constituir uma barreira de acesso aos serviços. Como unidade de vizinhança, conside- 
raram-se o setor censitário do Censo Demográfico 2000 e a situação da população ali residente caracterizada pelo Índice Paulista de Vulnerabilidade Social - IPVS, que consiste em uma tipologia que classifica o setor censitário criado para o Censo Demográfico 2000, segundo sua vulnerabilidade à pobreza. Para tanto, este indicador combina duas dimensões: socioeconômica, que expressa o nível de renda dos moradores e sua capacidade de mantê-la e gerá-la, tendo sido identificada por meio da renda e do nível de escolaridade do responsável pelo domicílio; e demográfica, que representa o ciclo de vida das famílias residentes no setor censitário, sendo operacionalizada pela idade do responsável pelo domicílio e a presença de crianças pequenas (FERREIRA et al., 2006).

Já no nível do DRS situa-se a organização do sistema de saúde, tais como disponibilidade de profissionais e serviços, presença do setor público e complexidade do sistema de saúde. A oferta de serviços públicos em atenção básica está expressa pelo porcentual de pessoas cadastradas no Programa Saúde da Família - PSF, enquanto o porcentual de beneficiários de planos de assistência médica, e o número de médicos por habitantes representam o grau de complexidade do sistema de saúde.

Foi incorporada na análise a variável raça/cor, considerada uma variável social e não apenas demográfica, dado a grande associação entre esse atributo e desigualdade social (CARDOSO et al., 2005), sendo avaliada como um fator capacitante.

As variáveis dependentes dos modelos referentes à utilização dos serviços de saúde e ao tipo de serviço utilizado podem ser definidas como: 


\section{Nível do indivíduo (i)}

- Faixa etária (variáveis dummies com a faixa de 15 a 19 anos como categoria de referência):

$\mathrm{x}_{1 \mathrm{ijk}}$ : variável dummy para pessoas com idade entre 20 e 44 anos;

$\mathrm{x}_{2 \mathrm{ijk}}$ : variável dummy para pessoas com idade entre 45 e 59 anos;

$\mathrm{x}_{3 \mathrm{ijk}}$ : variável dummy para pessoas com 60 anos e mais de idade.

- Sexo:

$x_{4 i j k}$ : assume valor 1 (um) para mulheres e 0 (zero) para pessoas homens;

- Raça/cor:

$\mathrm{x}_{5 \mathrm{ijk}}$ : assume valor 1 (um) para pessoas de cor preta ou parda e 0 (zero) para brancas ou amarelas;

- Escolaridade:

$\mathrm{x}_{6 \mathrm{ijk}}$ : assume valor 0 (zero) para pessoas com pelo menos oito anos de estudo e 1 (um) para aquelas com menos de oito anos de estudo.

• Posse de convênio ou plano de saúde:

$\mathrm{x}_{7 \mathrm{ijk}}$ : assume valor 1 (um) para pessoas com posse de convênio ou plano de saúde e 0 (zero) caso contrário.

- Renda familiar per capita (variáveis dummies com a faixa de mais de dois salários mínimos per capita como categoria de referência):

$\mathrm{x}_{\mathrm{8ijk}}$ : assume valor 1 (um) para pessoas com renda familiar per capita de até $1 / 2$ salário mínimo e 0 (zero) para as demais faixas de renda;

$\mathrm{x}_{9 \mathrm{ijk}}$ : assume valor 1 (um) para pessoas com renda familiar per capita entre mais de 1/2 até um salário mínimo e 0 (zero) para as demais faixas de renda; $\mathrm{x}_{10, \mathrm{ijk}}$ : assume valor 1 (um) para pessoas com renda familiar per capita entre mais de um até dois salários mínimos 0 (zero) para as demais faixas de renda 


\section{Nível do setor censitário (j)}

• Classificação do setor censitário segundo o IPVS:

$x_{11, j k}$ : assume valor 1 (um) para setores censitários classificados como áreas de média, alta ou muito alta vulnerabilidade à pobreza e 0 (zero) para os demais casos. Essa classificação corresponde aos estratos amostrais da PCV.

\section{Nível do DRS - Departamento Regional de Saúde (k)}

$\mathrm{x}_{12, k}$ : número de médicos por habitantes no DRS.

$\mathrm{x}_{13, \mathrm{k}}$ : porcentual de beneficiários de planos de saúde no DRS.

$\mathrm{x}_{14, \mathrm{k}}$ : porcentual de pessoas cadastradas no Programa de Saúde da Família (PSF) no DRS.

Os tamanhos das amostras para os três níveis do modelo estão apresentados na Tabela 3.

Tabela 3 - Tamanho das amostras utilizadas na construção dos modelos de regressão logística multiníveis. Estado de São Paulo. 2006

\begin{tabular}{l|c|c|c}
\hline Modelo & $\begin{array}{c}\text { Nível 3 } \\
\text { (DRS) }\end{array}$ & $\begin{array}{c}\text { Nível 2 (Setor } \\
\text { Censitário) }\end{array}$ & $\begin{array}{c}\text { Nível 1 } \\
\text { (Indivíduo) }\end{array}$ \\
\hline Condição de utilização de serviços de saúde & 17 DRS & 1474 & 41930 \\
Tipo de serviço de saúde utilizado & 17 DRS & 1456 & 12798 \\
\hline
\end{tabular}

FONTE: Fundação Seade. Pesquisa de Condições de Vida - PCV. Elaboração do autor.

\subsubsection{Modelo - Condição de utilização de serviços de saúde}

A variável referente à utilização dos serviços de saúde possui distribuição de probabilidade de Bernoulli e pode ser escrita como $y_{i j k}=1$ se o indivíduo $i$, residente no setor censitário $j$, pertencente ao DRS $k$ utilizou serviços de saúde, e zero (0) em caso contrário. 
A taxa de utilização dos serviços de saúde para um determinado indivíduo $\left(y_{i j k}\right)$ corresponde a $E\left(y_{i j k} \mid \boldsymbol{x}_{i j k}\right)=\operatorname{Pr}\left(y_{i j k}=1 \mid \boldsymbol{x}_{i j k}\right)$, em que $\boldsymbol{x}_{i j k}$ refere-se às características do indivíduo que influenciam a probabilidade da ocorrência do evento, ou seja, utilização dos serviços de saúde.

Supondo que a $\operatorname{Pr}\left(y_{i j k}=1 \mid \boldsymbol{x}_{i j k}\right)$ possa ser escrita como:

$$
\operatorname{Pr}\left(y_{i j k}=1 \mid \boldsymbol{x}_{i j k}\right)=\operatorname{logit}^{-1}\left(\boldsymbol{\beta}^{\prime} \boldsymbol{x}\right) \equiv \frac{e^{\beta x}}{1+\theta^{\beta^{\beta} x}}
$$

Assim,

$$
\operatorname{logit}\left\{\operatorname{Pr}\left(y_{i j k}=1 \mid \boldsymbol{x}_{i j k}\right)\right\} \equiv \ln \left\{\frac{\operatorname{Pr}\left(y_{i j k}=1 \mid x_{i j k}\right)}{1-\operatorname{Pr}\left(y_{i j k}=1 \mid x_{i j k}\right)}\right\}=\boldsymbol{\beta}^{\prime} \boldsymbol{x} \text {. }
$$

A equação (4) constitui a forma usual de apresentação do modelo de regressão logística a partir da abordagem de modelos lineares generalizados, em que a função de ligação corresponde ao logito (McCULLAGH e NELDER, 1989).

Nessa abordagem, não há no nível do indivíduo o termo residual $\varepsilon_{\mathrm{ijk}}$, uma vez que a relação entre a probabilidade e as variáveis que influenciam o evento é determinística, apesar de as respostas geradas pela distribuição de Bernoulli serem aleatórias (RABEHESKETH e SKRONDAL, 2008).

O modelo logístico em três níveis pode ser escrito como:

\section{Nível do indivíduo (i)}

$$
\begin{aligned}
& \operatorname{Logit}\left\{\operatorname{Pr}\left(y_{i j k}=1 \mid x_{i j k}, \eta_{1 j k}\right)\right\}=\eta_{1 j k}+\beta_{1} x_{1 i j k}+\beta_{2} x_{2 i j k}+\beta_{3} x_{3 i j k}+ \\
& \beta_{4} x_{4 i j k}+\beta_{5} x_{5 i j k}+\beta_{6} x_{6 i j k}+\beta_{7} x_{7 i j k}+\beta_{8} x_{1 i j k} x_{6 i j k}+ \\
& \beta_{9} x_{2 i j k} x_{6 i j k}+\beta_{10} x_{3 i j k} x_{6 i j k}
\end{aligned}
$$


onde: $\left(\mathbf{x}_{i j k}=x_{1 i j k}, x_{2 i j k}, x_{3 i j k}, x_{4 i j k}, x_{5 i j k}, x_{6 i j k}, x_{7 i j k}\right)^{\mathrm{t}}$ é vetor com as variáveis no nível do individuo no setor j e DRS k;

$x_{1 i j k} x_{6 i j k}$ representa a interação entre idade e escolaridade (pessoas com 20 a 44 anos e pelo menos oito anos de estudo);

$x_{2 i j k} x_{6 i j k}$ representa a interação entre idade e escolaridade (pessoas com 45 e 59 anos e pelo menos oito anos de estudo);

$x_{3 i j k} x_{6 i j k}$ representa a interação entre idade e escolaridade (pessoas com 60 anos e mais e pelo menos oito anos de estudo);

$\eta_{1 j k}$ representa o intercepto que varia entre os setores censitários e os DRS.

\section{Nível do setor censitário (j)}

$$
\eta_{1 j k}=\pi_{11 k}+\pi_{12} x_{11, j k}+\varsigma_{j k}^{(2)}
$$

onde:

$\pi_{12}$ corresponde ao efeito da condição de vulnerabilidade à pobreza do setor censitário na utilização dos serviços de saúde;

$\varsigma_{j k}^{(2)}$ corresponde ao intercepto aleatório que varia entre os setores censitários; $\pi_{11 k}$ representa o intercepto que varia entre os DRS.

\section{Nível do DRS ( $k$ )}

$$
\pi_{11 k}=\gamma_{111}+\gamma_{112} x_{12, k}+\gamma_{113} x_{13, k}+\gamma_{114} x_{14, k}+\varsigma_{k}^{(3)}
$$

onde:

$x_{12, k}, x_{13, k}, x_{14, k}, x_{15, k}$ é vetor com as variáveis no nível do DRS k;

$\gamma_{111}$ corresponde ao intercepto; 
$\gamma_{112}$ corresponde ao efeito do número de médicos por 1.000 habitantes no DRs na utilização dos serviços de saúde;

$\gamma_{113}$ corresponde ao efeito do porcentual de beneficiários de planos de saúde no DRs na utilização dos serviços de saúde;

$\gamma_{114}$ corresponde ao efeito do porcentual de população cadastrada no PSF no DRs na utilização dos serviços de saúde;

$\varsigma_{k}^{(3)}$ corresponde ao intercepto aleatório que varia entre os DRS.

Os componentes de variância $\varsigma_{j k}^{(2)}$ e $\varsigma_{k}^{(3)}$ são supostos independentes, com $\varsigma_{j k}^{(2)} / \boldsymbol{x}_{i j k}, \varsigma_{k}^{(3)} \sim N\left(0, \psi^{(2)}\right)$ e $\varsigma_{k}^{(3)} / \boldsymbol{x}_{i j k} \sim N\left(0, \psi^{(3)}\right)$

O modelo pode ser reescrito como:

$$
\begin{aligned}
\operatorname{Logit}\left\{\operatorname{Pr}\left(y_{i j k}=1 \mid \mathbf{x}_{i j k}, \eta_{1 j k}\right)\right\}=\beta_{1} x_{1 i j k}+\beta_{2} x_{2 i j k}+\beta_{3} x_{3 i j k}+ \\
\beta_{4} x_{4 i j k}+\beta_{5} x_{5 i j k}+\beta_{6} x_{6 i j k}+\beta_{7} x_{7 i j k}+\beta_{8} x_{1 i j k} x_{6 i j k}+ \\
\beta_{9} x_{2 i j k} x_{6 i j k} \quad \beta_{10} x_{3 i j k} x_{6 i j k}+\pi_{12} x_{11, j k}+\varsigma_{j k}^{(2)}+\gamma_{111}+ \\
\gamma_{112} x_{12, k}+\gamma_{113} x_{13, k}+\gamma_{114} x_{14, k}+s_{k}^{(3)}
\end{aligned}
$$

E fazendo, $\pi_{12-}=\beta_{11}, \gamma_{111}=\beta_{0}, \gamma_{112-}=\beta_{12}, \gamma_{113}=\beta_{13}, \gamma_{114-}=\beta_{14}$. O modelo ficará:

$$
\begin{aligned}
& \operatorname{Logit}\left\{\operatorname{Pr}\left(y_{i j k}=1 \mid \mathbf{x}_{i j k}, \eta_{1 j k}\right)\right\}=\left(\beta_{0}+\varsigma_{j k}^{(2)}+\varsigma_{k}^{(3)}\right)+\beta_{1} x_{1 i j k}+ \\
& \beta_{2} x_{2 i j k}+\beta_{3} x_{3 i j k}+\beta_{4} x_{4 i j k}+\beta_{5} x_{5 i j k}+\beta_{6} x_{6 i j k}+\beta_{7} x_{7 i j k}+ \\
& \beta_{8} x_{1 i j k} x_{6 i j k}+\beta_{9} x_{2 i j k} x_{6 i j k} \beta_{10} x_{3 i j k} x_{6 i j k}+\beta_{11} x_{11, j k}+\beta_{12} x_{12, k}+ \\
& \beta_{13} x_{13, k}+\beta_{14} x_{14, k}
\end{aligned}
$$


A equação (9) equivale a um modelo de regressão com efeitos mistos, em que o intercepto é aleatório, segundo o setor censitário e o DRS. Todos os demais componentes do modelo são fixos, ou seja, seu efeito na probabilidade de um indivíduo utilizar serviços de saúde é constante, independentemente do setor censitário ou do DRS em que o indivíduo reside.

As variáveis renda familiar per capita $\left(x_{8 j k}, x_{9 j k}, x_{10 j k}\right)$ e posse de convênio ou plano de saúde $\left(x_{7 j k}\right)$ não foram consideradas simultaneamente no modelo, uma vez que a grande associação existente entre elas implica problemas de multicolinearidade. Assim, foram processados dois modelos: um com renda familiar per capita e outro com a condição de posse de convênio ou plano de saúde.

As interações foram incorporadas no modelo porque, entre as pessoas mais velhas, a proporção de indivíduos com fundamental incompleto é muito maior do que entre os mais jovens. Assim, para as pessoas mais idosas, a baixa escolaridade pode estar refletindo o grau de ensino de sua geração e não necessariamente uma barreira para a utilização dos serviços de saúde. Portanto, para a verificação do fator escolaridade como um facilitador ou barreira para a utilização dos serviços de saúde, torna-se necessário o controle da idade na sua análise.

\subsubsection{Modelo - Tipo de serviço utilizado}

Para o modelo referente ao tipo de serviço utilizado pode-se definir $y_{i j k}^{r}=1$ para utilização de serviços gratuitos de saúde, ou seja, aqueles referentes ao SUS, e $y_{i j k}^{r}=0$ para utilização de serviços pré-pagos, isto é, planos e convênios médicos. Não foram 
consideradas as situações em que ocorreu pagamento para realização do atendimento.

Analogamente à equação (9), o modelo pode ser escrito como:

$$
\begin{aligned}
& \operatorname{Logit}\left\{\operatorname{Pr}\left(y_{i j k}^{r}=1 \mid \mathbf{x}_{i j k}, \eta_{1 j k}\right)\right\}=\left(\beta_{0}^{r}+\varsigma_{j k}^{(2)}+\varsigma_{k}^{(3)}\right)+\beta_{1}^{r} x_{1 i j k}+ \\
& \beta_{2}^{r} x_{2 i j k}+\beta_{3}^{r} x_{3 i j k}+\beta_{4}^{r} x_{4 i j k}+\beta_{5}^{r} x_{5 i j k}+\beta_{6}^{r} x_{6 i j k}+\beta_{11}^{r} x_{11, j k}+ \\
& \beta_{12}^{r} x_{12, k}+\beta_{13}^{r} x_{13, k}+\beta_{14}^{r} x_{14, k}+\beta_{15}^{r} x_{8 i j k}+\beta_{16}^{r} x_{9 i j k}+\beta_{17}^{r} x_{10 i j k}
\end{aligned}
$$

Os componentes de variância $\varsigma_{j k}^{(2)}$ e $\varsigma_{k}^{(3)}$ são supostos independentes, com $\varsigma_{j k}^{(2)} / \boldsymbol{x}_{i j k}, \varsigma_{k}^{(3)} \sim N\left(0, \psi^{(2)}\right)$ e $\varsigma_{k}^{(3)} / \boldsymbol{x}_{i j k} \sim N\left(0, \psi^{(3)}\right)$.

Para cada modelo foram calculados os coeficientes de correlação intraclasse entre os setores censitários e para os DRS.

O coeficiente de correlação intraclasse no modelo de componentes de variância com três níveis pode ser expresso como:

$$
\begin{aligned}
& \rho(D R S) \equiv \frac{\psi^{(s)}}{\psi^{(2)}+\psi^{(s)}+\pi^{2} / 3} \\
& \rho(S C, D R S) \equiv \frac{\psi^{(2)}+\psi^{(3)}}{\psi^{(2)}+\psi^{(3)}+\pi^{2} / 3}
\end{aligned}
$$

onde: SC refere-se ao setor censitário e DRS ao Departamento Regional de Saúde; $\psi^{(2)}>0$ corresponde à variância do segundo nível (setor censitário); $\psi^{(3)}>0$ corresponde à variância do terceiro nível (DRS); e $\pi^{2} / 3$ refere-se à variância devida ao indivíduo (primeiro nível) (RABE - HESKETH e SKRONDAL, 2008).

Essa medida expressa a similaridade existente entre os residentes no mesmo DRS (ou no mesmo setor censitário) em relação à utilização de serviços de saúde (ou tipo de serviço utilizado). Assim, quanto maior for o valor de $\rho$, maior será a homogeneidade do DRS (ou setor censitário) no que diz respeito à variável de interesse 
e maior será a heterogeneidade entre eles. No presente caso, valores altos de $\rho$ indicam diferenças entre os DRS (ou setores censitários) em relação à proporção de pessoas que utilizaram serviços de saúde nos últimos 30 dias (ou tipo de serviço utilizado). Já valores pequenos refletem a homogeneidade dos DRS (ou setores censitários) para essas variáveis.

Como $\psi^{(2)}>0$ e $\psi^{(3)}>0$, tem-se que $\rho(S C, D R S)>\rho(D R S)$, implicando maior semelhança entre indivíduos de um determinado DRS que residem no mesmo setor censitário, em relação àqueles residentes nesse mesmo DRS mas em outro setor censitário.

A correlação intraclasse $(\rho)$ assume valores entre 0 e 1 , sendo que o valor 1 ocorre quando, em cada DRS (ou setor censitário), todos os elementos possuem o mesmo valor para a variável de interesse. O valor zero, ao contrário, indica que o comportamento da variável de interesse não depende do DRS (ou setor censitário).

No tipo de estudo ora realizado, em que as unidades que compõem os níveis do modelo são setores censitários e agrupamentos de setores censitários ou municípios, como no caso dos DRS, os valores de $\rho$ são pequenos, a maioria abaixo de 0,15 (KALTON 1983).

Também foram calculadas as razões de vantagem (odds ratio) para os fatores do modelo: $R C=\frac{\operatorname{pr}\left(y_{i j k}=1 \mid x_{i j k}\right) / 1-\operatorname{pr}\left(y_{i j k}=1 \mid x_{i j k}\right)}{\operatorname{Pr}\left(y_{i j k}=1 \mid x_{i j k}^{\prime}\right) / 1-\operatorname{Pr}\left(y_{i j k}=1 \mid x_{i j k}\right)}$, em que $\boldsymbol{x}_{i j k}$ e $\boldsymbol{x}_{i j k}^{\prime} \mid$ correspondem às características do indivíduo que influenciam a probabilidade da ocorrência do evento 
$\left(y_{i j k}=1\right)$. No modelo de regressão logística, as razões de vantagem podem ser escritas

como: $\mathrm{RC}=e^{\beta_{z}}$, em que z corresponde à z-ésima variável no modelo.

\subsubsection{Variáveis utilizadas no estudo}

O Quadro 1 apresenta as variáveis utilizadas no trabalho, sendo que suas

definições e conceitos encontram-se no Anexo 3.

Quadro 1 - Variáveis utilizadas no estudo

\begin{tabular}{|c|c|c|}
\hline Variável & Fonte & Ano \\
\hline $\begin{array}{l}\text { - Condição de utilização de serviços de saúde } \\
0 \text { - Não utilizou nos últimos } 30 \text { dias } \\
1 \text { - Utilizou nos últimos } 30 \text { dias }\end{array}$ & \multirow{7}{*}{ Seade - PCV } & \multirow{7}{*}{2006} \\
\hline $\begin{array}{l}\text { • Tipo de serviço utilizado } \\
1 \text { - Utilizou o SUS } \\
1 \text { - Utilizou plano ou convênio médico }\end{array}$ & & \\
\hline $\begin{array}{l}\text { Sexo } \\
0-\text { Masculino } \\
1-\text { Feminino }\end{array}$ & & \\
\hline $\begin{array}{l}\text { Faixa Etária } \\
\begin{array}{l}1-15 \text { a } 19 \text { anos } \\
2-20 \text { a } 44 \text { anos } \\
3-45 \text { a } 59 \text { anos } \\
4-60 \text { anos e mais }\end{array}\end{array}$ & & \\
\hline $\begin{array}{l}\text { - Raça/cor } \\
\quad 0 \text { - Branca e amarela } \\
1 \text { - Preta, parda e indigena }\end{array}$ & & \\
\hline $\begin{array}{l}\text { - Renda familiar per capita (em sal. min. de set/2006) } \\
\text { 1 - Até } 1 / 2 \text { salário mínimo } \\
2 \text { - Mais de } 1 \frac{1}{2} \text { a } 1 \text { salário mínimo } \\
3 \text { - Mais de } 1 \text { a } 2 \text { salários mínimos } \\
\text { 4 - Mais de } 2 \text { salários mínimos }\end{array}$ & & \\
\hline $\begin{array}{l}\text { - Condição de posse de convênio ou plano de saúde } \\
0 \text { - Possui convênio } \\
1 \text { - Não possui convênio }\end{array}$ & & \\
\hline
\end{tabular}

(continua) 
Quadro 1 - Variáveis utilizadas no estudo

(conclusão)

\begin{tabular}{|c|c|c|}
\hline Variável & Fonte & Ano \\
\hline $\begin{array}{l}\text { - Nível de escolaridade } \\
0 \text { - Pelo menos fundamental completo } \\
1 \text { - Sem fundamental completo }\end{array}$ & & \\
\hline $\begin{array}{l}\text { - Tipo de estabelecimento procurado } \\
1 \text { - Pronto-socorro } \\
\text { 2- Hospital } \\
3 \text { - Clínica ou consultório médico } \\
5 \text { - Posto ou centro de saúde (fixo ou não) } \\
6 \text { - Laboratório ou centro de diagnóstico } \\
7 \text { - Outros }\end{array}$ & & \\
\hline $\begin{array}{l}\text { - Atendimento marcado com antecedência } \\
1 \text { - Com agendamento } \\
2 \text { - Sem agendamento }\end{array}$ & & \\
\hline $\begin{array}{r}\text { - Índice Paulista de Vulnerabilidade Social - IPVS } \\
0 \text { - Grupos 1,2 e } 3 \text { (sem vulnerabilidade à pobreza) } \\
1 \text { - Grupos 4,5 e } 6 \text { (com vulnerabilidade à pobreza) }\end{array}$ & Seade & 2000 \\
\hline - Número de médicos por 1.000 habitantes & $\begin{array}{l}\text { Seade - } \\
\text { CRM/SP }\end{array}$ & $\begin{array}{l}\text { Dezembro } \\
\text { de } 2006\end{array}$ \\
\hline $\begin{array}{l}\text { Porcentual de beneficiários de planos e convênios de } \\
\text { assistência médica }\end{array}$ & ANS/Datasus & $\begin{array}{l}\text { Dezembro } \\
\text { de } 2006\end{array}$ \\
\hline $\begin{array}{l}\text { Porcentual de pessoas cadastradas no Programa } \\
\text { Saúde da Família - PSF }\end{array}$ & Datasus & 2006 \\
\hline
\end{tabular}

Para a variável sobre agendamento para realização do atendimento, consideraramse, na categoria Com agendamento, as pessoas que marcaram o atendimento no próprio estabelecimento em que foi atendido, em outro local ou por telefone. A categoria Sem agendamento engloba os atendimentos de urgência, campanhas de saúde, vacinação e outros. 


\subsubsection{Processamento dos dados}

Todos os cálculos estatísticos foram realizados com o programa computacional STATA versão 10.0, com os modelos de regressão processados por meio do módulo GLLAMM.

As estimativas do modelo foram obtidas utilizando-se os pesos amostrais, sendo utilizados dez pontos de quadratura para obtenção das estimativas.

Todos os demais cálculos foram realizados em planilha Excel para Windows 2007.

\subsection{Eficiência}

Para a determinação do grau de eficiência dos DRS na utilização dos recursos em saúde, utilizou-se a Análise por Envoltória de Dados (Data Envelopment Analysis $D E A)$.

Essa técnica desenvolvida por Charnes, Cooper e Rhodes, em 1978, tem sido empregada em larga escala na avaliação de programas e projetos de órgãos governamentais, organizações não-governamentais e, mais recentemente, em empresas do setor privado. Segundo Banker et al. (1984), a DEA permite aos gestores avaliações ex post da eficiência relativa dos resultados alcançados, por meio da estimação da razão de eficiência técnica para cada unidade analisada, que consiste na relação entre os resultados observados para os objetos do estudo (unidades) e os insumos associados aos recursos disponibilizados para que sejam alcançados tais resultados.

Na DEA as observações são denominadas Unidades Tomadoras de Decisão, cuja sigla em inglês é DMUs - Decision Making Units - e correspondem às unidades sob 
avaliação no estudo. Para a validade do estudo, é necessário que sob as mesmas condições as unidades obtenham os mesmos resultados.

Os resultados observados para as DMUs correspondem ao numerador da razão de eficiência, e são denominados outputs ou produtos. Os insumos são denominados inputs e correspondem aos recursos despendidos para a obtenção dos resultados. Por meio da DEA é possível relacionar vários outputs e inputs em uma mesma razão de eficiência, que varia em uma escala de 0 a 1 , em que o zero representa ineficiência e 1 a eficiência máxima diante dos insumos disponíveis.

Em termos matemáticos a razão de eficiência pode ser expressa por:

$$
h_{k}=\frac{\sum_{j=1}^{m} u_{j} y_{j k}}{\sum_{i=1}^{n} v_{i} x_{i k}} \leq 1
$$

Para $k=1,2, \ldots 17$ e $u_{j}>0$ e $v_{i}>0$.

$h_{k}$ representa a razão de eficiência para $m$ variáveis de resultados e $n$ variáveis de insumos em $k$ DMUs.

$\sum_{j=1}^{m} u_{j} y_{j k}$ : representa o conjunto dos resultados obtidos e $y_{j k}$ representa o j-ésimo output.

$\sum_{i=1}^{n} v_{i} x_{i k}$ : representa o conjunto dos insumos obtidos e $x_{i k}$ representa o i-ésimo input.

$u_{j}$ e $v_{i}$ correspondem aos pesos associados, respectivamente, aos resultados e insumos.

Assim, o modelo DEA consiste em encontrar o conjunto de pesos $u_{j}$ e $v_{i}$ maximizem $h_{k}$, ou seja, as combinações lineares $\left(\sum_{j=1}^{m} u_{j} y_{j k}\right.$ e $\left.\sum_{i=1}^{n} v_{i} x_{i k}\right)$ que tornam máxima a razão de eficiência. 
Os dois modelos clássicos em DEA são utilizados no estudo. O modelo CCR (Charnes, Cooper, e Rhodes) ou CRS (Constant Return to Scale) pressupõe retornos constantes de escalas, ou seja, para um crescimento dos recursos ocorre um aumento proporcional nos resultados. Matematicamente realiza-se a maximização de $h_{k}=\sum_{j=1}^{m} u_{j} y_{j k} \operatorname{com} \sum_{i=1}^{n} v_{i} x_{i k}=1$ e $\sum_{j=1}^{m} u_{j} y_{j k}-\sum_{i=1}^{n} v_{i} x_{i k} \leq 0 ; u_{j}>0$ e $v_{i}>0$.

O segundo modelo denominado BCC (Banker, Charnes e Cooper) ou VRS (Variable Return to Scale) não pressupõe proporcionalidade entre inputs e outputs; por exemplo, o aumento dos gastos em saúde implicará crescimento na produção ambulatorial não proporcional aos recursos investidos. Segundo Belloni (2000 apud NOVA, 2007)4, o modelo BCC, ao permitir que a produtividade máxima varie em função da escala de produção, possibilita a utilização de unidades de portes distintos. Em termos matemáticos, a razão a ser maximizada é $h_{k}=\sum_{j=1}^{m} u_{j} y_{j k}-u_{k}$.

A relação entre inputs e outputs estabelecida pelos modelos CCR e BCC pode ser visualizada no Gráfico 2, em que se relaciona a produção ambulatorial e a despesa em saúde O retorno constante de escala, pressuposto pelo modelo CCR, é visualizado na figura da esquerda, em que para cada aumento na despesa ocorre um aumento proporcional na produção ambulatorial. Já a figura à direita mostra que o acréscimo nas despesas provoca tanto o aumento proporcional na produção ambulatorial quanto o ganho de escala até a relativa estabilidade da produção ambulatorial.

\footnotetext{
${ }^{4}$ Belloni JA (Departamento de Engenharia de Produção e Sistemas UFSC). Uma metodologia de avaliação da eficiência produtiva de Universidades Federais Brasileiras. [Tese de Doutorado]. 2000. Nova SPCC (Faculdade de Economia de Administração FEA-USP). Capacitação no software Frontier Analyst. [manual]. 2007.
} 
Gráfico 2 - Exemplo da relação entre despesas totais em saúde (input) e produção ambulatorial (output) pressuposta nos modelos CCR e BCC

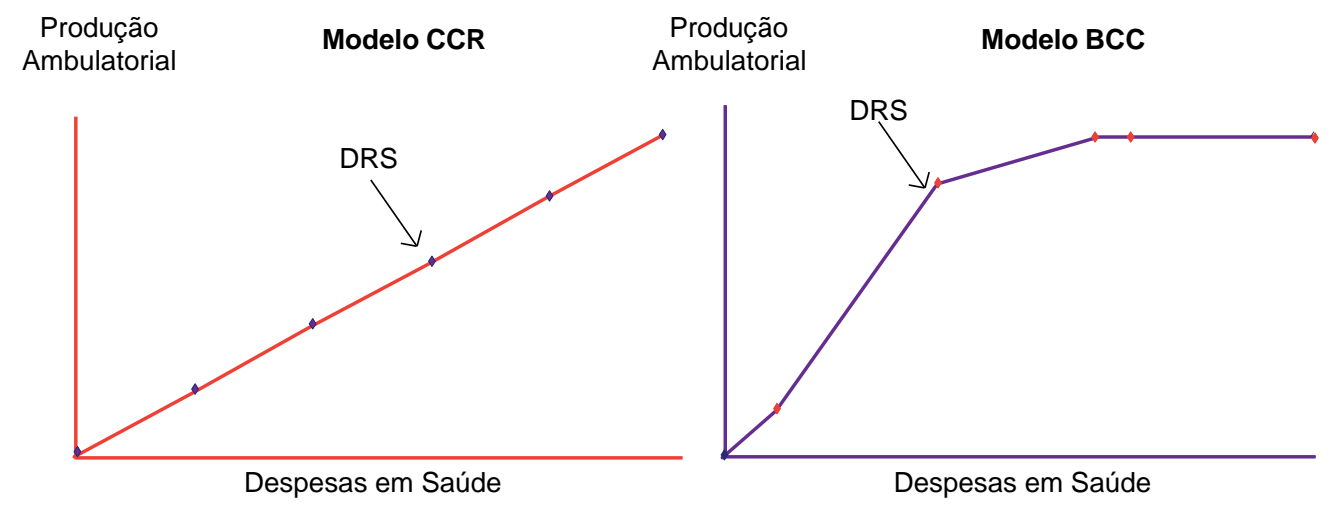

FONTE: Elaboração do autor.

No presente estudo considera-se DMU o Departamento Regional de Saúde - DRS, tendo-se assim, 17 DMUs. Um DRS é considerado eficiente quando, comparado aos demais, atinge um grau de produção condizente com a quantidade de insumos. Em contraposição, uma regional de saúde é classificada como ineficiente quando diante do total de recursos despendidos, os resultados alcançados são menores que do que os esperados (em comparação ao conjunto das outras 16 analisadas). Esse fato indica que a eficiência não está nos resultados alcançados, mas sim na relação entre resultados e insumos.

A escolha dos inputs no modelo baseou-se na relação existente entre a variável candidata a input e o output, além do fato de que os indicadores selecionados devem ser relevantes para o gestor.

Assim, para analisar a eficiência na produção dos serviços de saúde no DRS, buscaram-se, entre as variáveis de resultados, aquelas que sintetizassem a oferta do 
sistema público de saúde. Para tanto, optou-se por utilizar o total dos procedimentos ambulatoriais e hospitalares realizados no DRS, pois essas duas dimensões resumem a produção do setor de saúde, que foi expressa por duas variáveis: total da produção ambulatorial, incluindo-se atenção básica, média e alta complexidades; e total de internações de residentes.

Dado o ano do estudo, 2006, não foi possível identificar para os procedimentos ambulatoriais de média e alta complexidades o montante que corresponde aos residentes no DRS, pois essa informação passou a estar disponível a partir de 2008. Para esse ano, o DRS de Barretos é o que, proporcionalmente, apresenta maior disparidade entre a produção de residentes e não-residentes - 110,8\%, ou seja, aproximadamente $11 \%$ da produção correspondente à população residente é realizada com não-residentes. A seguir têm-se a Grande São Paulo (102,0\%), Bauru (101,4\%) e Ribeirão Preto (101,1\%). Por outro lado, Campinas e São José do Rio Preto praticamente atingem 100\%. Já São João da Boa Vista (95,8\%) e Registro (95,7\%) constituem os DRS com menor taxa de atendimento de sua população residente (Gráfico 3).

Vis à vis a oferta dos serviços públicos disponibilizados pelo sistema público de saúde, tem-se o gasto em saúde como a variável síntese dos recursos despendidos para se atingir esse fim. Assim, utilizou-se como insumo ou input no modelo o gasto total em saúde realizado no DRS, que consiste na soma das despesas em saúde realizadas, em 2006, pelo município e Estado.

Duas fontes de despesas foram consideradas: as despesas de saúde na esfera municipal, que se referem ao montante das despesas com a administração direta e indireta 
com o setor de saúde realizado no âmbito do município, incluindo-se as transferências federais; e as despesas na esfera estadual relativas ao gasto realizado pelo governo estadual. A partir dessas duas fontes obteve-se o total das despesas em saúde composto pela soma das despesas municipais e estaduais, alocadas para o município.

Apesar da importância do gasto em saúde, a capacidade ambulatorial e hospitalar instalada e os recursos humanos disponíveis também apresentam potencial para influenciar na relação entre recursos despendidos e produção, pois, a diversidade do sistema de saúde no Estado de São Paulo pode ser expressa pelo tipo de rede instalada de estabelecimentos de saúde e seus diferentes níveis de complexidade. Assim, consideraram-se candidatos a inputs o número de leitos vinculados ao SUS e o número de médicos por 1.000 habitantes.

Gráfico 3 - Razão entre o total da produção ambulatorial de média e alta complexidades e o total da produção ambulatorial de média e alta complexidades entre os residentes no DRS, segundo Departamento Regional de Saúde. Estado de São Paulo. 2008.

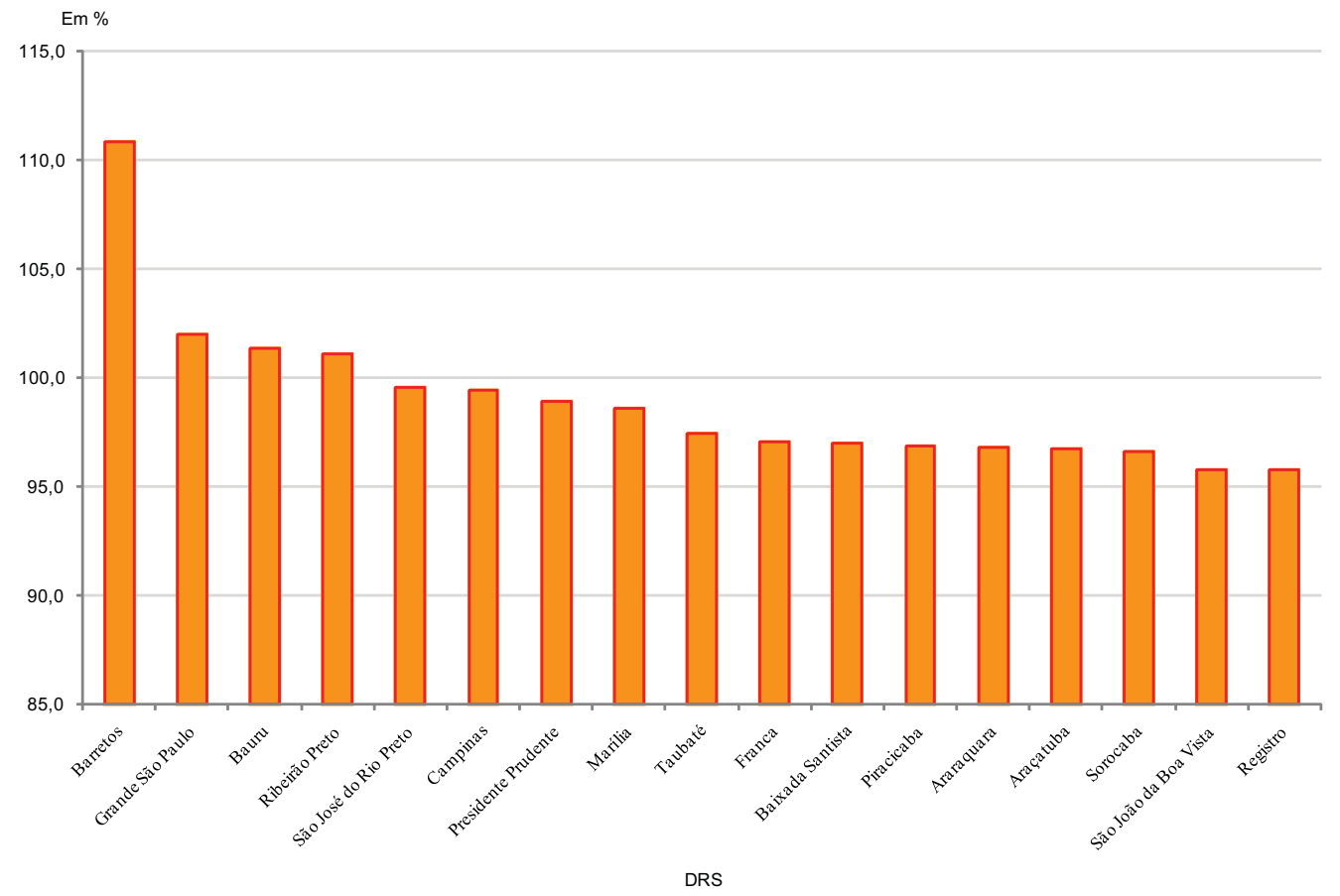

FONTE: Datasus. Sistema de Informações Ambulatoriais (SIA/SUS). Elaboração do autor. 


\subsubsection{Fonte de dados}

Para as variáveis relacionadas aos resultados, foram utilizados registros administrativos derivados do Sistema de Informações Ambulatoriais - SIA/SUS - e Sistema de Informações Hospitalares - SIH/SUS, disponíveis para consulta pública no sítio do sistema Datasus (http://www.datasus.gov.br).

O SIA/SUS apresenta o número de atendimentos e tipos de procedimentos realizados para todos os municípios brasileiros desde 1994. Essas informações têm como fonte o Boletim de Produção Ambulatorial (BPA) preenchido pelas unidades ambulatoriais, inclusive com a produção ambulatorial correspondente ao Programa Saúde da Família - PSF.

Já o SIH/SUS consiste no consolidado das informações referentes às internações hospitalares ocorridas nas unidades hospitalares participantes do SUS. A fonte das informações é a AIH (Autorização de Internação Hospitalar), enviada pelas unidades hospitalares para gestores municipais (se em gestão plena) ou estaduais (para os demais).

A Tabela 4 apresenta os valores referentes à produção ambulatorial e hospitalar nos Departamentos Regionais de Saúde - DRS em 2006.

As informações sobre gastos municipais em saúde foram obtidas do Sistema de informações sobre Orçamentos Públicos em Saúde - Siops, que é constituído por um banco de dados sobre despesas e receitas referentes a ações e serviços de saúde de responsabilidade do poder público. Os dados informados são de responsabilidade do município e, desde 2002, de preenchimento obrigatório. Em 2006, todos os 645 municípios do Estado de São Paulo haviam informado o campo referente à despesa 
total com saúde. As informações do Siops estão disponíveis para consulta pública no sítio do sistema Datasus (http://www.datasus.gov.br).

Tabela 4 - Produção ambulatorial, número de internações, segundo Departamento Regional de Saúde - DRS. Estado de São Paulo. 2006

\begin{tabular}{|c|c|c|c|c|c|}
\hline \multirow[b]{2}{*}{$\begin{array}{l}\text { Departamento Regional de } \\
\text { Saúde - DRS }\end{array}$} & \multicolumn{4}{|c|}{ Produção ambulatorial } & \multirow{2}{*}{\begin{tabular}{|c}
$\begin{array}{l}\text { Produção } \\
\text { hospitalar }\end{array}$ \\
Total da \\
interna- \\
ções dos \\
residentes
\end{tabular}} \\
\hline & Total & $\begin{array}{l}\text { Atenção } \\
\text { básica }\end{array}$ & $\begin{array}{c}\text { Média e } \\
\text { alta comple- } \\
\text { xidades }\end{array}$ & $\begin{array}{c}\text { Participação } \\
\text { da atenção } \\
\text { básica no to- } \\
\text { tal da pro- } \\
\text { dução ambu- } \\
\text { latorial (\%) }\end{array}$ & \\
\hline Estado de São Paulo & 659905857 & 256000071 & 403905786 & 38,8 & 2257438 \\
\hline DRS 01 - Grande São Paulo & 305548984 & 101185108 & 204363876 & 33,1 & 934975 \\
\hline DRS 02 - Araçatuba & 8474148 & 4190661 & 4283487 & 49,5 & 49649 \\
\hline DRS 03 - Araraquara & 11558255 & 5676595 & 5881660 & 49,1 & 51668 \\
\hline DRS 04 - Baixada Santista & 31472280 & 13977993 & 17494287 & 44,4 & 83581 \\
\hline DRS 05 - Barretos & 9533051 & 4194390 & 5338661 & 44,0 & 31474 \\
\hline DRS 06 - Bauru & 29187975 & 11133415 & 18054560 & 38,1 & 120973 \\
\hline DRS 07 - Campinas & 60617537 & 22819830 & 37797707 & 37,6 & 195821 \\
\hline DRS 08 - Franca & 9817483 & 4267769 & 5549714 & 43,5 & 41005 \\
\hline DRS 09 - Marília & 23985922 & 12454142 & 11531780 & 51,9 & 89280 \\
\hline DRS 10 - Piracicaba & 16525370 & 7488741 & 9036629 & 45,3 & 69139 \\
\hline DRS 11 - Presidente Prudente & 14480789 & 7162440 & 7318349 & 49,5 & 55229 \\
\hline DRS 12 - Registro & 4519247 & 2431801 & 2087446 & 53,8 & 14416 \\
\hline DRS 13 - Ribeirão Preto & 23783178 & 10476656 & 13306522 & 44,1 & 80679 \\
\hline DRS 14 - São João da Boa Vista & 13629079 & 7000548 & 6628531 & 51,4 & 62553 \\
\hline DRS 15 - São José do Rio Preto & 30860668 & 11474835 & 19385833 & 37,2 & 118598 \\
\hline DRS 16 - Sorocaba & 33855015 & 15826489 & 18028526 & 46,7 & 139484 \\
\hline DRS 17 - Taubaté & 32056876 & 14238658 & 17818218 & 44,4 & 118914 \\
\hline
\end{tabular}

FONTE: Datasus Sistema de Informações Ambulatoriais (SIA/SUS) Sistema de Informações Hospitalares (SIH/ SUS). Elaboração do autor. 
O gasto estadual municipalizado foi obtido por meio do trabalho realizado por Colaiacovo (2007), ${ }^{5}$ que alocou os gastos estaduais em saúde, segundo os cinco blocos de transferência do Termo de Limite Financeiro Global publicado pela Portaria GM/ 699, de 30/06/2006, e alterada pela Portaria GM 372/2007. Os recursos estaduais foram alocados aos blocos de recursos previstos nesse termo: Bloco I - Atenção Básica PAB fixo e PAB variável, Bloco II - Atenção de Média e Alta Complexidade; Bloco III - Vigilância em Saúde, Bloco IV - Assistência Farmacêutica; e Bloco V - Gestão do SUS.

Do total de 95 unidades de despesas - UD identificadas, discriminaram-se 50, ou seja, 45 não foram incluídas no estudo, tais como Laboratórios de Saúde Pública e Núcleos de Gestão Assistencial - NGA, que estão incorporados no total da execução orçamentária da UD - DRS. Para as 50 UDs que entraram no estudo, apurou-se um total de gastos com saúde, no valor de R \$ 4.169.860.179, com recursos do tesouro do Estado para todos os 645 municípios (COLAIACOVO, 2007). ${ }^{6}$

Para o número de leitos vinculados ao SUS, utilizou-se o Cadastro Nacional de Estabelecimentos de Saúde (CNES), que consiste no consolidado gerado pelo Datasus a partir das informações enviadas pelas Secretarias Municipais e Estaduais de Saúde através do Sistema de Cadastro Nacional de Estabelecimentos de Saúde (CNES/SUS), conforme determina a Portaria MS/SAS nº 51, de 21/06/1995. Esse cadastro apresenta informações sobre tipo de estabelecimentos de saúde, esfera administrativa, tipo de

\footnotetext{
${ }^{5}$ Colaiacovo IAL (Secretaria Estadual da Saúde - CPS/SES). Apuração dos gastos em saúde com recursos do tesouro do Estado de São Paulo [mimeo]. 2007.

${ }^{6}$ Id. ibid.
} 
atendimento prestado, tipo de gestão, recursos humanos, etc., disponíveis para consulta pública no sítio do sistema Datasus (http://www.datasus.gov.br).

Para o número de médicos por 1.000 habitantes, utilizaram-se as informações consolidadas pela Fundação Seade relativas ao total de médicos registrados no Conselho Regional de Medicina -CRM/SP, em dezembro de 2006, segundo município de residência.

A Tabela 5 apresenta os valores referentes aos recursos a serem utilizados no estudo.

Tabela 5 - Despesas em saúde, leitos SUS e médicos por mil habitantes, segundo Departamento Regional de Saúde - DRS. Estado de São Paulo. 2006

\begin{tabular}{|c|c|c|c|c|c|c|c|c|c|c|c|}
\hline \multirow[b]{2}{*}{$\begin{array}{l}\text { Departamento Regional de } \\
\text { Saúde - DRS }\end{array}$} & \multicolumn{8}{|c|}{ Despesa em saúde (Em R\$1.000) } & \multirow[b]{2}{*}{$\begin{array}{c}\text { Leitos } \\
\text { SUS }\end{array}$} & \multirow[b]{2}{*}{$\begin{array}{l}\text { Participação de } \\
\text { leitos SUS no } \\
\text { total de leitos } \\
(\%)\end{array}$} & \multirow[b]{2}{*}{$\begin{array}{l}\text { Número de } \\
\text { médicos } \\
\text { (Em mil hab.) }\end{array}$} \\
\hline & \multicolumn{2}{|c|}{ Total } & \multicolumn{3}{|c|}{ Município } & \multicolumn{2}{|c|}{ Estado } & $\begin{array}{c}\text { Participação das } \\
\text { despesas do } \\
\text { município no } \\
\text { total das } \\
\text { despesas (\%) }\end{array}$ & & & \\
\hline Estado de São Paulo & 14810 & 950 & 10 & 641 & 090 & 4169 & 860 & 71,8 & 51211 & 59,4 & \\
\hline DRS 01 - Grande São Paulo & 7672 & 870 & & 968 & 129 & 2704 & 740 & 64,7 & 21451 & 53,5 & 2,50 \\
\hline DRS 02 - Araçatuba & 256 & 417 & & 204 & 688 & 51 & 729 & 79,8 & 1241 & 72,7 & 1,24 \\
\hline DRS 03 - Araraquara & 277 & 998 & & 223 & 852 & 54 & 146 & 80,5 & 1119 & 61,1 & 1,28 \\
\hline DRS 04 - Baixada Santista & 625 & 199 & & 534 & 137 & 91 & 063 & 85,4 & 2038 & 63,2 & 1,86 \\
\hline DRS 05 - Barretos & 150 & 305 & & 112 & 386 & 37 & 919 & 74,8 & 849 & 65,1 & 1,43 \\
\hline DRS 06 - Bauru & 474 & 336 & & 306 & 077 & 168 & 258 & 64,5 & 3678 & 76,2 & 1,59 \\
\hline DRS 07 - Campinas & 1412 & 167 & 1 & 206 & 996 & 205 & 170 & 85,5 & 3952 & 58,2 & 2,26 \\
\hline DRS 08 - Franca & 202 & 425 & & 160 & 118 & 42 & 307 & 79,1 & 811 & 54,6 & 1,27 \\
\hline DRS 09 - Marília & 361 & 658 & & 277 & 280 & 84 & 379 & 76,7 & 2020 & 69,2 & 1,57 \\
\hline DRS 10 - Piracicaba & 384 & 819 & & 345 & 708 & 39 & 110 & 89,8 & 1364 & 52,8 & 1,46 \\
\hline DRS 11 - Presidente Prudente & 223 & 435 & & 163 & 156 & 60 & 279 & 73,0 & 1184 & 62,2 & 1,62 \\
\hline DRS 12 - Registro & 155 & 314 & & 73 & 370 & 81 & 944 & 47,2 & 276 & 77,7 & 0,71 \\
\hline DRS 13 - Ribeirão Preto & 482 & 886 & & 337 & 413 & 145 & 473 & 69,9 & 1885 & 64,4 & 2,99 \\
\hline DRS 14 - São João da Boa Vista & 234 & 903 & & 187 & 273 & 47 & 631 & 79,7 & 1201 & 62,2 & 1,29 \\
\hline DRS 15 - São José do Rio Preto & 450 & 221 & & 350 & 248 & 99 & 973 & 77,8 & 2182 & 53,5 & 2,05 \\
\hline DRS 16 - Sorocaba & 687 & 288 & & 518 & 118 & 169 & 170 & 75,4 & 3325 & 78,4 & 1,31 \\
\hline DRS 17 - Taubaté & 758 & 711 & & 672 & 142 & 86 & 569 & 88,6 & 2635 & 64,1 & 1,71 \\
\hline
\end{tabular}

FONTE: Datasus. Sistema de Informações sobre Orçamentos Públicos em Saúde - Siops; CNES; Colaiacovo (2007). Elaboração do autor. NOTA: Os valores monetários encontram-se em reais correntes de 2006. 


\subsubsection{O modelo de eficiência técnica}

Para a construção do modelo, as variáveis foram categorizadas em outputs - total da produção ambulatorial e o total de internações de residentes. Como inputs - despesa total em saúde, número de leitos SUS e médicos por mil habitantes. As variáveis despesa total com saúde, número de leitos SUS, total da produção ambulatorial e total das internações foram utilizadas na escala logarítmica, devido ao grande diferencial entre os valores observados para os 17 DRS.

A Tabela 6 apresenta a matriz de correlação de Pearson entre os inputs e outputs, comprovando a relação existente entre essas variáveis.

Tabela 6 - Matriz de correlação de Pearson entre inputs e outputs para o modelo de eficiência

\begin{tabular}{c|c|c|c}
\hline \multirow{2}{*}{ Output } & \multicolumn{3}{c}{ Input } \\
\cline { 2 - 4 } & $\begin{array}{c}\text { LN da despesa } \\
\text { total em saúde }\end{array}$ & $\begin{array}{c}\text { LN do número } \\
\text { de leitos SUS }\end{array}$ & $\begin{array}{c}\text { Médicos por } \\
1.000 \text { habitantes }\end{array}$ \\
\hline LN do total da produção ambulatorial & 0,966 & 0,971 & 0,711 \\
LN do total de internações & 0,949 & 0,989 & 0,668 \\
\hline
\end{tabular}

FONTE: Elaboração do autor.

Duas medidas de eficiência foram calculadas: Eficiência Técnica (CCR), que correspondente à eficiência na utilização dos recursos independentemente das condições de produção, como, por exemplo, o porte e a complexidade do sistema de saúde existente no DRS; e a Eficiência Puramente Técnica (BCC), que fornece a eficiência considerandose implicitamente o porte e a complexidade do sistema de saúde do DRS. Neste caso, pressupõe-se no modelo um retorno da variável de escala, ou seja, o aumento dos gastos em saúde e da capacidade instalada implicará crescimento na produção ambulatorial 
não proporcional aos recursos investidos. Essa suposição mostra-se adequada no caso das regionais de saúde que englobam grandes populações e/ou sistemas de saúde muito complexos, como da Grande São Paulo e Campinas.

Os modelos DEA foram processados com orientação output, ou seja, busca-se a eficiência por meio da maximização da produção ambulatorial e hospitalar, pois não se considera factível pressupor a diminuição de recursos na área de saúde. A Tabela 7 apresenta os dados utilizados no processamento.

Tabela 7 - Componentes do modelo de análise envoltória de dados - DEA, segundo Departamentos Regionais de Saúde. Estado de São Paulo. 2006

\begin{tabular}{|c|c|c|c|c|c|}
\hline \multirow[b]{2}{*}{$\begin{array}{l}\text { Departamento Regional de } \\
\text { Saúde - DRS }\end{array}$} & \multicolumn{3}{|c|}{ Input } & \multicolumn{2}{|c|}{ Output } \\
\hline & $\begin{array}{c}\text { LN da } \\
\text { despesa } \\
\text { total em } \\
\text { saúde }\end{array}$ & $\begin{array}{l}\text { LN do } \\
\text { número de } \\
\text { leitos SUS }\end{array}$ & $\begin{array}{l}\text { Médicos por } \\
1.000 \text { hab. }\end{array}$ & $\begin{array}{l}\text { LN do total } \\
\text { da produção } \\
\text { ambulatorial }\end{array}$ & $\begin{array}{l}\text { LN do total } \\
\text { de inter- } \\
\text { nações }\end{array}$ \\
\hline DRS 01 - Grande São Paulo & 22,76 & 9,97 & 2,50 & 19,54 & 13,75 \\
\hline DRS 02 - Araçatuba & 19,36 & 7,12 & 1,24 & 15,95 & 10,81 \\
\hline DRS 03 - Araraquara & 19,44 & 7,02 & 1,28 & 16,26 & 10,85 \\
\hline DRS 04 - Baixada Santista & 20,25 & 7,62 & 1,86 & 17,26 & 11,33 \\
\hline DRS 05 - Barretos & 18,83 & 6,74 & 1,43 & 16,07 & 10,36 \\
\hline DRS 06 - Bauru & 19,98 & 8,21 & 1,59 & 17,19 & 11,70 \\
\hline DRS 07 - Campinas & 21,07 & 8,28 & 2,26 & 17,92 & 12,18 \\
\hline DRS 08 - Franca & 19,13 & 6,70 & 1,27 & 16,10 & 10,62 \\
\hline DRS 09 - Marília & 19,71 & 7,61 & 1,57 & 16,99 & 11,40 \\
\hline DRS 10 - Piracicaba & 19,77 & 7,22 & 1,46 & 16,62 & 11,14 \\
\hline DRS 11 - Presidente Prudente & 19,22 & 7,08 & 1,62 & 16,49 & 10,92 \\
\hline DRS 12 - Registro & 18,86 & 5,62 & 0,71 & 15,32 & 9,58 \\
\hline DRS 13 - Ribeirão Preto & 20,00 & 7,54 & 2,99 & 16,98 & 11,30 \\
\hline DRS 14 - São João da Boa Vista & 19,27 & 7,09 & 1,29 & 16,43 & 11,04 \\
\hline DRS 15 - São José do Rio Preto & 19,93 & 7,69 & 2,05 & 17,24 & 11,68 \\
\hline DRS 16 - Sorocaba & 20,35 & 8,11 & 1,31 & 17,34 & 11,85 \\
\hline DRS 17 - Taubaté & 20,45 & 7,88 & 1,71 & 17,28 & 11,69 \\
\hline
\end{tabular}

FONTE: Datasus; Colaiacovo (2007). Elaboração do autor. 


\subsubsection{Processamento dos dados}

O modelo DEA foi processado por meio do programa computacional FRONTIER ANALYST. Todos os demais cálculos foram realizados em planilha Excel para Windows 2007. 


\section{RESULTADOS}

m 2006, o Estado de São Paulo possuía 40.175.797 habitantes distribuídos em 645 municípios agregados em 17 Departamentos Regionais de Saúde. Desse total populacional, 75,9\% tinham mais de 14 anos de idade, equivalendo a um contingente de 30.507.936 pessoas (Tabela 8). ${ }^{1}$

A distribuição da população e o número de municípios são heterogêneos em relação aos departamentos regionais de saúde. Os municípios pertencentes aos DRS da Grande São Paulo (47,3\%), Campinas (9,6\%), Baixada Santista (4,0\%), Taubaté $(5,4 \%)$ e Sorocaba (5,3\%) englobavam, em 2006, quase 70\% das pessoas com mais de 14 anos. Já o DRS de São José do Rio Preto é o DRS possui o maior número de municípios (101), que agregavam 3,7\% da população de 15 anos e mais do Estado (Tabela 8).

Em relação à estrutura etária, observam-se no Estado, aumento da participação relativa dos grupos etários acima dos 30 anos na população total e diminuição da representatividade dos mais jovens, principalmente o segmento de menores de 15 anos. O processo de envelhecimento da população paulista é consequência de três

\footnotetext{
${ }^{1}$ Projeção populacional para julho de 2006, produzida pela Fundação Seade. Nesse modelo de projeção populacional, denominado método dos componentes demográficos, considera-se, na simulação dos possíveis cenários futuros para a população paulista, a interação das três variáveis responsáveis pelo crescimento populacional: fecundidade, mortalidade e migração (FUNDAÇÃO SEADE, 2005).
} 
tendências que se mantêm presentes nas últimas décadas: aumento da esperança de vida ao nascer; queda dos níveis de fecundidade; e redução das taxas de migração para o Estado (FUNDAÇÃO SEADE, 2005; CARVALHO e RODRIGUEZ-WONG, 2008).

Tabela 8 - Número de municípios e população, segundo Departamentos Regionais de Saúde - DRS. Estado de São Paulo. 2006

\begin{tabular}{|c|c|c|c|c|c|}
\hline \multirow[b]{2}{*}{$\begin{array}{l}\text { Departamento Regional de } \\
\text { Saúde - DRS }\end{array}$} & \multirow[b]{2}{*}{$\begin{array}{c}\text { Número } \\
\text { de } \\
\text { Municípios }\end{array}$} & \multirow[b]{2}{*}{$\begin{array}{l}\text { População } \\
\text { total }\end{array}$} & \multicolumn{3}{|c|}{ População de 15 anos e mais } \\
\hline & & & Total & $\begin{array}{l}\% \text { no total } \\
\text { do Estado }\end{array}$ & $\begin{array}{c}\text { \% no total da } \\
\text { população } \\
\text { do DRS }\end{array}$ \\
\hline Total do Estado & 645 & 40.175 .797 & 30.507 .936 & 100,0 & 75,9 \\
\hline DRS 01 - Grande São Paulo & 39 & 19.268.059 & 14.438 .924 & 47,3 & 74,9 \\
\hline DRS 02 - Araçatuba & 40 & 695.332 & 549.780 & 1,8 & 79,1 \\
\hline DRS 03 - Araraquara & 24 & 897.201 & 700.303 & 2,3 & 78,1 \\
\hline DRS 04 - Baixada Santista & 9 & 1.621 .827 & 1.231 .264 & 4,0 & 75,9 \\
\hline DRS 05 - Barretos & 19 & 406.120 & 315.393 & 1,0 & 77,7 \\
\hline DRS 06 - Bauru & 68 & 1.605 .026 & 1.237 .632 & 4,1 & 77,1 \\
\hline DRS 07 - Campinas & 42 & 3.785 .698 & 2.922 .663 & 9,6 & 77,2 \\
\hline DRS 08 - Franca & 22 & 643.197 & 486.238 & 1,6 & 75,6 \\
\hline DRS 09 - Marília & 62 & 1.069 .983 & 831.968 & 2,7 & 778 \\
\hline DRS 10 - Piracicaba & 26 & 1.371 .120 & 1.059 .954 & 3,5 & 77,3 \\
\hline DRS 11 - Presidente Prudente & 45 & 713.589 & 552.974 & 1,8 & 77,5 \\
\hline DRS 12 - Registro & 15 & 283.053 & 201.692 & 0,7 & 71,3 \\
\hline DRS 13 - Ribeirão Preto & 26 & 1.241 .179 & 955.126 & 3,1 & 77,0 \\
\hline DRS 14 - São João da Boa Vista & 20 & 778.921 & 604.866 & 2,0 & 77,7 \\
\hline DRS 15 - São José do Rio Preto & o 101 & 1.427 .282 & 1.141 .436 & 3,7 & 80,0 \\
\hline DRS 16 - Sorocaba & 48 & 2.176 .427 & 1.624 .947 & 5,3 & 74,7 \\
\hline DRS 17 - Taubaté & 39 & 2.191 .783 & 1.652 .776 & 5,4 & 75,4 \\
\hline
\end{tabular}

FONTE: Fundação Seade. Sistema de Estatísticas Vitais. Elaboração do autor. NOTA: Projeção populacional para julho de 2006. 
Esse processo de envelhecimento populacional é observado com diferentes graus de intensidade nos 17 DRS’s. Enquanto o DRS de São José do Rio Preto apresenta um índice de envelhecimento de 65,9, ${ }^{2}$ ou seja, para cada 10 crianças e adolescentes com até 14 anos residentes na região existem aproximadamente 66 pessoas de 60 anos e mais, Registro detém um índice de 35,2. Os DRS de Araçatuba (59,1), Marília (56,3), Presidente Prudente $(54,4)$, Barretos $(52,9)$, São João da Vista $(51,3)$ e Araraquara $(51,3)$ exibem índices acima de 50. Os departamentos com maior presença de população jovem são Registro (35,2), Taubaté (36,3), Grande São Paulo (36,5) e Sorocaba (37,1) (Gráfico 4).

Gráfico 4 - Índices de envelhecimento e de feminilidade, ${ }^{(1)}$ segundo Departamentos Regionais de Saúde. Estado de São Paulo. 2006.

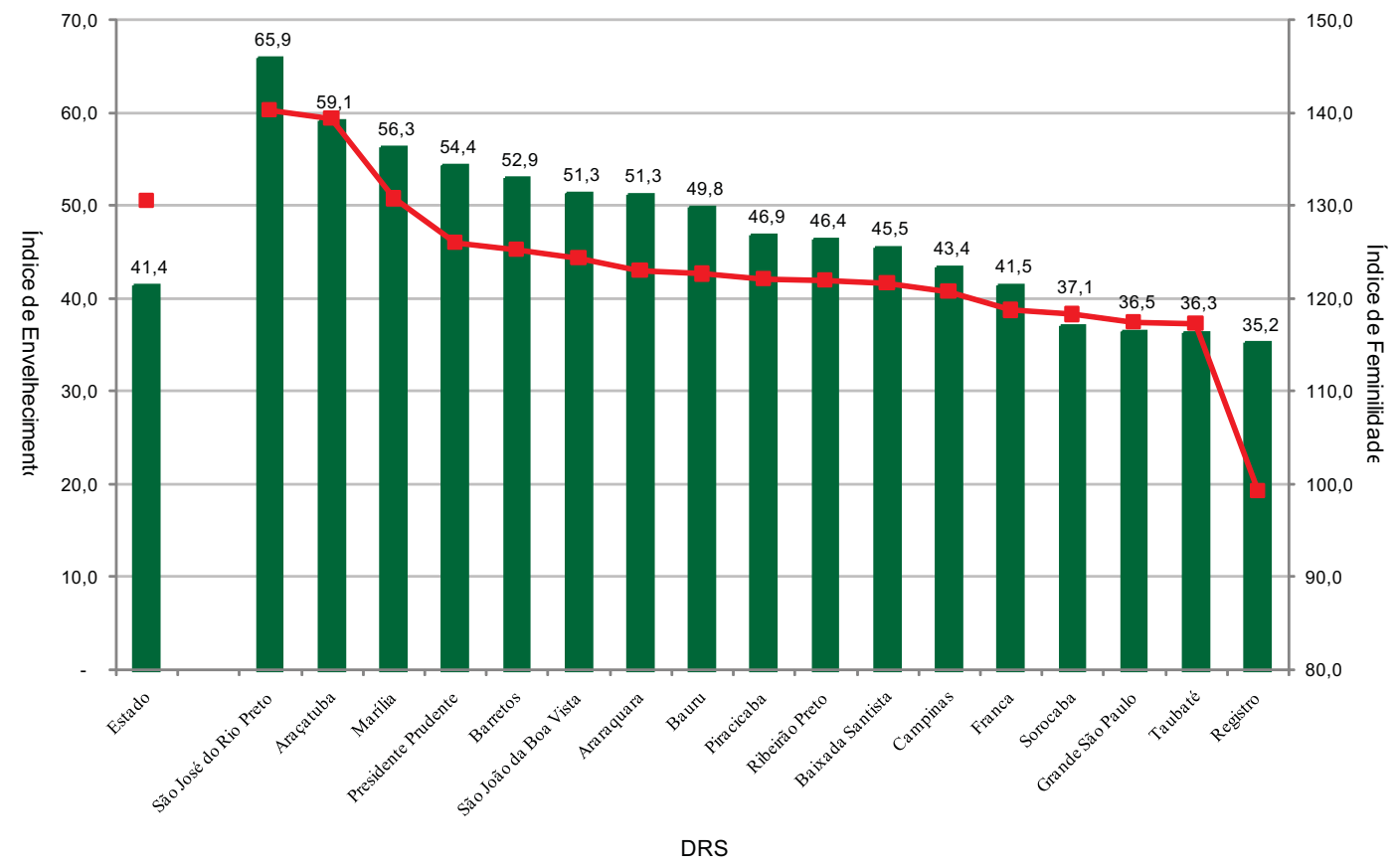

FONTE: Fundação Seade. Sistema de Estatísticas Vitais. Elaboração do autor.

NOTA: Projeção populacional para julho de 2006.

(1) Índice de feminilidade corresponde à razão entre a população feminina e a masculina multiplicada por 100.

\footnotetext{
${ }^{2} \mathrm{O}$ índice de envelhecimento corresponde à razão entre a população de 60 anos e mais e a população menor de 15 anos. Para fins de interpretação, esse coeficiente foi multiplicado por 100.
} 
A presença expressiva de população idosa torna importante a demanda por ações e profissionais de saúde voltados a esse público, como, por exemplo, médicos geriatras, fisioterapeutas e outros, pois, com o envelhecimento da população, aumentam a incidência e a prevalência das doenças crônicas não-transmissíveis, com destaque para a hipertensão arterial sistêmica e o diabetes melito, que constituem dois dos principais fatores de risco para as doenças cardiovasculares. Segundo Lebrão et al. (2008), em um estudo longitudinal realizado em 2006 no município de São Paulo com pessoas de 60 anos e mais, aproximadamente 62\% mencionaram hipertensão, 53\% dores crônicas, 21\% diabetes melito e 60\% já haviam sofrido algum tipo de queda.

Já nos DRS com grandes contingentes populacionais, como Grande São Paulo e Campinas, há necessidade de diversificação do tipo de profissionais e serviços a serem ofertados à população ali residente, pois, independentemente da importância relativa de determinado segmento na sua população, não é possível ignorar sua relevância em termos absolutos. Um exemplo disso é a Grande São Paulo, que, apesar de apresentar um dos menores índices de envelhecimento, concentrava 44\% das pessoas com 60 anos e mais do Estado.

Entre as pessoas com idade superior a 14 anos, em 2006, mais de 53\% possuíam de 20 a 44 anos, aproximadamente 11\% tinham menos de 20 anos, cerca de $21 \%$ estavam na faixa de 45 a 59 anos e 13\% encontravam-se na de 60 anos e mais. Essa estrutura etária varia em alguns DRS, com menor participação relativa de pessoas idosas (60 anos e mais) e aumento da representatividade do grupo de 20 a 44 anos, ou seja, pessoas em idade produtiva. É importante destacar que a presença de jovens de 15 a 19 aos é 
praticamente constante em todos os Departamentos Regionais de Saúde, com exceção de Registro (Tabela 9).

Tabela 9 - Distribuição da população de 15 anos e mais, por faixa etária, segundo Departamentos Regionais de Saúde - DRS. Estado de São Paulo. 2006

\begin{tabular}{|c|c|c|c|c|c|c|}
\hline \multirow[b]{2}{*}{$\begin{array}{l}\text { Departamento Regional de } \\
\text { Saúde - DRS }\end{array}$} & \multirow[b]{2}{*}{$\begin{array}{l}\text { População } \\
\text { de } 15 \text { anos } \\
\text { e mais }\end{array}$} & \multicolumn{5}{|c|}{ Faixa etária } \\
\hline & & Total & Total & $\begin{array}{c}15 \text { a } 19 \\
\text { anos }\end{array}$ & $\begin{array}{c}15 \text { a } 19 \\
\text { anos }\end{array}$ & $\begin{array}{c}15 \text { a } 19 \\
\text { anos }\end{array}$ \\
\hline Total do Estado & 75,9 & 100,0 & 11,2 & 54,4 & 21,3 & 13,1 \\
\hline DRS 01 - Grande São Paulo & 74,9 & 100,0 & 11,0 & 55,4 & 21,4 & 12,2 \\
\hline DRS 02 - Araçatuba & 79,1 & 100,0 & 10,6 & 52,3 & 21,4 & 15,7 \\
\hline DRS 03 - Araraquara & 78,1 & 100,0 & 11,0 & 53,4 & 21,2 & 14,4 \\
\hline DRS 04 - Baixada Santista & 75,9 & 100,0 & 10,9 & 53,3 & 21,3 & 14,4 \\
\hline DRS 05 - Barretos & 77,7 & 100,0 & 11,7 & 52,0 & 21,2 & 15,2 \\
\hline DRS 06 - Bauru & 77,1 & 100,0 & 11,3 & 53,0 & 20,9 & 14,8 \\
\hline DRS 07 - Campinas & 77,2 & 100,0 & 11,0 & 54,7 & 21,4 & 12,8 \\
\hline DRS 08 - Franca & 75,6 & 100,0 & 11,7 & 53,7 & 21,2 & 13,4 \\
\hline DRS 09 - Marília & 77,8 & 100,0 & 11,0 & 51,6 & 21,2 & 16,1 \\
\hline DRS 10 - Piracicaba & 77,3 & 100,0 & 11,2 & 53,8 & 21,2 & 13,8 \\
\hline DRS 11 - Presidente Prudente & 77,5 & 100,0 & 11,3 & 52,0 & 21,0 & 15,8 \\
\hline DRS 12 - Registro & 71,3 & 100,0 & 14,1 & 52,9 & 18,9 & 14,2 \\
\hline DRS 13 - Ribeirão Preto & 77,0 & 100,0 & 11,3 & 53,5 & 21,3 & 13,9 \\
\hline DRS 14 - São João da Boa Vista & 77,7 & 100,0 & 11,3 & 52,1 & 21,8 & 14,8 \\
\hline DRS 15 - São José do Rio Preto & 80,0 & 100,0 & 10,3 & 51,2 & 22,0 & 16,5 \\
\hline DRS 16 - Sorocaba & 74,7 & 100,0 & 12,4 & 54,8 & 20,3 & 12,6 \\
\hline DRS 17 - Taubaté & 75,4 & 100,0 & 11,8 & 55,1 & 21,2 & 11,8 \\
\hline
\end{tabular}

FONTE: Fundação Seade. Sistema de Estatísticas Vitais. Elaboração do autor. NOTA: Projeção populacional para julho de 2006.

A heterogeneidade econômica e social existente entre os 645 municípios do Estado de São Paulo, em 2006, permanece na ótica dos DRS, de acordo com o Índice Paulista de Responsabilidade Social - IPRS (FUNDAÇÃO SEADE, 2009). Os departamentos que englobam os municípios localizados ao longo dos eixos que acompanham as 
principais rodovias do Estado e se interceptam no Município de São Paulo concentram os maiores níveis de riqueza (Grupos 1 e 2). Os que englobam os municípios do interior do Estado, principalmente nas regiões norte e noroeste, que abrigam municípios pequenos, e registram baixos níveis de riqueza, mas com índices intermediários ou bons nos indicadores sociais (Grupos 3 e 4). Já os DRS que abrangem as tradicionais áreas deprimidas do Estado (Vale do Ribeira e região de Itapeva) concentram municípios pertencentes ao Grupo 5 (Gráfico 5).

Gráfico 5 - Distribuição dos municípios segundo o Índice Paulista de Responsabilidade Social - IPRS, por Departamento Regional de Saúde - DRS. Estado de São Paulo. 2006.



FONTE: Fundação Seade. Índice Paulista de Responsabilidade Social - IPRS.

Esses resultados indicam que, em relação à situação socioeconômica, os DRS podem ser classificados em quatro grupos: um formado por Baixada Santista, Grande São Paulo, Campinas e Piracicaba, que englobam municípios com níveis de riqueza municipal acima do observado para a maioria dos municípios paulistas (Grupos 1 e 2); 
outro composto por Taubaté e Sorocaba, que apresentam maior heterogeneidade em relação à realidade socioeconômica de seus municípios, dado que englobam, respectivamente, cidades importantes no Estado como São José dos Campos e Sorocaba, vis à vis regiões economicamente deprimidas como as cidades localizadas na Serra da Bocaina e na região de Itapeva; outro formado por Registro, Franca e São João da Boa Vista, expressiva presença de municípios pobres e com indicadores sociais deficientes;e por fim os demais DRS, cujos municípios apresentam, em sua maioria, baixo desenvolvimento econômico aliado a bons indicadores sociais, e com a presença de uma ou duas cidades-polos que respondem pela maior parte da economia regional.

\subsection{Procura de serviços de saúde}

Segundo a Pesquisa de Condições de Vida - PCV, em 2006, 34,4\% da população paulista de 15 anos e mais declarou ter procurado por serviços de saúde nos 30 dias anteriores à pesquisa, excluindo-se clínica ou consultório odontológico. Desses 91,3\% foram atendidos no mesmo dia da procura, correspondendo a 31,4\% das pessoas de 15 anos e mais.

Entre os que utilizaram serviços de saúde, 61,2\% foram atendidos gratuitamente, isto é, pelo o Sistema Único de Saúde - SUS, 35,1\% usaram planos ou convênios médicos e 3,7\% pagaram para ser atendidos. ${ }^{3}$

A análise dos intervalos de confiança de 95\% - IC da proporção de pessoas de 15 anos e mais que utilizaram serviços de saúde, por DRS, mostrou que os

\footnotetext{
${ }^{3}$ Considerou-se como tendo utilizado serviços de saúde pessoas que procuraram atendimento e foram atendidas no mesmo dia, inclusive as que tinham atendimento agendado.
} 
departamentos que englobam municípios localizados nas regiões norte e oeste do Estado apresentaram menor taxa de utilização de serviços de saúde, pois, quando comparados com a média estadual, os limites superiores do IC de 95\% situam-se abaixo de 31\%. São eles: São João da Boa Vista, Araraquara, Araçatuba, Ribeirão Preto, São José do Rio Preto e Franca. Em patamares ligeiramente superiores, porém ainda abaixo da média estadual, situam-se os DRS de Piracicaba, Presidente Prudente e Barretos. Em torno da média estadual, estão Baixada Santista, Bauru, Taubaté, Sorocaba e Registro. Acima da média encontram-se Campinas, Grande São Paulo e Marília, sendo que este último registra a maior taxa de utilização de serviços - 40,4\% (Gráfico 6).

Gráfico 6 - Intervalo de Confiança de 95\% para o porcentual de pessoas de 15 anos e mais que utilizaram serviços de saúde nos últimos 30 dias, segundo Departamentos Regionais de Saúde - DRS. Estado de São Paulo. 2006

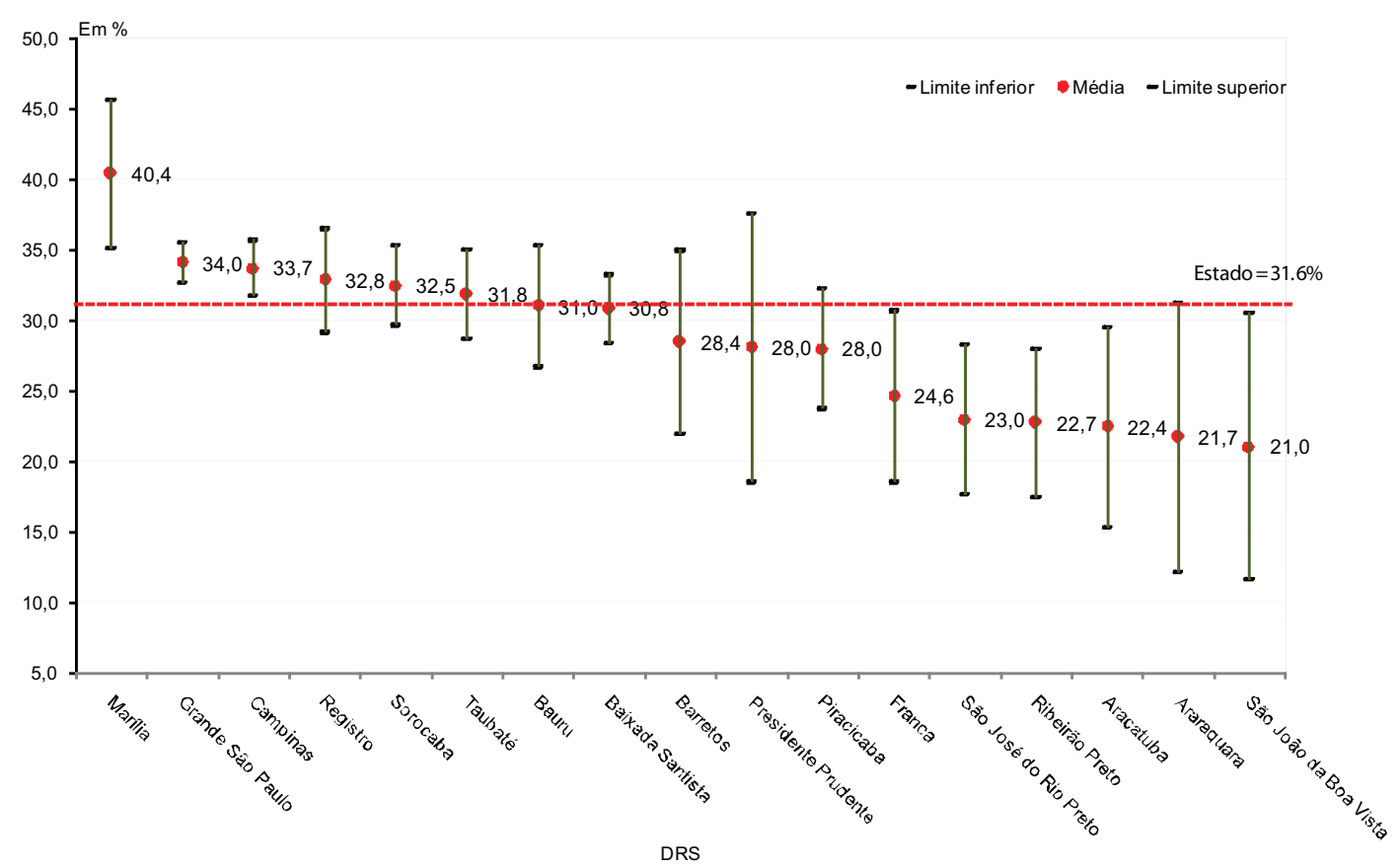

FONTE: Fundação Seade. Pesquisa de Condições de Vida - PCV. Elaboração do autor.

NOTA: Exclusive os indivíduos que pagaram para ser atendidos. 
Esses resultados mostram um componente espacial na utilização dos serviços de saúde, com as regiões economicamente mais desenvolvidas do Estado apresentando os maiores porcentuais de utilização. Os DRS localizados no interior do Estado de São Paulo, mesmo aqueles que englobam municípios caracterizados como polos regionais, em termos econômicos e de oferta de serviços de saúde, como Ribeirão Preto e São José do Rio Preto, apresentam menor utilização de serviços de saúde. Já aqueles com municípios situados em regiões metropolitanas ou em seu entorno - como a Grande São Paulo, Campinas, Taubaté e Sorocaba - registram maior taxa de utilização. As exceções ocorrem em Marília - na região noroeste do Estado - que se destaca por apresentar o maior porcentual de utilização de serviços de saúde da pesquisa, e Registro, que, apesar de historicamente constituir-se como um dos "bolsões” de pobreza do Estado de São Paulo, possui uma das maiores taxas de utilização dos serviços de saúde (Gráfico 6).

A parcela da população usuária do SUS também se distingue regionalmente. Os DRS que englobam os maiores e economicamente mais desenvolvidos municípios do Estado apresentam proporcionalmente menor demanda dos serviços do SUS e, em contrapartida, maior consumo de serviços privados de saúde. Esse cenário é observado nos departamentos de Taubaté (63,5\%), Grande São Paulo (62,5\%), Baixada Santista (61,1\%) e Campinas (56,7\%) que apresentam taxas de utilização do SUS abaixo da média estadual e formam uma grande mancha urbana em torno da capital. No restante do Estado, é grande a dependência da população ao SUS, sendo que no DRS de Registro 93,4\% das pessoas de 15 anos e mais que procuraram serviços de saúde utilizaram o SUS (Gráfico 7). 
O DRS de Araraquara apresenta um erro amostral relativo de 36,8\%, o que torna imprecisa qualquer inferência sobre essa região.

Gráfico 7 - Intervalo de Confiança de 95\% para o porcentual de pessoas de 15 anos e mais que utilizaram SUS, segundo Departamentos Regionais de Saúde - DRS. Estado de São Paulo. 2006

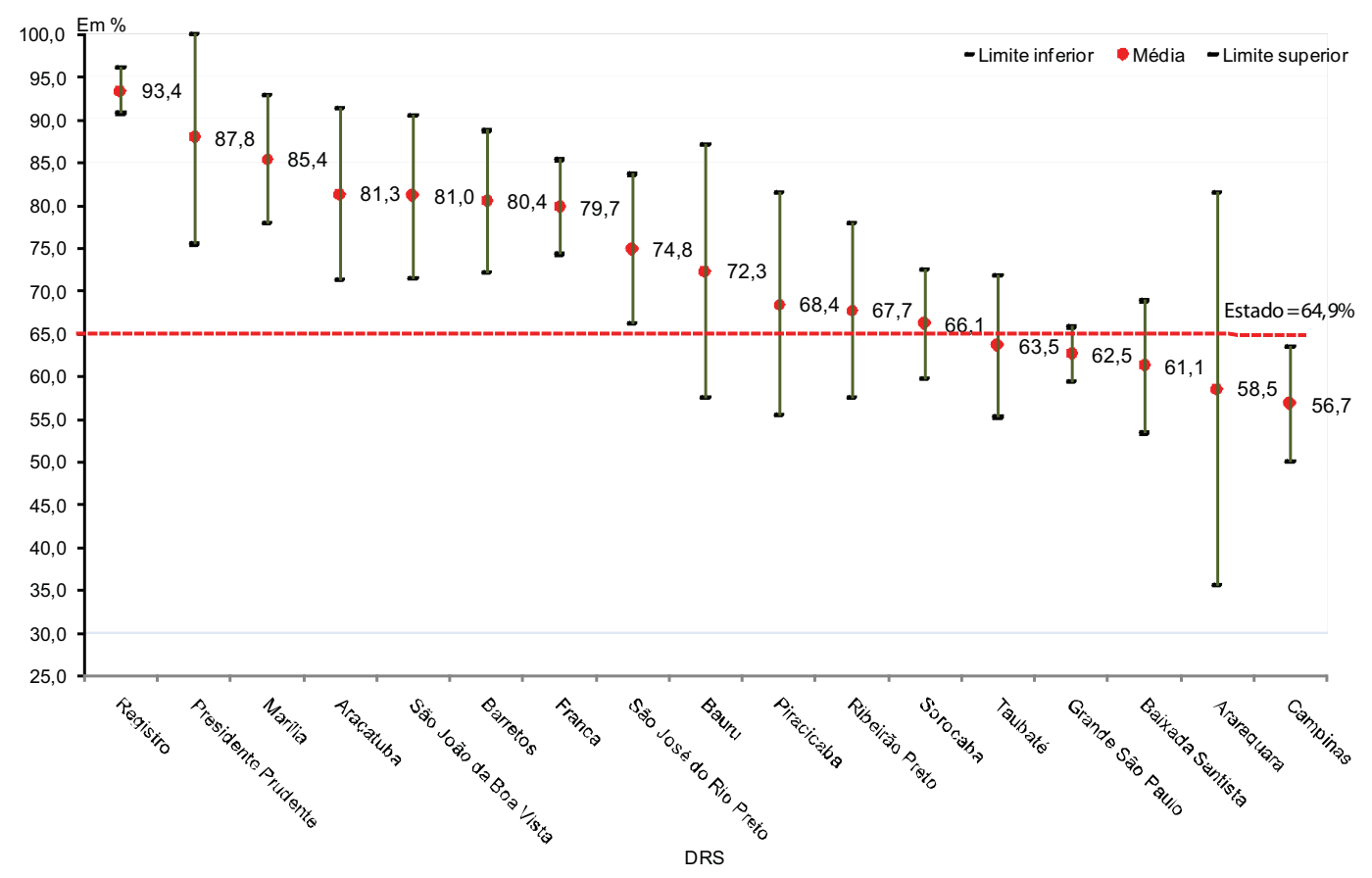

FONTE: Fundação Seade. Pesquisa de Condições de Vida - PCV. Elaboração do autor.

\subsubsection{Tipo de estabelecimento procurado}

Quanto ao tipo de estabelecimento procurado, verificou-se que o posto ou centro de saúde foi o escolhido por aproximadamente 30,0\% das pessoas que utilizaram serviços de saúde; clínicas e consultórios médicos, hospitais e pronto-socorro foram procurados por cerca de 20\% e laboratórios ou centro de diagnósticos, por quase 2,0\%.

Para os beneficiários de plano de saúde, a principal porta de entrada foi a clínica ou consultório médico (57,2\%) e, para os usuários do SUS, o centro ou posto de saúde (47,5\%). A procura por pronto-socorro foi muito mais elevada entre os usuários do 
SUS (27,7\%) do que entre os beneficiários de planos de saúde (14,1\%). Este diferencial pode estar refletindo, entre outros fatores, desde as dificuldades de acesso aos estabelecimentos indicados como primeira porta para o SUS - postos ou centro de saúde -, até o atendimento de urgência/emergência realizado no Sistema Único de Saúde (Tabela 10).

Tabela 10 - Distribuição das pessoas de 15 anos e mais que utilizaram serviços de saúde nos últimos 30 dias, segundo tipo de estabelecimento procurado e situação de pagamento. Estado de São Paulo. 2006

Em porcentagem

\begin{tabular}{|c|c|c|c|}
\hline \multirow{2}{*}{$\begin{array}{l}\text { Tipo de estabelecimento e } \\
\text { dsituação e pagamento }\end{array}$} & \multirow{2}{*}{ Total } & \multicolumn{2}{|c|}{ IC de $95 \%$} \\
\hline & & Mínimo & Máximo \\
\hline Utilizaram serviços de saúde & 31,4 & 30,5 & 32,6 \\
\hline Total & 100,0 & - & - \\
\hline Pronto-socorro & 22,5 & 21,1 & 24,0 \\
\hline Hospital & 22,0 & 20,5 & 23,6 \\
\hline Clínica ou consultório médico & 23,1 & 21,4 & 24,8 \\
\hline Posto ou centro de saúde & 30,3 & 28,5 & 32,2 \\
\hline Laboratório ou centro de diagnóstico & 1,7 & 1,3 & 2,2 \\
\hline Outro tipo de estabelecimento de saúde & 0,4 & 0,2 & 0,6 \\
\hline Utilizaram o SUS & 100,0 & - & - \\
\hline Pronto-socorro & 27,7 & 25,8 & 29,7 \\
\hline Hospital & 21,4 & 19,6 & 23,3 \\
\hline Clínica ou consultório médico & 2,3 & 1,8 & 2,8 \\
\hline Posto ou centro de saúde & 47,5 & 45,4 & 49,8 \\
\hline Laboratório ou centro de diagnóstico & 0,7 & 0,5 & 1,0 \\
\hline Outro tipo de estabelecimento de saúde & 0,4 & 0,2 & 0,7 \\
\hline Utilizaram plano ou convênio médico & 100,0 & - & - \\
\hline Pronto-socorro & 14,1 & 12,0 & 16,5 \\
\hline Hospital & 23,8 & 20,8 & 27,1 \\
\hline Clínica ou consultório médico & 57,2 & 53,8 & 60,5 \\
\hline Posto ou centro de saúde & 0,9 & 0,6 & 1,3 \\
\hline Laboratório ou centro de diagnóstico & 3,7 & 2,7 & 4,7 \\
\hline Outro tipo de estabelecimento de saúde & 0,3 & 0,1 & 0,5 \\
\hline
\end{tabular}

Fonte: Fundação Seade. Pesquisa de Condições de Vida - PCV. Elaboração do autor. 
Já a busca por laboratórios e centros de diagnósticos é proporcionalmente maior entre os portadores de planos de saúde (3,7\%) do que para os usuários do SUS (0,7\%). Quanto ao hospital, as diferenças observadas entre os usuários do SUS e de planos de saúde não foram estatisticamente significantes (Tabela 10).

Embora o centro ou posto de saúde seja o mais procurado pelos usuários do SUS (47,5\%) - um resultado esperado dado ser esta a primeira porta de entrada do sistema , a magnitude desse porcentual não é a mesma em todos os 17 departamentos de saúde do Estado. Na Grande São Paulo e na Baixada Santista, os valores médios são respectivamente $42,3 \%$ e $41,4 \%$, sendo que o limite superior do intervalo de confiança de 95\% não atinge 47\%, que corresponde à média estadual. Já, Campinas, Bauru, Sorocaba e Registro atingem valores acima de 53\%, seguidos de Taubaté com 50,7\%. O destaque é Marília, com 71,3\% dos usuários utilizando o centro ou posto de saúde (Tabela 11).

Os DRS de Araçatuba, Araraquara, Barretos, Franca, Piracicaba, Presidente Prudente, Ribeirão Preto, São João da Boa Vista e São José do Rio Preto apresentam erros-padrões elevados, o que torna imprecisa a inferência estatística para essas regiões. No entanto, os valores obtidos na amostra estão apresentados na Tabela 11, bem como o intervalo de confiança de 95\% e seu respectivo erro-padrão. 
Tabela 11- Proporção das pessoas de 15 anos e mais que utilizaram posto ou centro de saúde do SUS nos últimos 30 dias, segundo Departamentos Regionais de Saúde - DRS. Estado de São Paulo. 2006

\begin{tabular}{|c|c|c|c|c|}
\hline \multirow{3}{*}{$\begin{array}{l}\text { Departamento Regional } \\
\text { de Saúde - DRS }\end{array}$} & & & & Em porcentage \\
\hline & \multirow{2}{*}{ Total } & \multicolumn{2}{|c|}{ IC de $95 \%$} & \multirow{2}{*}{ Erro-padrão } \\
\hline & & Mínimo & Máximo & \\
\hline Total & 47,5 & 45,4 & 49,8 & 1,1 \\
\hline DRS 01 - Grande São Paulo & 42,3 & 39,1 & 45,6 & 1,7 \\
\hline DRS 02 - Araçatuba & 42,6 & 24,1 & 61,1 & 9,4 \\
\hline DRS 03 - Araraquara & 50,6 & 37,7 & 63,5 & 6,6 \\
\hline DRS 04 - Baixada Santista & 41,4 & 36,6 & 46,2 & 2,5 \\
\hline DRS 05 - Barretos & 46,0 & 30,7 & 61,3 & 7,8 \\
\hline DRS 06 - Bauru & 54,6 & 48,8 & 60,4 & 3,0 \\
\hline DRS 07 - Campinas & 53,4 & 47,1 & 59,6 & 3,2 \\
\hline DRS 08 - Franca & 46,7 & 27,2 & 66,1 & 9,9 \\
\hline DRS 09 - Marília & 71,3 & 62,8 & 79,9 & 4,4 \\
\hline DRS 10 - Piracicaba & 42,8 & 28,4 & 57,1 & 7,3 \\
\hline DRS 11 - Presidente Prudente & 65,2 & 56,1 & 74,3 & 4,7 \\
\hline DRS 12 - Registro & 54,7 & 47,9 & 61,6 & 3,5 \\
\hline DRS 13 - Ribeirão Preto & 62,6 & 49,3 & 75,8 & 6,8 \\
\hline DRS 14 - São João da Boa Vista & 52,0 & 39,3 & 64,8 & 6,5 \\
\hline DRS 15 - São José do Rio Preto & 57,5 & 46,0 & 69,0 & 5,9 \\
\hline DRS 16 - Sorocaba & 57,1 & 51,3 & 62,9 & 3,0 \\
\hline DRS 17 - Taubaté & 50,8 & 45,0 & 56,7 & 3,0 \\
\hline
\end{tabular}

Fonte : Fundação Seade. Pesquisa de Condições de Vida - PCV. Elaboração do autor.

\subsubsection{Agendamento para o atendimento}

Do total de pessoas que utilizaram serviços de saúde, 58,5\% tinham marcado previamente o atendimento. Entre os usuários do SUS, 51,4\% realizaram agendamento, contra 69,7\% dos beneficiários de planos e convênios médicos (Tabela 12).

Como era de se esperar a maior proporção desse procedimento ocorreu nos centros de saúde (88,0\%) e em clínicas e consultórios médicos (69,9\%). Nos hospitais, mais de 50\% das pessoas que utilizaram esse serviço haviam marcado com antecedência e, nos prontos-socorros cerca de 13\% (Tabela 12). 
Em relação ao agendamento, não há diferenças entre os usuários do SUS e de planos de saúde que utilizaram hospitais e prontos-socorros, sendo que nos hospitais mais de $50 \%$ dos usuários declararam ter agendado o atendimento. Já entre os que utilizaram clínicas e consultórios médicos, apesar de, em média, haver maior proporção de beneficiários de planos de saúde que declararam ter marcado previamente a consulta, essa diferença não é estatisticamente significante (Tabela 12).

Tabela 12 - Proporção das pessoas de 15 anos e mais que utilizaram serviços de saúde nos últimos 30 dias e que realizaram agendamento, segundo tipo de estabelecimento procurado e situação de pagamento. Estado de São Paulo. 2006

\begin{tabular}{|c|c|c|c|}
\hline \multirow{3}{*}{$\begin{array}{l}\text { Tipo de Estabelecimento e } \\
\text { situação de pagamento }\end{array}$} & \multirow{3}{*}{ Total } & \multicolumn{2}{|c|}{ Em porcentagem } \\
\hline & & \multicolumn{2}{|c|}{ IC $95 \%$} \\
\hline & & Mínimo & Máximo \\
\hline Total $^{1}$ & 58,5 & 56,7 & 60,3 \\
\hline Pronto-socorro & 12,9 & 10,6 & 15,3 \\
\hline Hospital & 53,2 & 49,2 & 57,2 \\
\hline Clínica ou consultório médico & 88,0 & 85,7 & 90,1 \\
\hline Posto ou centro de saúde & 69,9 & 67,0 & 72,6 \\
\hline Utilizaram o SUS & 51,4 & 49,3 & 53,5 \\
\hline Pronto-socorro & 12,2 & 9,7 & 14,7 \\
\hline Hospital & 52,2 & 47,1 & 57,3 \\
\hline Clínica ou consultório médico & 80,3 & 69,2 & 91,3 \\
\hline Posto ou centro de saúde & 70,0 & 67,2 & 72,8 \\
\hline Utilizaram plano ou convênio médico & 69,7 & 66,8 & 72,4 \\
\hline Pronto-socorro & 12,9 & 7,8 & 18,0 \\
\hline Hospital & 54,6 & 48,4 & 60,8 \\
\hline Clínica ou consultório médico & 88,6 & 86,3 & 91,0 \\
\hline Posto ou centro de saúde & $\ldots$ & $\ldots$ & $\ldots$ \\
\hline
\end{tabular}

FONTE: Fundação Seade. Pesquisa de Condições de Vida - PCV. Elaboração do autor. NOTA: (...) Dado não divulgado devido ao erro amostral.

(1) Consideraram-se todos os tipos de estabelecimentos investigados pela pesquisa, inclusive laboratório e centro de diagnósticos e outros tipos de estabelecimentos de saúde. 


\subsubsection{Posse de planos ou convênios médicos}

A posse de plano de saúde - considerada um fator de capacidade de consumo de serviços - também reflete situações desiguais segundo os departamentos de saúde do Estado de São Paulo. No grupo de indivíduos residentes em áreas metropolitanas e em polos regionais, como Grande São Paulo, Campinas, Baixada Santista, Ribeirão Preto e São José do Rio Preto, a proporção de beneficiários de planos de saúde situa-se acima da média estadual de 34,6\%. Já nos departamentos de Registro e Marília, o porcentual de beneficiários não atinge 20\% da população de 15 anos e mais (Gráfico 8).

Gráfico 8 - Intervalo de Confiança de 95\% para proporção de beneficiários de planos e convênios médicos, segundo Departamentos Regionais de Saúde - DRS. Estado de São Paulo. 2006

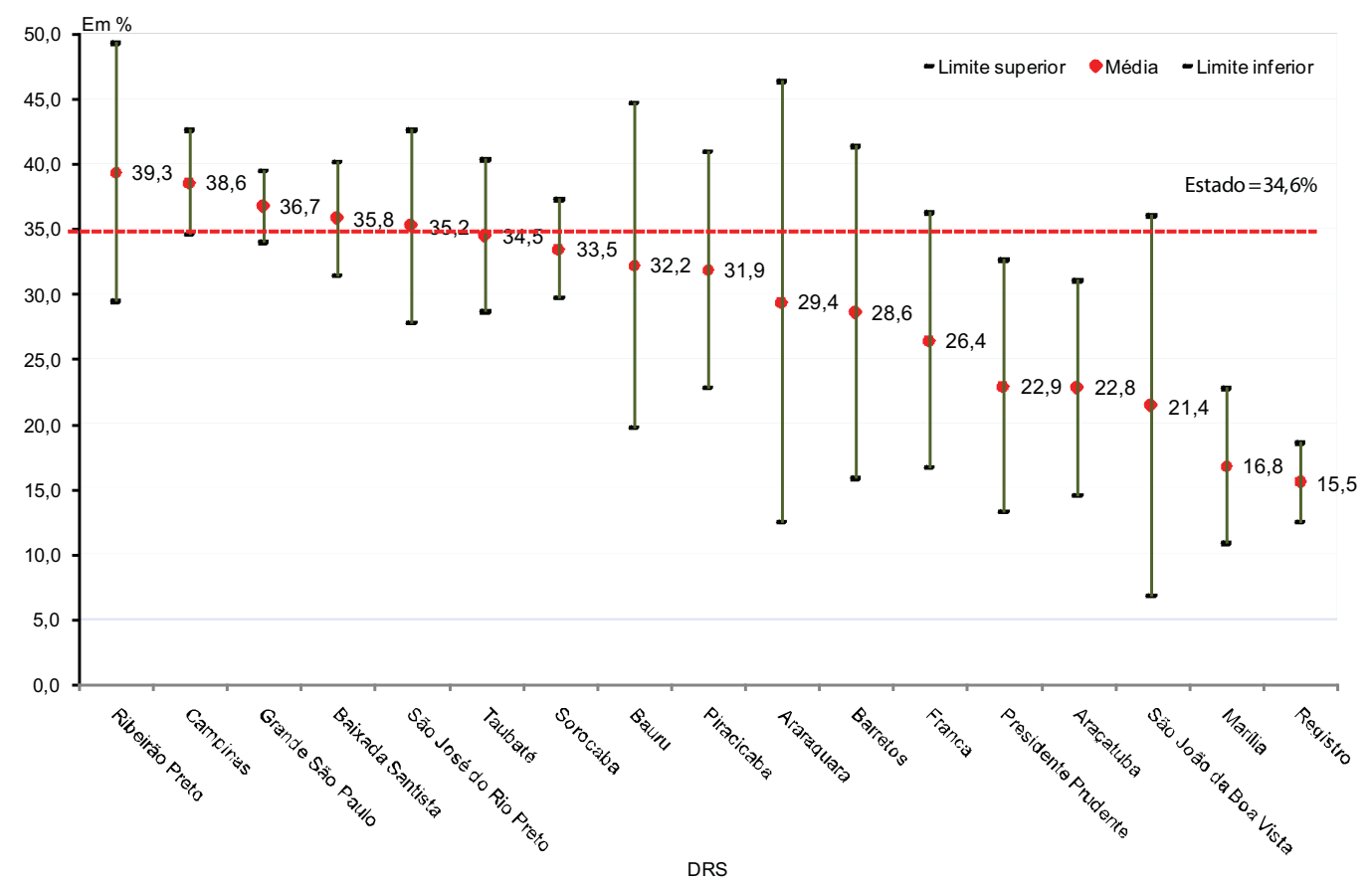

FONTE: Fundação Seade. Pesquisa de Condições de Vida - PCV. Elaboração do autor. 
Dos beneficiários de planos de saúde que utilizaram serviços de saúde, 12,4\% usaram o SUS, com significativas diferenças regionais, refletindo provavelmente a heterogeneidade dos planos e convênios médicos existentes nas diversas regiões: enquanto em Campinas e na Baixada Santista essa proporção foi de, respectivamente, 6,1\% e 7,3\%, na Grande São Paulo correspondeu a 11,0\%, em Taubaté situou-se em torno de 12,5\% e, em Registro, chegou a 55,4\% (Gráfico 9).

Gráfico 9 - Intervalo de Confiança de 95\% para a taxa de utilização do SUS entre os beneficiários de planos e convênios médicos, segundo Departamentos Regionais de Saúde - DRS. Estado de São Paulo. 2006

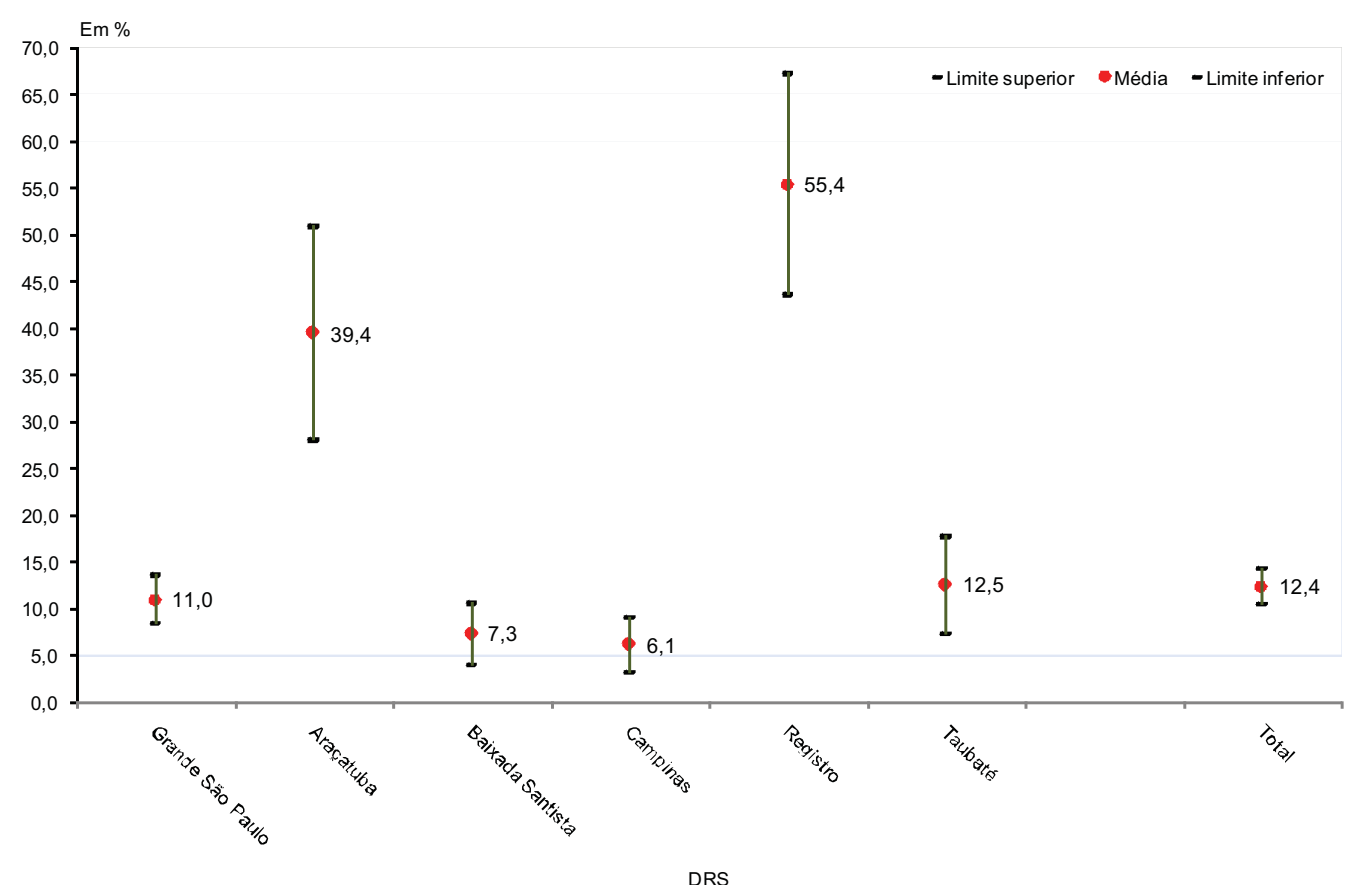

FONTE: Fundação Seade. Pesquisa de Condições de Vida - PCV. Elaboração do autor.

NOTA: Para os demais Departamentos Regionais de Saúde - DRS’s não foi possível obter estimativas dado que os erros amostrais situaram-se acima de $47 \%$.

Entre os beneficiários de planos de saúde que utilizaram o SUS, 37,1\% procuraram posto ou centro de saúde e 62,9\% buscaram outros tipos de estabelecimentos de saúde. Quando se considera a taxa de utilização do SUS entre beneficiários de planos de saúde segundo o tipo de estabelecimento procurado observa-se que: entre aqueles que procuraram prontos-socorros, 22,1\% utilizaram serviços do SUS; contra 12,9\% entre 
os que procuraram hospitais; e 2,0\% entre os que procuraram clínicas ou consultórios e laboratórios ou centos de diagnósticos. Esses resultados mostram a importância do SUS na oferta dos serviços de urgência/emergência (pronto-socorro), dos serviços alta complexidade (hospitais) e até mesmo na atenção básica (postos e centros de saúde) em termos de localização e acessibilidade geográfica (Gráfico 10).

Gráfico 10 - Intervalo de Confiança de 95\% para a taxa de utilização do SUS entre os beneficiários de planos e convênios médicos, segundo tipo de estabelecimento procurado. Estado de São Paulo. 2006

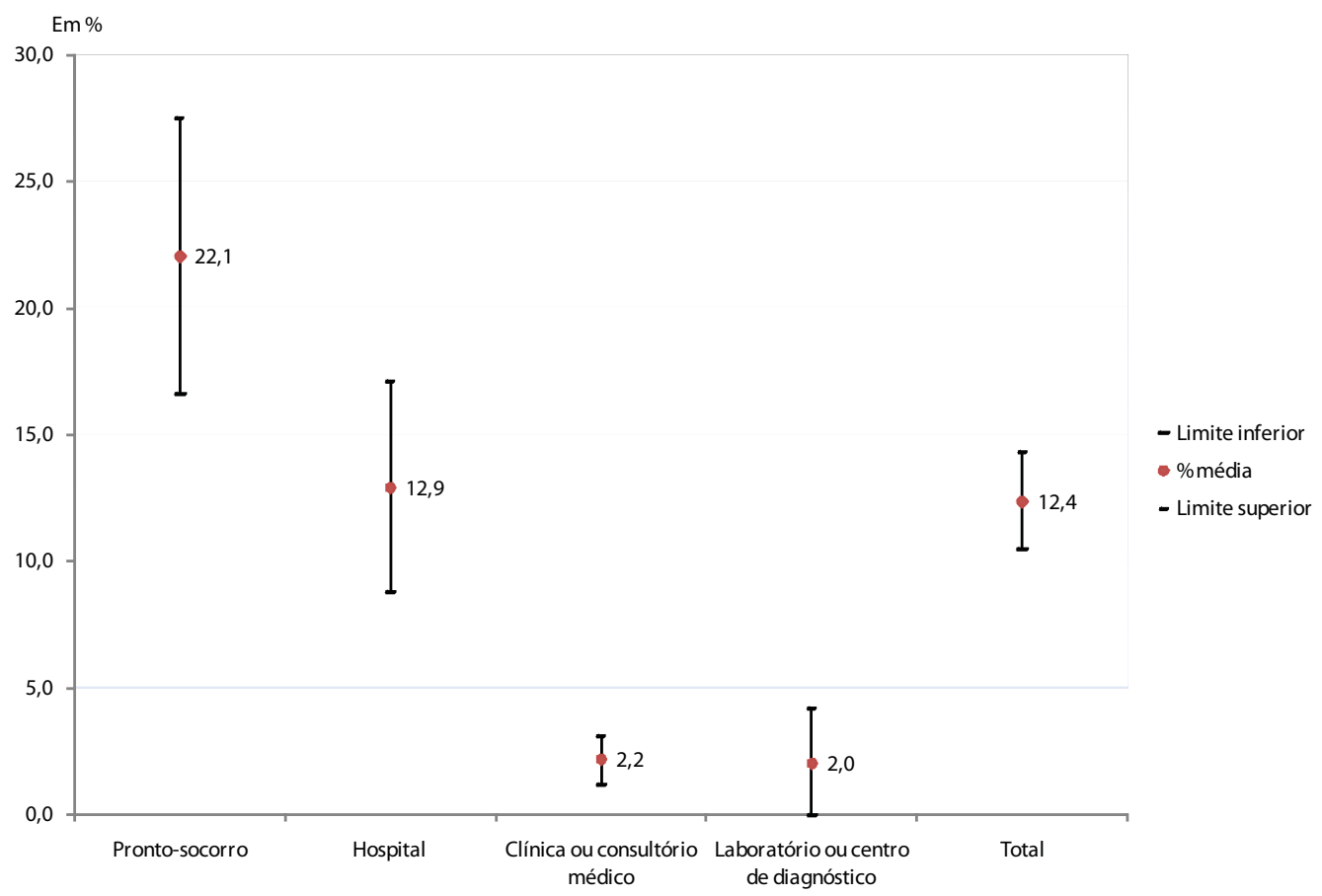

FONTE: Fundação Seade. Pesquisa de Condições de Vida - PCV. Elaboração do autor.

NOTA: Na categoria “Total” consideraram-se todos os tipos de estabelecimentos investigados pela pesquisa, inclusive laboratório e centro de diagnósticos e outros tipos de estabelecimentos de saúde.

\subsection{Padrão de utilização dos serviços de saúde}

A partir de uma análise univariada, foi possível identificar que, entre os fatores individuais associados à utilização dos serviços, de saúde destacam-se o sexo e a idade, com maior uso entre as mulheres e as pessoas mais velhas. A condição de posse de 
plano e convênio médio é um componente importante para a utilização dos serviços de saúde, com taxa de utilização entre os beneficiários de 35,9\%, contra 29,3\% dos nãobeneficiários. Não se mostraram estatisticamente significantes para diferenciar a utilização dos serviços de saúde o nível de renda, a escolaridade, a raça/cor dos indivíduos, e o local de moradia, expresso pelo indicador de vulnerabilidade social (Tabela 13).

Tabela 13 - Distribuição das pessoas de 15 anos e mais e proporção que utilizaram serviços de saúde, segundo variáveis explicativas individuais. Estado de São Paulo. 2006

Em porcentagem

\begin{tabular}{|c|c|c|c|c|c|c|}
\hline \multirow{3}{*}{$\begin{array}{c}\text { Variáveis } \\
\text { explicativas }\end{array}$} & \multicolumn{3}{|c|}{ Total } & \multicolumn{3}{|c|}{ Utilizou serviços de saúde } \\
\hline & \multirow{2}{*}{ Total } & \multicolumn{2}{|c|}{ IC de $95 \%$} & \multirow{2}{*}{ Total } & \multicolumn{2}{|c|}{ IC de $95 \%$} \\
\hline & & Mínimo & Máximo & & Mínimo & Máximo \\
\hline Sexo & 100,0 & - & - & 31,6 & 30,6 & 32,6 \\
\hline Homens & 46,5 & 45,9 & 47,0 & 25,5 & 24,3 & 26,7 \\
\hline Mulheres & 53,5 & 53,0 & 54,1 & 36,9 & 35,5 & 38,3 \\
\hline Idade & 100,0 & - & - & 31,6 & 30,6 & 32,6 \\
\hline De 15 a 19 anos & 11,6 & 11,1 & 12,2 & 22,9 & 21,0 & 24,9 \\
\hline De 20 a 44 anos & 52,4 & 51,3 & 53,5 & 29,4 & 28,3 & 30,5 \\
\hline De 45 a 59 anos & 20,8 & 20,1 & 21,5 & 34,6 & 32,5 & 36,8 \\
\hline 60 anos e mais & 15,2 & 14,3 & 16,1 & 41,6 & 39,2 & 44,2 \\
\hline Raça/cor & 100,0 & - & - & 31,6 & 30,6 & 32,6 \\
\hline Branca e amarela & 69,81 & 68,24 & 71,33 & 31,0 & 29,8 & 32,3 \\
\hline Preta, parda e indigena & 30,19 & 28,67 & 31,76 & 32,9 & 31,4 & 34,5 \\
\hline Escolaridade & 100,0 & - & - & 31,6 & 30,6 & 32,6 \\
\hline Ensino fundamental completo & 56,6 & 55,3 & 58,0 & 29,0 & 27,8 & 30,2 \\
\hline Renda familiar per capita & 100,0 & - & - & 31,6 & 30,6 & 32,6 \\
\hline Até 1/2 salário mínimo & 16,9 & 15,8 & 18,0 & 32,0 & 30,3 & 33,7 \\
\hline Mais de $1 / 2$ a 1 salário mínimo & 28,8 & 27,3 & 30,3 & 31,5 & 30,0 & 33,0 \\
\hline Mais de 1 a 2 salários mínimos & 31,2 & 29,7 & 32,6 & 31,4 & 29,8 & 33,1 \\
\hline Mais de 2 salários mínimos & 23,2 & 20,6 & 26,2 & 31,6 & 28,7 & 34,7 \\
\hline Posse de plano de saúde & 100,0 & - & - & 31,6 & 30,6 & 32,6 \\
\hline Sim & 34,6 & 32,8 & 41,4 & 35,9 & 34,3 & 37,6 \\
\hline Não & 65,4 & 63,7 & 67,2 & 29,3 & 28,2 & 30,5 \\
\hline Residentes em áreas vulneráveis & 100,0 & - & - & 31,6 & 30,6 & 32,6 \\
\hline Sim & 44,7 & 42,0 & 47,4 & 31,4 & 30,5 & 32,3 \\
\hline Não & 55,3 & 52,6 & 58,0 & 31,7 & 30,0 & 33,5 \\
\hline
\end{tabular}

FONTE: Fundação Seade. Pesquisa de Condições de Vida - PCV. Elaboração do autor. 
A elaboração de modelos de regressão logística com efeitos mistos tornou possível identificar o efeito de cada DRS para a condição de utilização dos serviços de saúde de seus moradores, além de permitir a incorporação de variáveis ecológicas relacionadas às características do sistema de saúde. Para tanto, três níveis de componentes de variância foram considerados: individuo, setor censitário e DRS.

Dois modelos foram construídos com a variável resposta correspondendo à condição de utilização dos serviços de saúde e às explicativas descritas na Tabela 13, além de três variáveis ecológicas: número de médicos por mil habitantes, porcentual de beneficiários de planos de saúde e porcentual de população cadastrada no PSF. O primeiro modelo considerou, entre as variáveis explicativas, a renda familiar per capita dos indivíduos, expressa em salários mínimos de setembro de 2006. No segundo modelo, a renda foi substituída pela condição de posse de plano de saúde pelo indivíduo (Tabela 14).

No Modelo 1 - Renda, as variáveis relacionadas ao indivíduo - raça/cor, escolaridade, renda familiar per capita - não se mostraram significantes estatisticamente ao nível de 5\%. No nível do DRS não foram estatisticamente significantes o número de médicos por mil habitantes e o porcentual de beneficiários de planos de saúde. Os fatores que se mostraram estatisticamente significantes ao nível de 5\% foram idade, sexo, local de residência dos indivíduos (setor censitário com maior vulnerabilidade à pobreza pelo IPVS) e proporção da população cadastrada no PSF no DRS. A escolaridade mostrou-se significante em determinadas faixas etárias (Tabela 14).

No Modelo 2 - Plano, em que a renda familiar per capita é substituída pela condição de posse de plano de saúde ou convênio médico, as variáveis raça/cor e as relacionadas 
ao DRS, como o número de médicos por mil habitantes e o porcentual de beneficiários

de planos de saúde, tornam-se significantes no modelo. Além disso, a condição de

beneficiário de plano de saúde mostra-se significante, ou seja, altera positivamente a probabilidade de um indivíduo utilizar serviços de saúde, independentemente das demais características consideradas (Tabela 14).

Tabelas 14 - Estimativas referentes à parte fixa dos modelos de regressão logística com efeitos mistos para condição de utilização de serviços de saúde. Estado de São Paulo. 2006

\begin{tabular}{|c|c|c|c|c|c|c|}
\hline \multirow[b]{2}{*}{ Componentes do Modelo } & \multicolumn{3}{|c|}{ Modelo 1 - Renda } & \multicolumn{3}{|c|}{ Modelo 2 - Plano } \\
\hline & Coeficiente & $\begin{array}{l}\text { Razão de } \\
\text { vantagem }\end{array}$ & $\begin{array}{l}\text { Valor } \\
\text { de p }\end{array}$ & Coeficiente & $\begin{array}{l}\text { Razão de } \\
\text { vantagem }\end{array}$ & $\begin{array}{l}\text { Valor } \\
\text { de p }\end{array}$ \\
\hline$\beta_{0}$ Constante & $-2,543$ & - & 0,000 & $-2,304$ & - & 0,000 \\
\hline $\begin{array}{l}\text { Faixa etária (cat. ref. } 15 \text { a } 19 \\
\text { anos) }\end{array}$ & - & - & - & - & - & - \\
\hline$\beta_{1}$ De 20 a 44 anos & 0,324 & 1,38 & 0,000 & 0,292 & 1,34 & 0,009 \\
\hline$\beta_{2}$ De 45 a 59 anos & 0,435 & 1,54 & 0,000 & 0,419 & 1,52 & 0,000 \\
\hline$\beta_{3} 60$ anos e mais & 0,483 & 1,62 & 0,000 & 0,473 & 1,60 & 0,010 \\
\hline$\beta_{4}$ Mulheres & 0,516 & 1,68 & 0,000 & 0,534 & 1,71 & 0,000 \\
\hline$\beta_{5}$ Pretos e pardos & 0,076 & 1,08 & 0,076 & 0,090 & 1,09 & 0,006 \\
\hline $\begin{array}{l}\beta_{6} \text { Ensino fundamental } \\
\text { incompleto }\end{array}$ & $-0,137$ & 0,87 & 0,314 & $-0,052$ & 0,95 & 0,546 \\
\hline$\beta_{7}$ Posse de plano de saúde & - & - & - & 0,366 & 1,44 & 0,000 \\
\hline $\begin{array}{l}\beta_{8} \text { Pessoas de } 20 \text { a } 44 \text { anos e } \\
\text { fundamental incompleto }\end{array}$ & 0,100 & 1,11 & 0,481 & 0,113 & 1,12 & 0,272 \\
\hline $\begin{array}{c}\beta_{9} \text { Pessoas de } 45 \text { a } 59 \text { anos e } \\
\text { fundamental incompleto }\end{array}$ & 0,376 & 1,46 & 0,019 & 0,371 & 1,45 & 0,001 \\
\hline $\begin{array}{l}\beta_{10} \text { Pessoas de } 60 \text { anos e } \\
\text { mais e fundamental } \\
\text { incompleto }\end{array}$ & 0,631 & 1,88 & 0,002 & 0,648 & 1,95 & 0,006 \\
\hline $\begin{array}{l}\beta_{11} \text { Setor censitário } \\
\text { classificado como } \\
\text { vulnerável pelo IPVS }\end{array}$ & 0,019 & 1,02 & 0,044 & 0,083 & 1,09 & 0,052 \\
\hline $\begin{array}{l}\beta_{12} \text { Número de médicos por } \\
\text { mil habitantes }\end{array}$ & 0,123 & 1,13 & 0,335 & $-0,040$ & 0,96 & 0,001 \\
\hline $\begin{array}{l}\beta_{13} \% \text { de beneficiários de } \\
\text { planos de saúde }\end{array}$ & 0,006 & 1,01 & 0,208 & 0,015 & 1,02 & 0,000 \\
\hline $\begin{array}{l}\beta_{14} \% \text { de população } \\
\text { cadastrada no PSF }\end{array}$ & 0,009 & 1,01 & 0,044 & 0,006 & 1,01 & 0,000 \\
\hline $\begin{array}{l}\text { Renda familiar per capita } \\
\text { (cat. ref. mais de } 2 \text { salários } \\
\text { mínimos) }\end{array}$ & - & - & - & - & - & - \\
\hline$\beta_{15}$ Até 1/2 salário mínimo & 0,051 & 1,05 & 0,461 & - & & - \\
\hline $\begin{array}{l}\beta_{16} \text { Mais de } 1 / 2 \text { a } 1 \text { salário } \\
\text { mínimo }\end{array}$ & $-0,018$ & 0,98 & 0,778 & - & & - \\
\hline $\begin{array}{l}\beta_{17} \text { Mais de } 1 \text { a } 2 \text { salários } \\
\text { mínimos }\end{array}$ & $-0,030$ & 0,97 & 0,643 & - & & - \\
\hline
\end{tabular}

FONTE: Fundação Seade. Pesquisa de Condições de Vida - PCV. Datasus. CRM/SP. Elaboração do autor. 
As razões de vantagens para cada componente do Modelo 2 - Plano mostram que o sexo do indivíduo é uma das variáveis mais importantes para explicar a utilização dos serviços de saúde, com vantagem para as mulheres $(1,71)$.

A variável idade apresenta comportamento distinto segundo a escolaridade das pessoas. Os indivíduos mais velhos utilizam mais os serviços de saúde do que os mais novos, no entanto, entre pessoas da mesma faixa etária, o grau de escolaridade constitui um fator associado à utilização de serviços, com os menos escolarizados tendendo a uma maior utilização. O efeito da escolaridade é maior para os mais idosos - 45 a 59 anos e 60 anos e mais -, sendo que, entre os jovens de 15 a 19 anos, o nível de escolaridade não está associado à condição de utilização dos serviços de saúde (Gráfico 11).

Essa interação entre idade e escolaridade pode estar refletindo tanto a maior prevalência de baixa escolaridade entre as pessoas idosas quanto piores condições de saúde dessas pessoas, o que faz com que procurem os serviços de saúde. Já entre os mais jovens - menos de 45 anos -, não se observa esse evento. Merece destaque o fato de a escolaridade não constituir um fator diferenciador para a utilização de serviços para grande parcela da população e, quando isso ocorre, as pessoas com baixa escolaridade e mais idosas, e presumivelmente com maior necessidade, estão tendo acesso aos serviços de saúde. A ausência da associação entre escolaridade e utilização de serviços de saúde já havia sido observado por Travassos et al. (2006), em algumas regiões do Brasil, como Sudeste, Sul e especificamente no Estado de São Paulo. 
Gráfico 11 - Razão de vantagem para condição de utilização dos serviços de saúde, segundo faixa etária e escolaridade. Estado de São Paulo. 2006

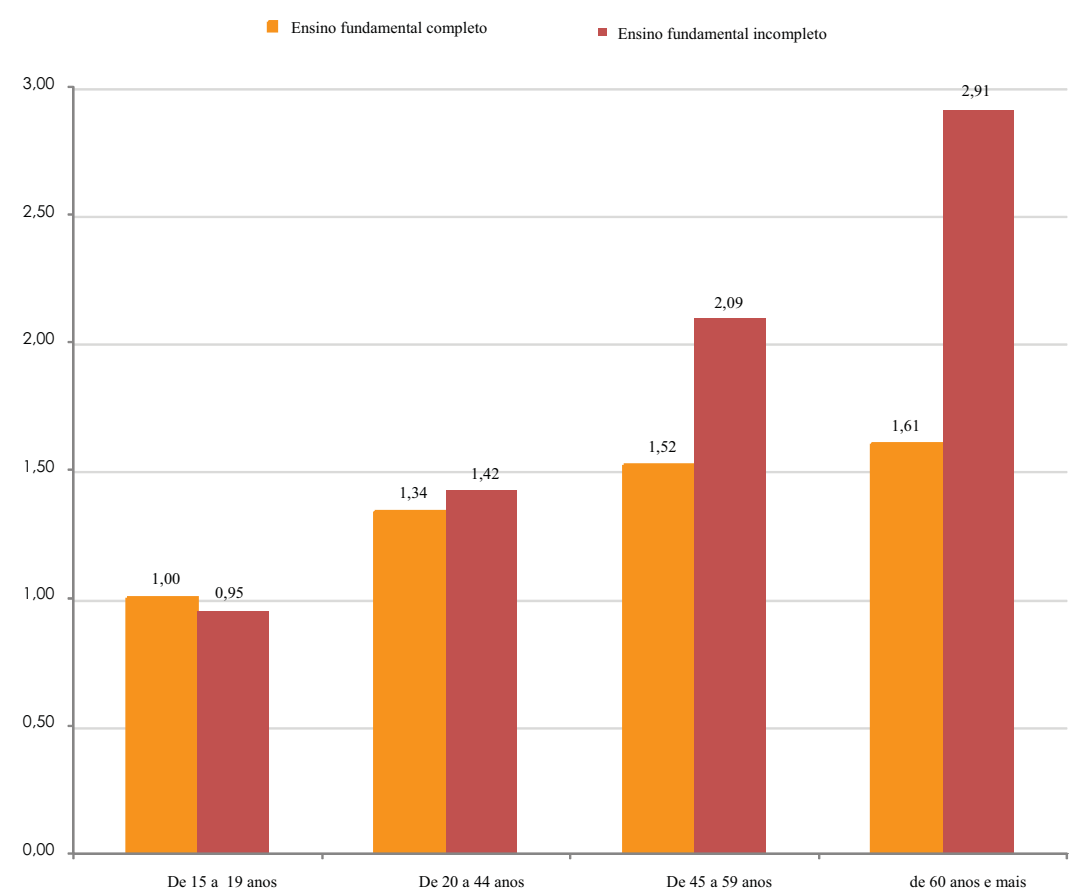

FONTE: Fundação Seade. Pesquisa de Condições de Vida - PCV. Datasus. CRM/SP. Elaboração do autor.

A condição de posse de plano ou convênio médico, que expressa capacidade de pagamento do usuário, deixa os beneficiários em vantagem $(1,44)$ para a utilização dos serviços de saúde em relação aos não-beneficiários.

Os indivíduos de cor preta ou parda tendem a utilizar mais os serviços de saúde - razão de vantagem de 1,09, da mesma forma que os residentes em setores censitários considerados áreas pobres (Grupo 6 do IPVS) ou mais vulneráveis à pobreza (Grupos 4 e 5 ).

Entre as variáveis ecológicas, o porcentual de beneficiários de planos de saúde no DRS se mostrou como uma das mais importantes para explicar a probabilidade de um indivíduo utilizar serviços de saúde. A cada 1\% de acréscimo no porcentual de 
beneficiários de planos de saúde no DRS, a vantagem para o indivíduo ali residente aumenta na ordem de $\mathrm{e}^{0,015 x(\text { aumento no porcentual) }}$. Assim, em duas regiões com respectivamente 20\% e 35\% de beneficiários, a vantagem de uma pessoa residente nessa última é de 1,25 (Gráfico 12).

O porcentual de população cadastrada no PSF situa-se em segundo lugar de importância nesse conjunto de variáveis. A cada 1\% de aumento na proporção de população coberta pelo Programa Saúde da Família, a vantagem para utilização de serviços cresce na ordem de $\mathrm{e}^{0,006 x(a u m e n t o ~ n o ~ p o r c e n t u a l) . ~ P o r ~ e x e m p l o, ~ o ~ a u m e n t o ~ d e ~} 10 \%$ na cobertura do PSF eleva a chance da utilização de serviços de saúde na ordem de 1,06, controladas as demais características (Gráfico 12).

Gráfico 12 - Razões de vantagem para condição de utilização dos serviços de saúde, segundo porcentual de beneficiários de planos e convênios médicos no DRS e porcentual de população cadastrada no PSF no DRS. Estado de São Paulo. 2006

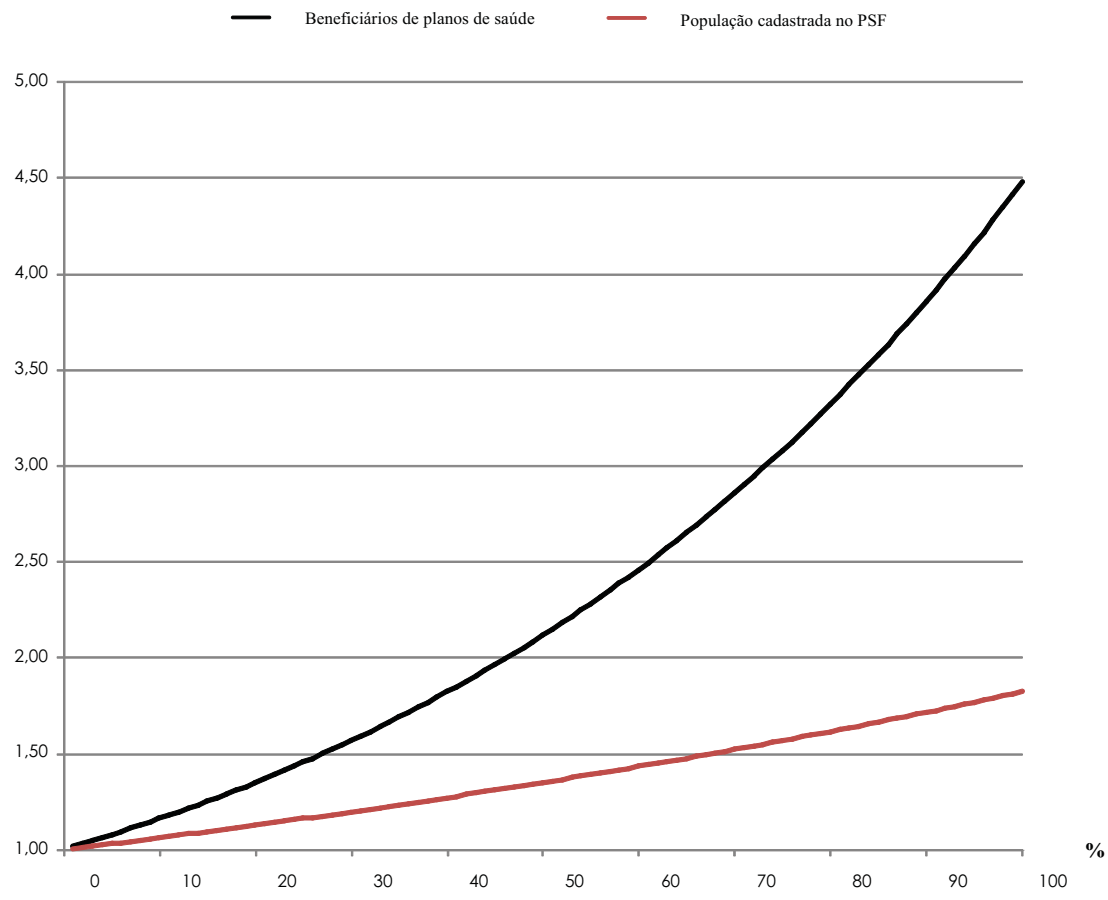

FONTE: Fundação Seade. Pesquisa de Condições de Vida - PCV. Datasus. CRM/SP. Elaboração do autor. 
Esses resultados poderiam ser, a princípio, incoerentes, dado que o DRS de Registro possui apenas 7,9\% de beneficiários de planos de saúde entre sua população e apresenta uma das maiores taxas de utilização dos serviços de saúde (32,8\%). De forma análoga, tem-se o DRS de Marília, com 12,3\% de beneficiários e 40,4\% de pessoas de 15 anos e mais que declararam ter utilizado serviços de saúde nos últimos 30 dias. No entanto, em Registro, a proporção de população cadastrada no PSF é de 56\% e, em Marília é de 42\%, o que aumenta a chance de utilização de serviços de saúde nessas regiões. Porém, essa relação não é simples nem direta, pois existem outras variáveis que influenciam nessa probabilidade, além do componente aleatório específico de cada DRS, como, por exemplo, o de Araçatuba, que apresenta mais de 50\% da população cadastrada e uma das menores taxas de utilização de serviços de saúde entre os DRS (22,7\%).

Assim, tanto a posse individual do plano ou convênio médico quanto a maior presença de operadoras no departamento predispõem a maior utilização dos serviços de saúde. Da mesma forma, a presença do PSF também contribui para uma maior utilização dos serviços de saúde. É importante destacar a relação de complementaridade observada na distribuição espacial do PSF e das operadoras de planos e convênios médicos. Nesse caso, observa-se uma relação inversa, ou seja, nos DRS em que a presença do PSF é expressiva, há menor participação da medicina supletiva (Gráfico 13). 
Gráfico 13 - Dispersão entre o porcentual de beneficiários de planos e convênios médicos no DRS e porcentual de população cadastrada no PSF no DRS. Estado de São Paulo. 2006

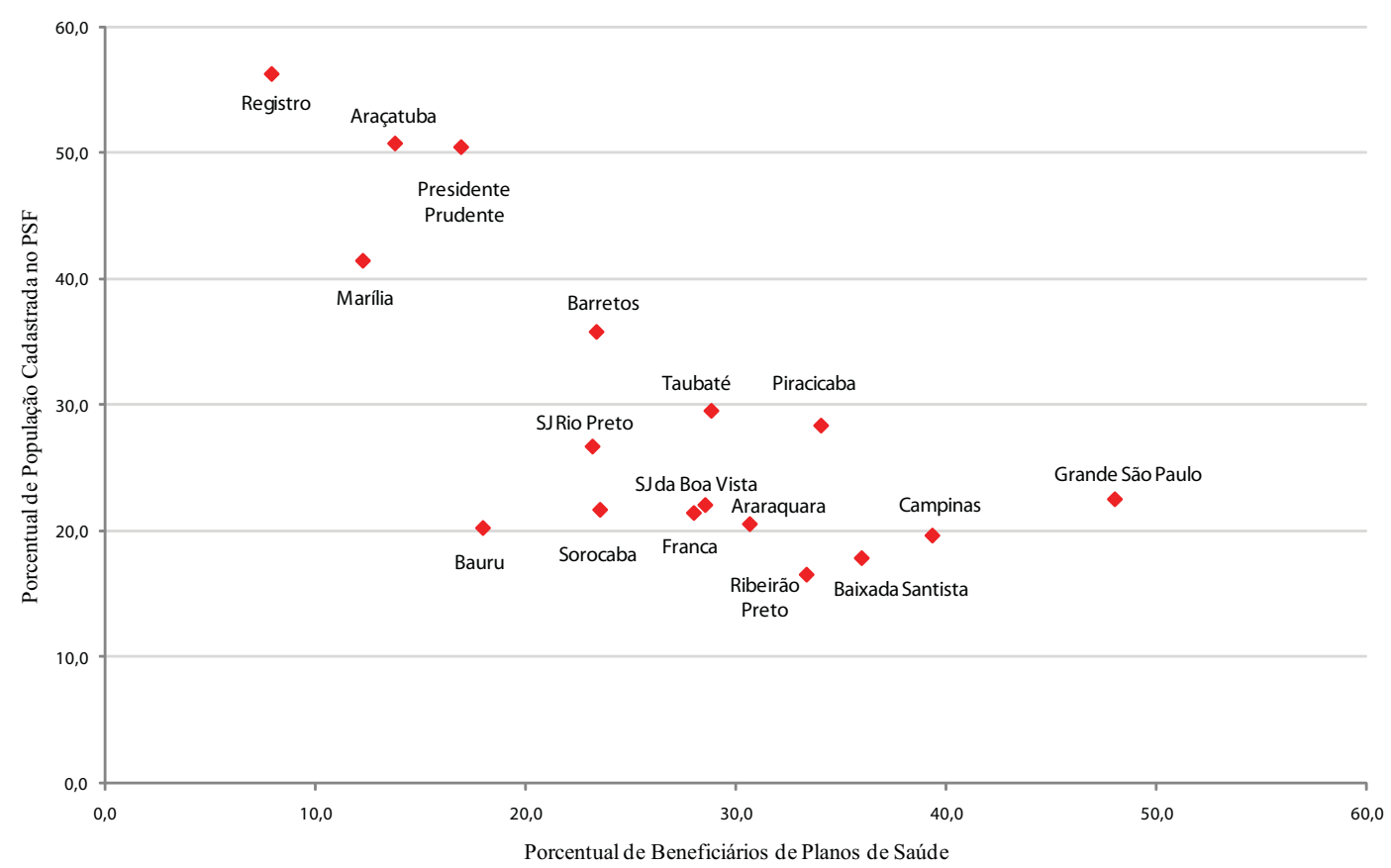

FONTE: Fundação Seade. CRM/SP. Datasus. Elaboração do autor.

Já a associação negativa entre número de médicos por mil habitantes e utilização de serviços de saúde, aparentemente um efeito contrário do esperado, pode ser observada no Gráfico 14 em que apresenta a relação entre essas duas variáveis segundo os 17 DRS. Verifica-se que departamentos regionais de saúde com valores acima de 2 médicos por mil habitantes registram taxa de utilização de serviços de saúde abaixo da média estadual, sendo que o contrário é observado em Registro, com menos de um médico por mil habitantes (Gráfico 14).

Dois fatores podem contribuir para esses resultados. O primeiro é o fato de estar sendo considerado o número de médicos registrados no DRS e não o seu vínculo de trabalho. Assim, departamentos regionais de saúde com poucos médicos por mil 
habitantes, como Registro, podem na verdade ter um maior número desses profissionais ali trabalhando, em consequência da forma de organização do sistema de saúde, que torna disponível à população esse tipo de profissional. O segundo fator é que nos DRS com importantes escolas de medicinas, como Ribeirão Preto e São José do Rio Preto, os valores elevados de médicos por habitantes podem estar associados ao período de registro no CRM, que é realizado no momento da formatura (Gráfico 14).

Gráfico 14 - Dispersão entre o porcentual de pessoas que utilizaram serviços de saúde e o número de médicos por mil habitantes no DRS. Estado de São Paulo. 2006

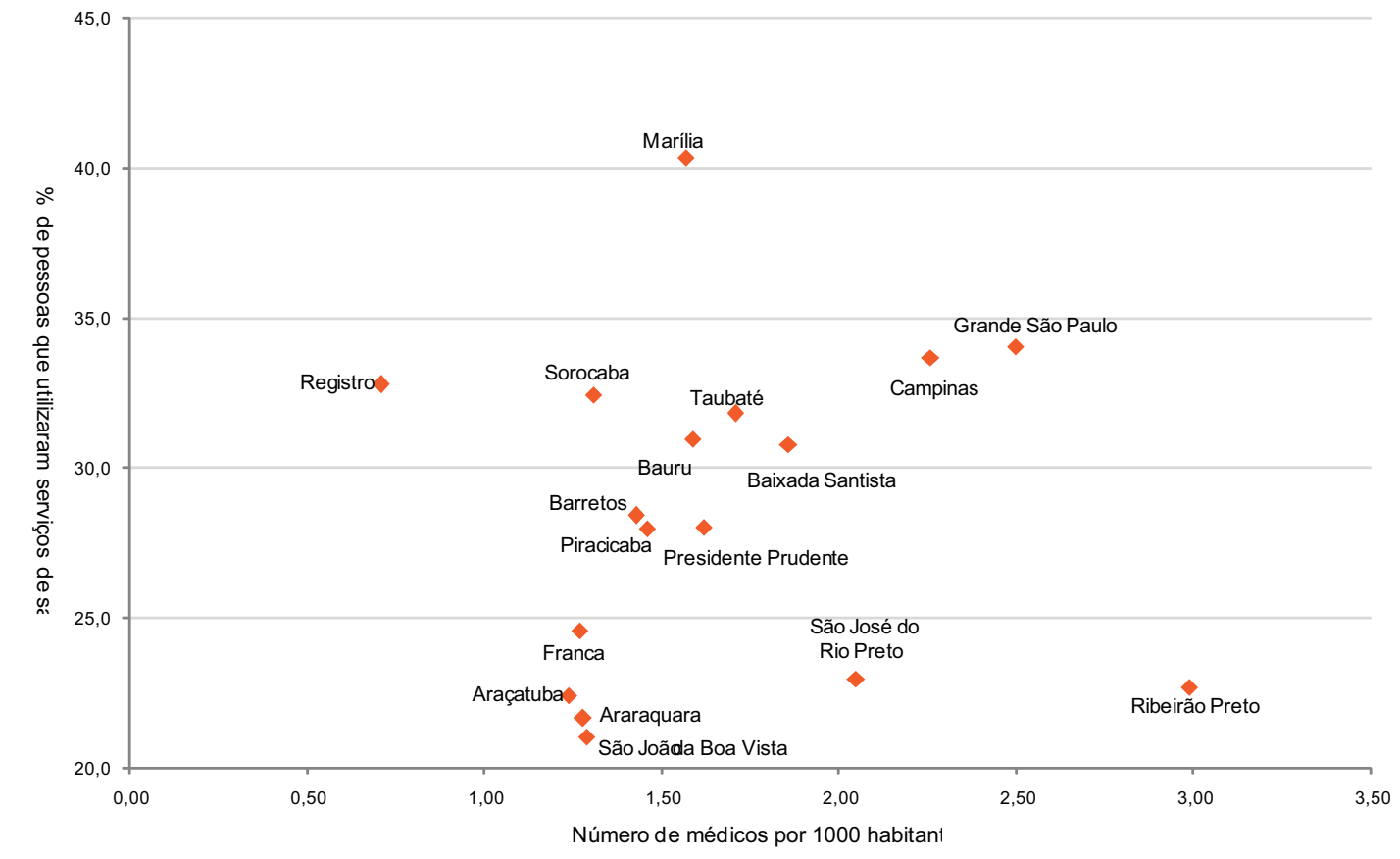

FONTE: Fundação Seade. CRM/SP. Pesquisa de Condições de Vida - PCV. Elaboração do autor.

Esses resultados permitem concluir que, entre as variáveis individuais, as mais importantes são os fatores demográficos sexo e idade, seguidos da condição de posse de plano ou convênio médico, que expressa capacidade de pagamento. Entre as variáveis ecológicas, mostraram-se importantes a disponibilidade da medicina suplementar expressa pela proporção de beneficiários de planos de saúde - e a presença do PSF. 
Em relação aos componentes aleatórios do modelo, apesar de o setor censitário e o

DRS se mostrarem significantes ao nível de 5\%, respectivamente $\psi^{(2)}=0,1464$ e $\psi^{(3)}=0,0135$, o cálculo dos coeficientes de correlação intraclasse indicou que tanto os setores censitários e $(\rho(S C, D R S)=0,046)$ como os DRS $(\rho(D R S)=0,004)$ são internamente heterogêneos em relação à utilização dos serviços de saúde. Isso significa que a simples condição de residência em municípios pertencentes ao mesmo DRS não torna os indivíduos mais similares em relação à utilização dos serviços de saúde do que os residentes em municípios pertencentes a outros DRS.

\subsection{Padrão de utilização do Sistema Único de Saúde - SUS}

Com o universo de análise restrito apenas às pessoas de 15 anos e mais que utilizaram serviços de saúde nos 30 dias anteriores à entrevista de a Pesquisa de Condições de Vida - PCV, foi possível determinar o perfil dos usuários do SUS. Para tanto, construiu-se um modelo de regressão logística com efeitos mistos análogo ao elaborado para a condição de utilização de serviços de saúde, sendo que no presente caso a variável resposta foi o tipo de serviço utilizado (SUS versus plano ou convênio médico.

Os resultados obtidos indicam que a renda familiar per capita é a variável mais importante para diferenciar os usuários do SUS: as pessoas com renda de até 1⁄2 salário mínimo apresentam uma vantagem na utilização do SUS de 16,02, quando comparadas àquelas com renda acima de dois salários mínimos per capita. Conforme aumenta o nível de renda, sua importância diminui para a identificação do usuário do SUS (Tabela 15). 
Tabelas 15 - Estimativas referentes à parte fixa do modelo de regressão logística com efeitos mistos para tipo de serviço de saúde utilizado. Estado de São Paulo. 2006

\begin{tabular}{|c|c|c|c|}
\hline \multirow[b]{2}{*}{ Componentes do Modelo } & \multicolumn{3}{|c|}{ Estimativas } \\
\hline & Coeficiente & $\begin{array}{l}\text { Razão de } \\
\text { vantagem }\end{array}$ & Valor de $\mathrm{p}$ \\
\hline$\beta_{0}$ Constante & 0,212 & - & 0,220 \\
\hline Faixa etária (cat. ref. 15 a 19 anos) & - & - & - \\
\hline$\beta_{1}$ De 20 a 44 anos & $-0,470$ & 0,63 & 0,000 \\
\hline$\beta_{2}$ De 45 a 59 anos & $-0,249$ & 0,78 & 0,169 \\
\hline$\beta_{3} 60$ anos e mais & $-0,283$ & 0,75 & 0,140 \\
\hline$\beta_{4}$ Mulheres & 0,048 & 1,05 & 0,683 \\
\hline$\beta_{5}$ Pretos e pardos & 0,289 & 1,34 & 0,000 \\
\hline$\beta_{6}$ Ensino fundamental incompleto & $-0,888$ & 2,43 & 0,000 \\
\hline $\begin{array}{l}\text { Renda familiar per capita (cat. ref. mais de } 2 \\
\text { salários mínimos) }\end{array}$ & - & - & - \\
\hline$\beta_{15}$ Até $1 / 2$ salário mínimo & 2,774 & 16,02 & 0,000 \\
\hline$\beta_{16}$ Mais de $1 / 2$ a 1 salário mínimo & 1,709 & 5,52 & 0,000 \\
\hline$\beta_{17}$ Mais de 1 a 2 salários mínimos & 0,935 & 2,54 & 0,000 \\
\hline $\begin{array}{l}\beta_{11} \text { Setor censitário classificado como vulnerável } \\
\text { pelo IPVS }\end{array}$ & 0,546 & 1,73 & 0,000 \\
\hline$\beta_{12}$ número de médicos por mil habitantes & 0,123 & 1,13 & 0,002 \\
\hline$\beta_{13} \%$ de beneficiários de planos de saúde & $-0,017$ & 0,98 & 0,000 \\
\hline$\beta_{14} \%$ de população cadastrada no PSF & 0,019 & 1,02 & 0,000 \\
\hline
\end{tabular}

FONTE: Fundação Seade. Pesquisa de Condições de Vida - PCV. Datasus. CRM/SP. Elaboração do autor.

A escolaridade também se mostrou um fator discriminante entre usuários do SUS e de planos de saúde, com os menos escolarizados utilizando mais o SUS (razão de vantagem de 2,54). Os negros (pretos e pardos) também utilizam mais o SUS do que os brancos e amarelos (razão de vantagem de 1,34), da mesma forma que as pessoas que residem em setores censitários com maior grau de vulnerabilidade à pobreza $(1,73)$. O sexo não é uma variável que discrimina a utilização do SUS ou plano de saúde, assim como a idade, exceto a faixa etária de 20 a 44 anos, que concentra a maior parte da população economicamente ativa e, por consequência, grande parte dos beneficiários de convênios médicos vinculados a empresas (Tabela 15). 
Entre as variáveis ecológicas observou-se que nos DRS com maior proporção de beneficiários de planos de saúde há menores chances de utilização do SUS e, ao contrário, naqueles com maior presença do PSF, aumentam as chances de utilização do SUS. Em relação ao número de médicos por mil habitantes, quanto maior for o número de médicos, maior é a chance de utilização do SUS (Tabela 15).

Os componentes aleatórios do modelo mostraram-se significantes ao nível de 5\%, respectivamente $\psi^{(2)}=0,3932$ e $\psi^{(3)}=0,1011$. Além disso, o cálculo dos coeficientes de correlação intraclasse indicou que tanto os setores censitários $(\rho(S C, D R S)=0,131)$ como os DRS $(\rho(D R S)=0,027)$ são internamente mais homogêneos em relação à utilização do tipo de serviços utilizados. Isto significa que a simples condição de residência em municípios pertencentes ao mesmo DRS torna os indivíduos mais similares em relação ao tipo de serviços utilizados - SUS ou planos de saúde.

Já os residentes no mesmo setor censitário são mais parecidos do que os que moram em diferentes setores censitários, dado sua homogeneidade em relação aos níveis de rendimentos observados nas famílias moradoras em um mesmo setor censitário, ou seja, famílias com níveis de renda similares tendem a residir em locais próximos uns aos outros (FERREIRA, 2004). ${ }^{1}$ Entre os resultados da Pesquisa de Condições de Vida, destaca-se a associação entre o nível de renda de um indivíduo e a condição de posse de plano de saúde. ${ }^{2}$

\footnotetext{
${ }^{1}$ Ferreira MP. (Faculdade de Saúde Pública USP). Homogeneidade intraclasse: estudo empírico sobre setores censitários como unidades primárias de amostragem. [Dissertação de Mestrado]. 2004.

${ }^{2}$ A associação entre renda familiar per capita e condição de plano de saúde para o universo em estudo foi verificada por meio de um teste de hipóteses, em que a hipótese nula consistiu na suposição de independência entre as variáveis. Para esse teste, o valor de p foi de $0,000 \mathrm{com}$ a estatística $\mathrm{F}_{4,5528}=298$, ou seja, pode-se afirmar que existe associação estatística entre as duas variáveis. Os cálculos foram realizados considerando-se o desenho amostral. A variável renda familiar per capita foi operacionalizada conforme sua utilização no estudo.
} 
As probabilidades preditas para uma pessoa de 15 anos e mais utilizar o SUS, segundo as características consideradas no modelo, são apresentadas na Tabela 16. Assim, para os DRS de Registro, Marília e Araçatuba, constata-se que a probabilidade mediana para uma pessoa utilizar o SUS é maior que $90 \%$ e nunca inferior a $40 \%$, enquanto para Campinas, Grande São Paulo e Baixada Santista o valor mediano é inferior a $70 \%$.

Tabela 16 - Valor mediano da probabilidade marginal de utilização do SUS entre pessoas de 15 anos e mais dado o modelo de regressão logística de efeitos mistos, segundo Departamentos Regionais de Saúde. Estado de São Paulo. 2006

\begin{tabular}{|c|c|c|c|c|c|}
\hline \multirow{2}{*}{$\begin{array}{l}\text { Departamento Regional } \\
\text { de Saúde - DRS }\end{array}$} & \multicolumn{5}{|c|}{ Percentis (em \%) } \\
\hline & 10 & 25 & Mediana & 75 & 90 \\
\hline Registro & 72,5 & 85,3 & 94,3 & 97,4 & 98,4 \\
\hline Marília & 67,1 & 75,5 & 89,7 & 94,7 & 96,6 \\
\hline Araçatuba & 66,1 & 77,9 & 90,5 & 95,5 & 97,9 \\
\hline Presidente Prudente & 75,7 & 84,0 & 90,4 & 93,7 & 95,9 \\
\hline Barretos & 75,3 & 77,4 & 87,5 & 92,3 & 94,0 \\
\hline São José do Rio Preto & 45,6 & 65,1 & 82,8 & 91,5 & 95,7 \\
\hline Bauru & 32,1 & 55,5 & 80,2 & 90,8 & 94,8 \\
\hline Araraquara & 35,5 & 50,9 & 79,0 & 89,1 & 94,6 \\
\hline São João da Boa Vista & 50,2 & 57,6 & 76,7 & 84,6 & 89,3 \\
\hline Piracicaba & 47,0 & 60,2 & 76,1 & 84,5 & 89,3 \\
\hline Franca & 33,7 & 55,6 & 76,2 & 89,8 & 95,3 \\
\hline Sorocaba & 47,6 & 51,8 & 75,8 & 84,8 & 92,2 \\
\hline Ribeirão Preto & 48,9 & 61,0 & 76,0 & 88,9 & 95,3 \\
\hline Taubaté & 40,9 & 55,5 & 74,5 & 88,6 & 94,5 \\
\hline Campinas & 28,4 & 46,2 & 68,2 & 85,0 & 92,8 \\
\hline Grande São Paulo & 29,1 & 45,1 & 67,2 & 85,1 & 92,6 \\
\hline Baixada Santista & 30,5 & 48,8 & 68,9 & 82,0 & 90,8 \\
\hline
\end{tabular}

FONTE: Fundação Seade. Pesquisa de Condições de Vida - PCV. Datasus. CRM/SP. Elaboração do autor. 


\subsection{Eficiência na utilização dos serviços de saúde}

A análise dos três inputs - ln (despesa total em saúde), ln (número de leitos SUS) e número de médicos por mil habitantes - mostrou forte associação entre eles, com os coeficientes de correlação linear de Pearson entre ln(despesa total em saúde) e ln(número de leitos SUS) e número de médicos por mil habitantes respectivamente iguais a 0,93 e 0,65. Já a correlação entre ln(número de médicos SUS) e número de médicos por mil habitantes foi de 0,66. Esses resultados, que indicam a possibilidade da utilização de apenas uma variável de input sem perda expressiva de informação, aliados ao pequeno número de observações para a construção do modelo de eficiência - 17 DRS, fizeram com que se optasse por trabalhar com apenas um input - despesa total em saúde expresso na escala logarítmica. ${ }^{1}$ A Figura 3 apresenta o modelo final de eficiência.

\begin{tabular}{|c|c|c|}
\hline Recursos (INPUTS) & $\begin{array}{l}\text { Assistência à } \\
\text { Saúde }\end{array}$ & Resultados (OUTPUTS) \\
\hline \multirow{2}{*}{$\begin{array}{c}\text { Despesa total em saúde } \\
\text { (composta pelo gasto municipal } \\
\text { e estadual alocado ao } \\
\text { município) }\end{array}$} & & - Produção ambulatorial \\
\hline & & $\begin{array}{l}\text { - Total das internações dos } \\
\text { residente: }\end{array}$ \\
\hline
\end{tabular}

Figura 3 - Modelo empírico de eficiência FONTE: Elaboração do autor.

Para esse modelo, os escores de eficiência técnica e eficiência puramente técnica para os 17 Departamentos Regionais de Saúde estão apresentados na Tabela 17.

\footnotetext{
${ }^{3}$ Dadas as propriedades matemáticas da função logarítmica, a correlação entre as variáveis expressas na escala logarítmica se mantém na escala original. Assim, pode-se afirmar que a despesa total em saúde é correlacionada com o número de leitos SUS e o número de médicos por mil habitantes.
} 
Tabela 17 - Eficiência técnica e puramente técnica, segundo Departamentos Regionais de Saúde DRS’s. Estado de São Paulo. 2006

\begin{tabular}{|c|c|c|}
\hline $\begin{array}{l}\text { Departamento Regional } \\
\text { de Saúde - DRS }\end{array}$ & Eficiência técnica & $\begin{array}{c}\text { Eficiência puramente } \\
\text { técnica }\end{array}$ \\
\hline Média do Estado & 98,1 & 98,7 \\
\hline Desvio padrão & 1,6 & 1,4 \\
\hline DRS 01 - Grande São Paulo & 100,0 & 100,0 \\
\hline DRS 02 - Araçatuba & 95,3 & 97,2 \\
\hline DRS 03 - Araraquara & 96,7 & 97,3 \\
\hline DRS 04 - Baixada Santista & 98,5 & 98,6 \\
\hline DRS 05 - Barretos & 98,7 & 100,0 \\
\hline DRS 06 - Bauru & 99,6 & 99,9 \\
\hline DRS 07 - Campinas & 98,4 & 98,6 \\
\hline DRS 08 - Franca & 97,3 & 98,3 \\
\hline DRS 09 - Marília & 99,7 & 100,0 \\
\hline DRS 10 - Piracicaba & 97,2 & 97,4 \\
\hline DRS 11 - Presidente Prudente & 99,2 & 100,0 \\
\hline DRS 12 - Registro & 93,9 & 95,1 \\
\hline DRS 13 - Ribeirão Preto & 98,2 & 98,2 \\
\hline DRS 14 - São João da Boa Vista & 98,6 & 100,0 \\
\hline DRS 15 - São José do Rio Preto & 100,0 & 100,0 \\
\hline DRS 16 - Sorocaba & 98,7 & 98,9 \\
\hline DRS 17 - Taubaté & 97,7 & 97,8 \\
\hline
\end{tabular}

FONTE: Elaboração do autor.

Em relação à eficiência técnica, quando se espera que os resultados alcançados sejam proporcionais aos recursos investidos, ou seja, o aumento da produção ambulatorial e hospitalar seja proporcional aos gastos, tem-se como média estadual o valor de 98,1\%, com 11 DRS atingindo um escore de eficiência superior a este valor, o que pode ser considerado elevado (BARDAHAN et al., 1998). Grande São Paulo e São José do Rio Preto atingiram escore igual a 100\% (Tabela 17). 
Ao definir como totalmente eficientes os DRS da Grande São Paulo e São José do Rio Preto - escores iguais a 100\% -, estabelece-se como parâmetro de eficiência a relação entre o gasto e a produção dos serviços ambulatoriais e hospitalares existentes nesses locais. No entanto, pode não ser factível aos demais DRS atingirem essa relação, devido às especificidades daqueles dois departamentos. A Grande São Paulo diferenciase dos demais DRS em relação ao porte e à complexidade dos serviços de saúde ali localizados, mais de 50\% das despesas em saúde no Estado, sendo 35\% de responsabilidade estadual; mais de 41\% das internações realizadas no Estado em 2006 eram de residentes dessa regional; e 67\% da sua produção ambulatorial referia-se a procedimentos de média e alta complexidades. Já São José do Rio Preto distingue-se por constituir um importante polo regional de saúde do Estado de São Paulo, expresso pelo grau de complexidade de sua produção ambulatorial: 63\% em média e alta complexidades.

Se considerarmos como critério de eficiência escores acima de 98\% (BARDAHAN et al., 1998), têm-se 11 DRS classificados como eficientes na utilização dos recursos: Grande São Paulo (100,0\%), São José do Rio Preto (100,0\%), Marília (99,7\%), Bauru (99,6\%), Presidente Prudente (99,2\%), Sorocaba (98,7\%), Barretos (98,7\%), São João da Boa Vista (98,6\%), Baixada Santista (98,5\%), Campinas (98,4\%) e Ribeirão Preto (98,2\%). Como não-eficientes classificam-se os departamentos de Taubaté (97,7\%), Franca (97,3\%), Piracicaba (97,2\%), Araraquara (96,7\%), Araçatuba (95,2\%) e Registro (93,9\%) (Tabela 17). 
Quando se estima a eficiência puramente técnica, ou seja, pressupondo que os departamentos de saúde possuem realidades diversas e, portanto, não é possível esperar um retorno constante de escala na aplicação dos recursos em assistência à saúde, a eficiência média estadual passa a ser de 98,7\%. Dos 17 DRS, seis atingem o escore de 100\%: Grande São Paulo, São José do Rio Preto, São João da Boa Vista, Barretos, Presidente Prudente e Marília. Considerando-se como critério de eficiência valores do escore acima de 98\%, têm-se 12 DRS classificados como eficientes, com a incorporação do DRS de Franca no grupo dos eficientes. (Tabela 17).

Adotando-se o critério de eficiência puramente técnica e considerando como eficientes os DRS com escore acima de 98\%, verifica-se que esse grupo, composto por 12 departamentos regionais de saúde, respondia por 86\% da população do Estado em 2006 (Tabela 18).

Eles se diferenciavam dos classificados como não-eficientes por apresentarem maior gasto per capita em saúde $\mathrm{R}$ \$ 365,94 e R \$ 327,84, respectivamente, e maior participação do governo estadual na composição das despesas em saúde (29,7\% e 17,1\%). Em relação à produção ambulatorial, verifica-se que, entre os eficientes, os procedimentos de média e alta complexidades respondiam por 62,2\% da produção total, contra 53,5\% dos não-eficientes. Além disso, o total de procedimentos ambulatoriais por habitantes é maior entre o grupo dos eficientes $(16,5$ contra 13,1$)$. Já a taxa de internações é praticamente igual entre os dois grupos (55,1 e 54,3 por mil habitantes, respectivamente) (Tabela 18). 
Tabela 18 - População, despesa per capita em saúde, participação de procedimentos de média e alta complexidades no total dos procedimentos ambulatoriais, número de procedimentos ambulatoriais e internações, segundo Departamentos Regionais de Saúde. Estado de São Paulo. 2006

\begin{tabular}{|c|c|c|c|c|c|}
\hline $\begin{array}{l}\text { Departamento Regional } \\
\text { de Saúde - DRS }\end{array}$ & $\begin{array}{c}\text { População } \\
\text { (\%) }\end{array}$ & $\begin{array}{l}\text { Despesa per } \\
\text { capita } \text { em } \\
\text { saúde }(\mathrm{R} \$ \text { de } \\
2006)\end{array}$ & $\begin{array}{c}\text { Participação de } \\
\text { procedimentos } \\
\text { ambulatoriais } \\
\text { de média e alta } \\
\text { complexidade } \\
\text { no total da } \\
\text { produção } \\
\text { ambulatorial }\end{array}$ & $\begin{array}{l}\text { Número de } \\
\text { procedimen- } \\
\text { tos ambula- } \\
\text { toriais por } \\
\text { habitantes }\end{array}$ & $\begin{array}{l}\text { Internações de } \\
\text { residentes por } \\
\text { mil habitantes }\end{array}$ \\
\hline Total do Estado & 100,0 & 360,75 & 61,2 & 16,1 & 55,0 \\
\hline DRS 01 - Grande São Paulo & 47,9 & 389,93 & 66,9 & 15,5 & 47,5 \\
\hline DRS 05 - Barretos & 1,0 & 361,95 & 56,0 & 23,0 & 75,8 \\
\hline DRS 11 - Presidente Prudente & 1,8 & 308,93 & 50,5 & 20,0 & 76,4 \\
\hline DRS 14 - São João da Boa Vista & 1,9 & 294,38 & 48,6 & 17,1 & 78,4 \\
\hline DRS 15 - São José do Rio Preto & 3,5 & 309,05 & 62,8 & 21,2 & 81,4 \\
\hline DRS 09 - Marília & 2,6 & 334,47 & 48,1 & 22,2 & 82,6 \\
\hline DRS 06 - Bauru & 4,0 & 292,25 & 61,9 & 18,0 & 74,5 \\
\hline DRS 16 - Sorocaba & 5,5 & 306,06 & 53,3 & 15,1 & 62,1 \\
\hline DRS 07 - Campinas & 9,5 & 363,43 & 62,4 & 15,6 & 50,4 \\
\hline DRS 04 - Baixada Santista & 4,1 & 375,17 & 55,6 & 18,9 & 50,2 \\
\hline DRS 08 - Franca & 1,6 & 307,94 & 56,5 & 14,9 & 62,4 \\
\hline DRS 13 - Ribeirão Preto & 3,0 & 391,39 & 55,9 & 19,3 & 65,4 \\
\hline Total Eficientes & 86,4 & 365,94 & 62,2 & 16,5 & 55,1 \\
\hline DRS 17 - Taubaté & 5,5 & 338,14 & 55,6 & 14,3 & 53,0 \\
\hline DRS 10 - Piracicaba & 3,4 & 273,73 & 54,7 & 11,8 & 49,2 \\
\hline DRS 03 - Araraquara & 2,3 & 294,84 & 50,9 & 12,3 & 54,8 \\
\hline DRS 02 - Araçatuba & 1,7 & 366,31 & 50,5 & 12,1 & 70,9 \\
\hline DRS 12 - Registro & 0,7 & 518,82 & 46,2 & 15,1 & 48,2 \\
\hline Total Não Eficientes & 13,6 & 327,84 & 53,5 & 13,1 & 54,3 \\
\hline
\end{tabular}

FONTE: Elaboração do autor.

A partir dos dados da Pesquisa de Condições de Vida - PCV, é possível comparar o acesso aos serviços de saúde entre os dois grupos de DRS - eficientes e não-eficientes -, bem como identificar entre os DRS considerados eficientes se existe diferença em termos da proporção da população que utilizou serviços gratuitos de saúde. 
Os resultados apresentados na Tabela 19 mostram que, no conjunto dos DRS considerados eficientes, registra-se maior proporção de utilização de serviços de saúde nos últimos 30 dias: 32,2\%, contra 27,7\% dos não eficientes. Já em relação à utilização do SUS, as diferenças observadas não foram estatisticamente significantes ao nível de $5 \%$ para os dois grupos.

Tabela 19 - Proporção da população que utilizou serviços de saúde e que utilizou o Sistema Único de Saúde nos últimos 30 dias, segundo grupos de DRS. Estado de São Paulo. 2006

Em porcentagem

\begin{tabular}{l|l|c|c}
\hline Grupos de DRS/ Acesso aos & \multirow{2}{*}{$\begin{array}{l}\text { População } \\
\text { serviços de saúde }\end{array}$} & \multicolumn{2}{|c}{ Intervalo de confiança de 5\% } \\
\cline { 3 - 4 } Utilização de serviços de saúde & & Mínimo & Máximo \\
\hline Eficientes & 32,2 & 31,1 & 33,3 \\
Com maior utilização do SUS & 28,1 & 25,2 & 31,2 \\
Com menor utilização do SUS & 30,7 & 29,1 & 32,4 \\
Grande São Paulo & 34,1 & 32,6 & 35,6 \\
Não-eficientes & 27,7 & 25,1 & 30,1 \\
Utilização do SUS & & & 66,8 \\
Eficientes & & 62,2 & 79,3 \\
Com maior utilização do SUS & 75,7 & 71,7 & 66,5 \\
Com menor utilização do SUS & 62,0 & 57,2 & 65,7 \\
Grande São Paulo & 62,5 & 59,3 & 73,7 \\
Não-eficientes & 67,4 & 60,5 & \\
\hline
\end{tabular}

FONTE: Elaboração do autor.

Entre os 12 DRS classificados como eficientes, foi possível identificar três subgrupos definidos segundo a proporção da população que utiliza o Sistema Único de Saúde. Assim, tem-se a criação de quatro grupos de DRS: eficientes com maior utilização do SUS (São João da Boa Vista, Presidente Prudente, Barretos, São José do Rio Preto, Marília e Franca); eficientes com menor utilização do SUS (Campinas, Bauru, Sorocaba, Baixada Santista e Ribeirão Preto); não eficientes e DRS da Grande São Paulo. A 
distinção da Grande São Paulo da análise deve-se à sua importância populacional, econômica e no sistema de saúde estadual. A Tabela 19 apresenta as características desses agrupamentos em relação a utilização dos serviços de do SUS.

O mapa 1 apresenta a distribuição espacial dos grupos indica que a eficiência na utilização dos recursos na produção dos serviços de saúde do SUS ocorre em áreas diferenciadas segundo as características do sistema de saúde, socioeconômicas e demográficas.

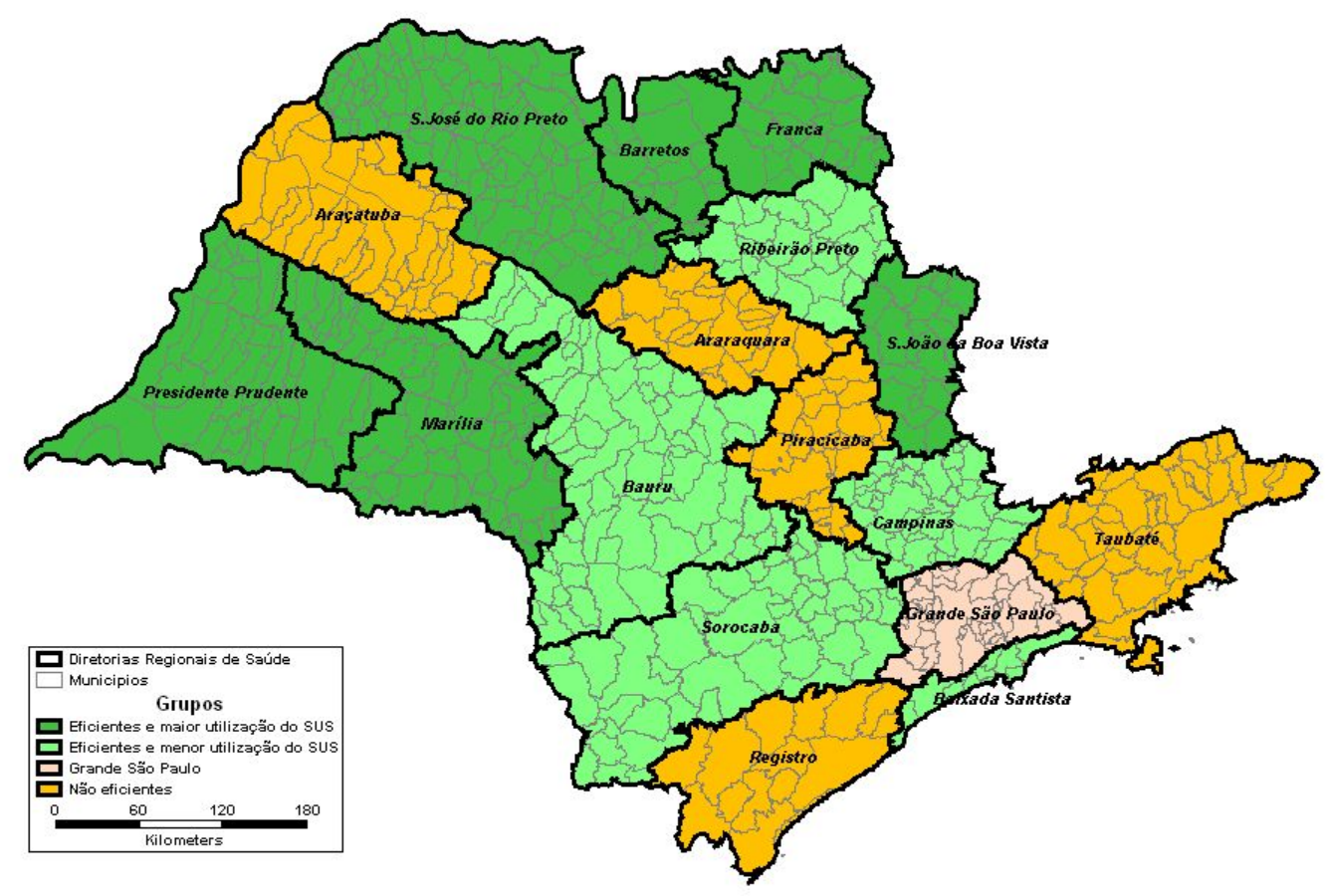

Mapa 1 - Departamentos Regionais de Saúde segundo eficiência puramente técnica e utilização do SUS. Estado de São Paulo. 2006. FONTE: Elaboração do autor. 
Tabela 20 - População, despesa per capita em saúde, participação dos gastos estaduais no total das despesas em saúde, participação dos procedimentos de média e alta complexidades no total dos procedimentos ambulatoriais e internações por mil habitantes, segundo grupos de DRS. Estado de São Paulo. 2006

\begin{tabular}{|c|c|c|c|c|c|}
\hline $\begin{array}{c}\text { Departamento } \\
\text { Regional de Saúde } \\
\text { - DRS }\end{array}$ & $\begin{array}{l}\text { População } \\
\text { (\%) }\end{array}$ & $\begin{array}{l}\text { Despesa per } \\
\text { capita em } \\
\text { saúde (R\$ de } \\
\text { 2006) }\end{array}$ & $\begin{array}{c}\text { \% da despesa } \\
\text { estadual na } \\
\text { despesa total }\end{array}$ & $\begin{array}{l}\text { \% da produção } \\
\text { ambulatorial de } \\
\text { média e alta } \\
\text { complexidade no } \\
\text { total da produção } \\
\text { ambulatorial }\end{array}$ & $\begin{array}{c}\text { Internações } \\
\text { de residentes } \\
\text { por mil } \\
\text { habitantes }\end{array}$ \\
\hline Total do Estado & 100,0 & 360,75 & 28,2 & 61,2 & 55 \\
\hline Grande São Paulo & 47,9 & 389,93 & 35,3 & 66,9 & 48 \\
\hline $\begin{array}{l}\text { Eficientes e com menor } \\
\text { utilização do SUS }\end{array}$ & 26,0 & 345,57 & 21,2 & 58,5 & 58 \\
\hline $\begin{array}{l}\text { Eficientes e com maior } \\
\text { utilização do SUS }\end{array}$ & 12,5 & 316,25 & 23,0 & 54,5 & 78 \\
\hline Não-eficientes & 13,6 & 327,84 & 17,1 & 53,5 & 54 \\
\hline
\end{tabular}

FONTE: Elaboração do autor. 


\section{DISCUSSÃO}

m um cenário em que a divisão territorial dos departamentos de saúde reflete a heterogeneidade socioeconômica e demográfica existente no Estado de São Paulo, as macrorregiões de saúde apresentam características distintas em relação a desenvolvimento econômico, estrutura etária de sua população, porte populacional e também uso dos serviços de saúde por parte de seus habitantes.

Esse fato pode ser comprovado pela maior proporção de pessoas que utilizaram serviços de saúde, em um intervalo de 30 dias, nas regiões que agregam os municípios economicamente mais desenvolvidos do Estado, e áreas metropolitanas. Já os departamentos localizados no interior do Estado, mesmo aqueles que englobam municípios caracterizados como polos regionais em termos de oferta de serviços de saúde, como Ribeirão Preto e São José do Rio Preto, apresentam menor utilização de serviços de saúde, com exceção de Registro e Marília. Nesse sentido, Neri e Soares (2002) mostraram que a procura por serviços de saúde tende a crescer à medida que aumenta a densidade populacional.

Entre os fatores associados à utilização dos serviços de saúde, destacam-se no nível individual a idade e o sexo, com as mulheres e os maiores de 60 anos registrando maior taxa de utilização dos serviços, respectivamente em relação aos homens e às 
pessoas mais jovens. Segundo Andersen (1995), os fatores demográficos são os que deveriam ser significantes em um sistema de saúde pautado pela equidade.

A outra variável individual que se mostrou importante no modelo é a condição de posse de plano de saúde ou convênio médico, ou seja, um indicador que expressa, além da capacidade de pagamento dos serviços de saúde, o acesso a uma rede de profissionais e serviços de saúde. Para Neri e Soares (2002), o consumo de serviços de saúde tende a aumentar quando há maior gasto com mensalidades de seguro-saúde e posse de planos com cobertura de consulta médica. Outro aspecto relevante refere-se ao fato de que a condição de posse de um plano de saúde está frequentemente associada à forma de inserção de um indivíduo no mercado de trabalho e, portanto, pessoas com distintos níveis de renda podem ser beneficiários de planos de saúde.

Já os níveis de escolaridade dos indivíduos apresentaram associações diferenciadas em relação à utilização dos serviços de saúde de acordo com a idade dos mesmos. Para os mais jovens, a escolaridade não é um fator relevante para diferenciar a utilização dos serviços de saúde, mas, entre os mais velhos, observou-se efeito inverso do esperado, ou seja, entre os menos escolarizados ocorre maior utilização dos serviços de saúde. Esse resultado pode estar expressando tanto a maior prevalência da baixa escolaridade entre os idosos quanto as piores condições de saúde dessas pessoas, fazendo com que procurem os serviços de saúde. No entanto, independentemente das causas da procura por atendimento desse segmento, observou-se que o princípio da equidade, em que o atendimento deve ser oferecido segundo as necessidades do indivíduo, está sendo satisfeito. 
A associação entre pessoas idosas com baixa escolaridade e maior procura por serviços de saúde já havia sido observada por Neri e Soares (2002), em estudo utilizando dados da PNAD para o Brasil. Já a ausência de associação entre escolaridade e utilização dos serviços de saúde foi constatada por Travassos et al. (2006) em algumas regiões do Brasil, inclusive o Estado de São Paulo.

Diferentemente do observado em outros estudos sobre acesso a serviços de saúde (NERI e SOARES, 2002), a renda familiar per capita do indivíduo, um indicador clássico sobre capacidade de pagamento, não se mostrou significante para diferenciar a utilização dos serviços de saúde. Esses resultados se alinham aos encontrados por Noronha e Andrade (2001), em que São Paulo foi identificado como o estado menos desigual, juntamente com o Rio de Janeiro, em relação ao indicador sobre desigualdade em saúde, que relaciona a proporção acumulada de pessoas que referiram algum problema de saúde à proporção acumulada de indivíduos pertencentes a determinada faixa de renda. Estudo realizado por Travassos et al. (2006), sobre desigualdade na utilização dos serviços entre as grandes regiões do Brasil e alguns estados brasileiros, mostra que, em São Paulo, a associação entre a renda e a utilização de serviços de saúde, apesar de se manter em 2003, não era tão marcante como aquela observada em 1998.

Da mesma forma, as pessoas de cor preta e parda tendem a utilizar mais os serviços de saúde, o mesmo ocorrendo com os residentes em áreas classificadas como vulneráveis à pobreza.

Entre as variáveis ecológicas, destacam-se aquelas relacionadas à oferta de serviços públicos e privados de saúde: o porcentual de beneficiários de planos de saúde e 
proporção da população cadastrada no Programa Saúde da Família. Assim, tanto a presença de operadoras de planos de saúde no DRS quanto o PSF predispõem maior utilização dos serviços de saúde pela população. Esse resultado contribui para explicar porquê Marília e Registro destacam-se em termos de utilização de serviços de saúde: nesses locais é expressiva a presença do PSF.

Observou-se no estudo, uma relação de complementaridade na distribuição espacial do PSF e das operadoras de planos de saúde e convênios médicos, ou seja, nos DRS em que há presença expressiva do PSF, existe menor participação da medicina suplementar. A importância do PSF como um "facilitador” para a utilização dos serviços de saúde insere-se no que Frenk (1992) denomina de poder de utilização, em que o sistema usa mecanismos para superar possíveis barreiras de acesso ao sistema de saúde pela população.

Em relação à população usuária do SUS, também verificaram-se diferenças regionais, porém com tendência oposta à observada para a utilização dos serviços de saúde. Os DRS que englobam os maiores e economicamente mais desenvolvidos municípios do Estado apresentam proporcionalmente menor demanda dos serviços do SUS e, em contrapartida, maior consumo de serviços privados de saúde. É importante observar que em alguns DRS o SUS é responsável por 80\% do atendimento, destacandose Registro e Marília.

Quanto ao tipo de estabelecimento procurado, verificou-se que a principal porta de entrada no sistema é o posto ou centro de saúde, para os usuários do SUS, e a clínica ou consultório médico, para os beneficiários de planos de saúde. A procura 
por pronto-socorro foi mais elevada entre os usuários do SUS do que para os beneficiários de planos de saúde, o que pode estar expressando desde as dificuldades de acesso aos estabelecimentos indicados como primeira porta do sistema até a maior prevalência de atendimentos de urgência/emergência realizados pelo SUS. A importância do papel do SUS na oferta dos serviços de urgência/emergência é confirmada quando se verifica a presença expressiva de beneficiários de planos que utilizaram o pronto-socorro.

O porcentual de beneficiários de planos de saúde que utilizaram o SUS permite inferir a respeito da variabilidade dos tipos de operadoras de planos de saúde existentes no Estado de São Paulo, que segundo Viana et al. (2008) configuram distintos cenários para os usuários de planos. Em determinados Departamentos Regionais de Saúde, chama a atenção a frequência com que beneficiários de planos de saúde utilizaram o SUS, com destaque para Registro e Araçatuba. Esses dados mostram o diferencial entre disponibilidade de serviços e recursos humanos existentes nas diversas regiões do Estado.

Os resultados obtidos pelo modelo de regressão também indicaram que, entre os usuários do SUS, encontram-se os mais pobres, os menos escolarizados, pretos e pardos e os residentes nas áreas mais pobres dos municípios. Observou-se ainda maior uso do SUS entre os muito jovens (15 a 19 anos) e os mais velhos (acima de 44 anos). Homens e mulheres utilizam o Sistema Único de Saúde de forma equitativa. Ribeiro et al. (2006) obtiveram resultados similares quando analisaram o perfil sociodemográfico dos usuários e não-usuários do SUS por meio da PNAD 2003. 
O PSF é um fator que aumenta a probabilidade de utilização do SUS pela população, ao contrário do observado em relação à presença de operadoras de planos e convênios médicos.

Assim, pode-se afirmar que, no Estado de São Paulo, a condição de utilização dos serviços de saúde associa-se às características individuais dos usuários - demográficas e socioeconômicas - e às condições de oferta do sistema de saúde. A diversidade existente entre suas regiões em termos de desenvolvimento econômico e social, não se reflete na condição de utilização dos serviços de saúde, mas sim no grau de dependência das suas populações ao SUS, com o PSF constituindo um importante instrumento para propiciar o acesso ao sistema de saúde.

A análise da eficiência no uso dos recursos do SUS na produção ambulatorial e no total das internações mostrou importantes diferenças regionais. Dos 17 DRS, 12 podem ser considerados eficientes pelo critério de eficiência puramente técnica, ou seja, pressupondo que os departamentos de saúde possuem realidades diversas e, portanto, não é possível esperar um retorno constante de escala na aplicação dos recursos em assistência à saúde.

Entre os DRS considerados eficientes, estão aqueles que englobam municípios localizados nas áreas metropolitanas ou em seu entorno, além importantes polos de produção de serviços em saúde, como, por exemplo, São José do Rio Preto, Bauru e Ribeirão Preto. A exceção é o DRS de Taubaté. Os DRS classificados como eficientes caracterizam-se por englobar quase todos os departamentos do interior do Estado que concentram municípios com baixo desenvolvimento econômico aliado a bons 
indicadores socioeconômicos e uma ou duas cidades-polos, que são responsáveis por grande parte da riqueza gerada na região.

Entre os não-eficientes, encontram-se DRS que se caracterizam pela concentração de municípios com níveis de riqueza acima do observado para a maioria dos municípios paulista, como Piracicaba, até aqueles com presença expressiva de municípios pobres e com indicadores sociais deficientes, como Registro.

Quando se comparam as regionais de saúde, segundo eficiência puramente técnica e indicadores de gastos em saúde, observou-se maior gasto per capita em saúde entre os considerados eficientes, além da maior participação do tesouro estadual na composição das despesas de saúde. As regionais classificadas como não-eficientes apresentam maior variabilidade na média dos gastos em saúde dos seus municípios. O DRS de Registro aparece como a exceção entre os não-eficientes, com o maior gasto per capita em saúde e a maior parcela do tesouro estadual nas despesas em saúde.

Em 2006, os municípios pertencentes às regionais consideradas eficientes pelo modelo também se mostraram, em média, mais eficazes em relação à cobertura da produção ambulatorial. Os indicadores de produção ambulatorial por habitantes tendem a ser maiores para o conjunto dos 12 DRS classificados como eficientes. Esse resultado também é confirmado quando se analisa apenas o número de internações por mil habitantes/ano no Departamento Regional de Saúde. Observou-se, ainda, que os DRS classificados como eficientes apresentam, em sua maioria, maior complexidade em relação à produção ambulatorial, além de maior taxa de utilização de serviços de saúde. 
Ao se considerarem simultaneamente eficiência puramente técnica e tipo de serviço de saúde utilizado, foi possível identificar os DRS eficientes e com maior utilização do SUS e aqueles eficientes e com menor utilização do SUS. O DRS da Grande São Paulo foi excluído dessa divisão, dada sua importância populacional, econômica e no sistema de saúde estadual.

O primeiro grupo engloba os departamentos eficientes na utilização dos recursos financeiros para produção em saúde no âmbito do SUS, em um contexto regional caracterizado pela presença do setor privado de saúde. O segundo grupo caracteriza-se pela condição de eficiência em um cenário em que o SUS é hegemônico no atendimento. Já entre os não-eficientes observaram-se duas situações: DRS com forte presença do setor privado, como Taubaté; e o caso de Registro, em que o SUS responde por praticamente todo o atendimento realizado.

No grupo dos DRS eficientes e com maior participação do SUS, identificaram-se menores gastos per capita e grau de complexidade em sua produção ambulatorial, em relação aos departamentos considerados eficientes e com menor participação do SUS. Esses resultados podem estar refletindo a forma de distribuição de recursos do SUS, já que parcela importante desses recursos é distribuída segundo procedimentos ambulatoriais e internações realizadas, o que acaba por refletir a capacidade instalada na região (UGÁ e PORTO, 2008).

Entre os departamentos eficientes, encontram-se tanto os que agregam municípios produtores de serviços de saúde de média e alta complexidades, quanto aqueles caracterizados pela produção ambulatorial em atenção básica, em especial programas 
específicos na área da atenção básica. Já, os DRS não-eficientes caracterizam-se por apresentar as duas situações.

Assim, os resultados obtidos pelo modelo DEA indicam que a eficiência na utilização dos recursos na produção dos serviços de saúde do SUS ocorre em áreas diferenciadas segundo as características do sistema de saúde, socioeconômicas e demográficas.

Metodologicamente, a heterogeneidade existente entre os DRS parece não ter influenciado os resultados, dado que Marinho (2003) afirma que a presença de heterocedasticidade nos dados pode levar a uma subestimativa dos valores de eficiência, ou seja, um DRS ser classificado como não-eficiente quando na verdade sua situação é muito diferente dos demais em relação às variáveis consideradas no modelo.

Os resultados obtidos constituem uma análise exploratória da eficiência na utilização dos recursos do SUS pelos municípios paulistas, usando como recorte territorial os 17 Departamentos Regionais de Saúde. Para tanto, empregou-se um ferramental matemático (Análise Envoltória de Dados - DEA), que, apesar de uso recente no Brasil, já apresenta uma série de trabalhos aplicados no campo da avaliação das políticas públicas.

Essa técnica matemática permite estabelecer, a partir dos dados observados, a relação de eficiência entre recursos e produção ambulatorial, bem como classificar as regionais de saúde a partir desta relação. Isso posto, os resultados aqui apresentados devem ser interpretados como indicativos, pois, como todo modelo matemático, este também é uma redução da realidade e, portanto, deve ser lido e interpretado como tal. 


\section{CONCLUSÃO}

1 o Estado de São Paulo, a heterogeneidade das condições econômicas, sociais e demográficas existentes nas diferentes regiões do Estado não se reflete na condição de procura e utilização dos serviços de saúde, mas sim no grau de dependência de suas populações ao Sistema Único de Saúde. Os resultados obtidos mostram um Estado de São Paulo menos desigual quanto ao acesso aos serviços de saúde, quando se consideram os resultados de estudos sobre utilização de serviços de saúde realizados a partir das bases de dados da PNAD para os anos 1998 e 2003. Já a ação do SUS mostra-se de acordo como a diretriz de equidade prevista na Lei Orgânica da Saúde.

O PSF é um fator que aumenta a probabilidade de utilização dos serviços de saúde, particularmente do SUS, pela população. Já em relação às operadoras de planos de saúde, a condição de posse do plano de saúde não é garantia para o atendimento, sendo necessário que a região tenha serviços e recursos humanos disponíveis, além de população com capacidade de pagamento.

Em síntese, mais do que os fatores associados ao acesso aos serviços de saúde tornam-se importantes investigações sobre os mecanismos de gestão do SUS, de tal forma a se compreender o que faz que DRS com indicadores similares em relação ao PSF apresentam taxas de utilização diferenciadas. Considerando-se na análise as condições econômicas, sociais e políticas em que ocorre a gestão do SUS regional. 
A eficiência na utilização dos recursos na produção dos serviços de saúde do SUS ocorre em áreas diferenciadas, segundo as características do sistema de saúde, socioeconômicas e demográficas. Entre os departamentos eficientes, encontram-se tanto aqueles que agregam municípios produtores de serviços de saúde de média e alta complexidades, quanto os DRS caracterizados pela produção ambulatorial em atenção básica, em especial programas específicos na área da atenção básica. Assim, a eficiência na produção de saúde é observada em diferentes contextos relacionados aos SUS, dado que ocorre tanto nos departamentos em que o setor privado é um simples coadjuvante quanto naqueles em que o setor privado é responsável por importante segmento do setor saúde.

Por fim, é importante destacar que os tipos de análises realizadas possuem os limites inerentes aos estudos quantitativos. Apesar disso, a pesquisa domiciliar por amostragem é um poderoso instrumento para levantamento de informações nas mais diversas áreas do conhecimento, bem como um importante meio para se testarem hipóteses aventadas em pesquisas qualitativas. Já os modelos matemáticos e estatísticos constituem valiosas ferramentas para desagregação de dados amostrais e combinação de diferentes fontes de informações. 


\section{ANEXOS}




\section{ANEXO 1 - Departamentos Regionais de Saúde}

Os Departamentos Regionais de Saúde - DRS foram criados em 28 de dezembro

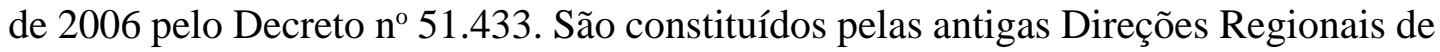
Saúde - DIR, que totalizavam 24 no Estado.

Os DRS’s estão alocados administrativamente na Coordenadoria de Regiões de Saúde da Secretaria da Saúde - SES. Sua finalidade é "I-contribuir para a qualidade de vida da população das respectivas regiões, coordenando, articulando e organizando e gerenciando o sistema de saúde locoregional; II-identificar a necessidade de compra de serviços de saúde; III - promover a articulação dos sistemas metropolitanos de saúde; IV-avaliar, acompanhar e estabelecer a cooperação técnica dos sistemas de saúde; V-tornar disponíveis e dar publicidade às informações de saúde e gerenciais que viabilizem o controle social do desempenho do sistema de saúde." (SÃO PAULO, Cap. II - Art. 40, 2006).

A relação dos municípios pertencentes aos 17 DRS’s estão apresentados no Quadro 1. 
Quadro 1 - Municípios pertencentes aos Departamentos Regionais de Saúde. Estado de São Paulo. 2009.

\begin{tabular}{|c|c|c|}
\hline DRS 01 - Grande São Paulo & DRS 02 - Araçatuba & DRS 03 - Araraquara \\
\hline Arujá & Alto Alegre & Américo Brasiliense \\
\hline Barueri & Andradina & Araraquara \\
\hline Biritiba Mirim & Araçatuba & Boa Esperança do Sul \\
\hline Caieiras & Auriflama & Borborema \\
\hline Cajamar & Avanhandava & Cândido Rodrigues \\
\hline Carapicuíba & Barbosa & Descalvado \\
\hline Cotia & Bento de Abreu & Dobrada \\
\hline Diadema & Bilac & Dourado \\
\hline Embu & Birigui & Gavião Peixoto \\
\hline Embu-Guaçu & Braúna & Ibaté \\
\hline Ferraz de Vasconcelos & Brejo Alegre & Ibitinga \\
\hline Francisco Morato & Buritama & Itápolis \\
\hline Franco da Rocha & Castilho & Matão \\
\hline Guararema & Clementina & Motuca \\
\hline Guarulhos & Coroado & Nova Europa \\
\hline Itapecerica da Serra & Gabriel Monteiro & Porto Ferreira \\
\hline Itapevi & Glicério & Ribeirão Bonito \\
\hline Itaquaquecetuba & Guaraçai & Rincão \\
\hline Jandira & Guararapes & Santa Ernestina \\
\hline Juquitiba & Guzolândia & Santa Lucia \\
\hline Mairiporã & Ilha Solteira & São Carlos \\
\hline Mauá & Itapura & Tabatinga \\
\hline Mogi das Cruzes & Lavínia & Taquaritinga \\
\hline Osasco & Lourdes & Trabiju \\
\hline Pirapora do Bom Jesus & \multirow{16}{*}{$\begin{array}{l}\text { Luiziânia } \\
\text { Mirandópolis } \\
\text { Murutinga do Sul } \\
\text { Nova Castilho } \\
\text { Nova Independência } \\
\text { Nova Lusitânia } \\
\text { Penápolis } \\
\text { Pereira Barreto } \\
\text { Piacatu } \\
\text { Rubiácea } \\
\text { Santo Antonio do Aracanguá } \\
\text { Santópolis do Aguapeí } \\
\text { Sud Mennucci } \\
\text { Suzanápolis } \\
\text { Turiúba } \\
\text { Valparaíso }\end{array}$} & \\
\hline Poá & & DRS 04 - Baixada \\
\hline Ribeirão Pires & & Santista \\
\hline Rio Grande da Serra & & \\
\hline Salesópolis & & Bertioga \\
\hline Santa Isabel & & Cubatão \\
\hline Santana de Parnaíba & & Guarujá \\
\hline Santo André & & Itanhaém \\
\hline São Bernardo do Campo & & Mongaguá \\
\hline São Caetano do Sul & & Peruíbe \\
\hline São Lourenço da Serra & & Praia Grande \\
\hline São Paulo & & Santos \\
\hline Suzano & & São Vicente \\
\hline Taboão da Serra & & \\
\hline \multirow[t]{2}{*}{ Vargem Grande Paulista } & & \\
\hline & & \\
\hline
\end{tabular}


Quadro 1 - Municípios pertencentes aos Departamentos Regionais de Saúde. Estado de São Paulo. 2009.

\begin{tabular}{|c|c|c|}
\hline DRS 05 - Barretos & DRS 06 - Bauru & DRS 06 - Bauru \\
\hline $\begin{array}{l}\text { Altair } \\
\text { Barretos } \\
\text { Bebedouro } \\
\text { Cajobi } \\
\text { Colina } \\
\text { Colômbia } \\
\text { Embaúba } \\
\text { Guaíra } \\
\text { Guaraci } \\
\text { Jaborandi } \\
\text { Monte Azul Paulista } \\
\text { Olímpia } \\
\text { Severínia } \\
\text { Taiaçu } \\
\text { Taiúva } \\
\text { Taquaral } \\
\text { Terra Roxa } \\
\text { Viradouro } \\
\text { Vista Alegre do Alto }\end{array}$ & $\begin{array}{l}\text { Águas de Santa Bárbara } \\
\text { Agudos } \\
\text { Anhembi } \\
\text { Arandu } \\
\text { Arealva } \\
\text { Areiópolis } \\
\text { Avaí } \\
\text { Avaré } \\
\text { Balbinos } \\
\text { Barão de Antonina } \\
\text { Bariri } \\
\text { Barra Bonita } \\
\text { Bauru } \\
\text { Bocaina } \\
\text { Bofete } \\
\text { Boracéia } \\
\text { Borebi } \\
\text { Botucatu } \\
\text { Brotas } \\
\text { Cabrália Paulista } \\
\text { Cafelândia } \\
\text { Cerqueira César } \\
\text { Conchas } \\
\text { Coronel Macedo } \\
\text { Dois Córregos } \\
\text { Duartina } \\
\text { Fartura } \\
\text { Getulina } \\
\text { Guaiçara } \\
\text { Iacanga } \\
\text { Iaras } \\
\text { Igaraçu do Tietê } \\
\text { Itaí } \\
\text { Itaju } \\
\text { Itaporanga } \\
\text { Itapuí } \\
\text { Laranjal Paulista } \\
\text { Lençóis Paulista } \\
\text { Iaua } \\
\text { Ana }\end{array}$ & $\begin{array}{l}\text { Lins } \\
\text { Lucianópolis } \\
\text { Macatuba } \\
\text { Manduri } \\
\text { Mineiros do Tietê } \\
\text { Paranapanema } \\
\text { Pardinho } \\
\text { Paulistânia } \\
\text { Pederneiras } \\
\text { Pereiras } \\
\text { Piraju } \\
\text { Pirajuí } \\
\text { Piratininga } \\
\text { Pongaí } \\
\text { Porangaba } \\
\text { Pratânia } \\
\text { Presidente Alves } \\
\text { Promissão } \\
\text { Reginópolis } \\
\text { Sabino } \\
\text { São Manuel } \\
\text { Sarutaiá } \\
\text { Taguaí } \\
\text { Taquarituba } \\
\text { Tejupá } \\
\text { Torre de Pedra } \\
\text { Torrinha } \\
\text { Uru }\end{array}$ \\
\hline
\end{tabular}


Quadro 1 - Municípios pertencentes aos Departamentos Regionais de Saúde. Estado de São Paulo. 2009.

\begin{tabular}{|c|c|c|}
\hline DRS 07 - Campinas & DRS 08 - Franca & DRS 09 - Marília \\
\hline Águas de Lindóia & Aramina & Garça \\
\hline Americana & Buritizal & Guaimbê \\
\hline Amparo & Cristais Paulista & Guarantã \\
\hline Artur Nogueira & Franca & Herculândia \\
\hline Atibaia & Guará & Iacri \\
\hline Bom Jesus dos Perdões & Igarapava & Ibirarema \\
\hline Bragança Paulista & Ipuã & Inúbia Paulista \\
\hline Cabreúva & Itirapuã & Ipaussu \\
\hline Campinas & Ituverava & Júlio Mesquita \\
\hline Campo Limpo Paulista & Jeriquara & Lucélia \\
\hline Cosmópolis & Miguelópolis & Lupércio \\
\hline Holambra & Morro Agudo & Lutécia \\
\hline Hortolândia & Nuporanga & Maracaí \\
\hline Indaiatuba & Orlândia & Mariápolis \\
\hline Itatiba & Patrocínio Paulista & Marília \\
\hline Itupeva & Pedregulho & Ocauçu \\
\hline Jaguariúna & Restinga & Óleo \\
\hline Jarinu & Ribeirão Corrente & Oriente \\
\hline Joanópolis & Rifaina & Oscar Bressane \\
\hline Jundiaí & Sales Oliveira & Osvaldo Cruz \\
\hline Lindóia & São Joaquim da Barra & Ourinhos \\
\hline Louveira & São José da Bela Vista & Pacaembu \\
\hline \multicolumn{3}{|l|}{ Monte Alegre do Sul } \\
\hline Monte Mor & DRS 09 - Marília & Paraguaçu Paulista \\
\hline \multicolumn{3}{|l|}{ Morungaba } \\
\hline Nazaré Paulista & Adamantina & Pedrinhas Paulista \\
\hline Nova Odessa & Álvaro de Carvalho & Platina \\
\hline Paulínia & Alvinlândia & Pompéia \\
\hline Pedra Bela & Arco-Íris & Pracinha \\
\hline Pedreira & Assis & Queiroz \\
\hline Pinhalzinho & Bastos & Quintana \\
\hline Piracaia & Bernardino de Campos & Ribeirão do Sul \\
\hline Santa Bárbara d’Oeste & Borá & Rinópolis \\
\hline Santo Antonio da Posse & Campos Novos Paulista & Sagres \\
\hline Serra Negra & Cândido Mota & Salmourão \\
\hline Socorro & Canitar & Salto Grande \\
\hline Sumaré & Chavantes & Santa Cruz do Rio Pardo \\
\hline Tuiuti & Cruzália & São Pedro do Turvo \\
\hline Valinhos & Echaporã & Tarumã \\
\hline Vargem & Espírito Santo do Turvo & Timburi \\
\hline Várzea Paulista & Fernão & Tupã \\
\hline \multirow[t]{3}{*}{ Vinhedo } & Flórida Paulista & Ubirajara \\
\hline & Florínia & Vera Cruz \\
\hline & Gália & \\
\hline
\end{tabular}


Quadro 1 - Municípios pertencentes aos Departamentos Regionais de Saúde. Estado de São Paulo. 2009.

\begin{tabular}{|c|c|c|}
\hline DRS 10 - Piracicaba & DRS 11 - Presidente Prudente & DRS 12 - Registro \\
\hline Águas de São Pedro & \multirow{41}{*}{ 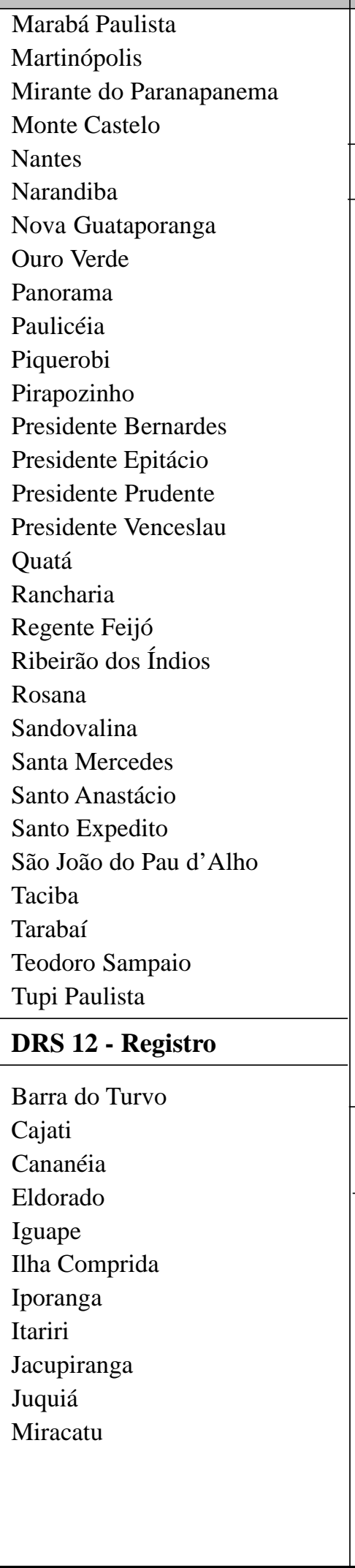 } & Pariquera-Açu \\
\hline Analândia & & Pedro de Toledo \\
\hline Araras & & Registro \\
\hline Capivari & & Sete Barras \\
\hline Charqueada & & DRS 13 - Ribeirão Preto \\
\hline Conchal & & \\
\hline Cordeirópolis & & Altinópolis \\
\hline Corumbataí & & Barrinha \\
\hline Elias Fausto & & Batatais \\
\hline Engenheiro Coelho & & Brodowski \\
\hline Ipeúna & & Cajuru \\
\hline Iracemápolis & & Cássia dos Coqueiros \\
\hline Itirapina & & Cravinhos \\
\hline Leme & & Dumont \\
\hline Limeira & & Guariba \\
\hline Mombuca & & Guatapará \\
\hline Piracicaba & & Jaboticabal \\
\hline Pirassununga & & Jardinópolis \\
\hline Rafard & & Luís Antônio \\
\hline Rio Claro & & Monte Alto \\
\hline Rio das Pedras & & Pitangueiras \\
\hline Saltinho & & Pontal \\
\hline Santa Cruz da Conceição & & Pradópolis \\
\hline Santa Gertrudes & & Ribeirão Preto \\
\hline Santa Maria da Serra & & Santa Cruz da Esperança \\
\hline São Pedro & & Santa Rita do Passa Quatro \\
\hline DRS 11 - Presidente Prudente & & santa Rosa do Viterbo \\
\hline \multirow{14}{*}{$\begin{array}{l}\text { Alfredo Marconc } \\
\text { Álvares Machado } \\
\text { Anhumas } \\
\text { Caiabu } \\
\text { Caiuá } \\
\text { Dracena } \\
\text { Emilianópolis } \\
\text { Estrela do Norte } \\
\text { Euclides da Cunl } \\
\text { Flora Rica } \\
\text { Iepê } \\
\text { Indiana } \\
\text { Irapuru } \\
\text { João Ramalho } \\
\text { Junqueirópolis }\end{array}$} & & São Simão \\
\hline & & Serra Azul \\
\hline & & Serrana \\
\hline & & \\
\hline & & DRS 14 - São João \\
\hline & & da Boa Vista \\
\hline & & \\
\hline & & Aguaí \\
\hline & & Águas da Prata \\
\hline & & Caconde \\
\hline & & Casa Branca \\
\hline & & Divinolândia \\
\hline & & Espírito Santo do Pinhal \\
\hline & & $\begin{array}{l}\text { Estiva Gerbi } \\
\text { Itapira } \\
\text { Itobi }\end{array}$ \\
\hline
\end{tabular}


Quadro 1 - Municípios pertencentes aos Departamentos Regionais de Saúde. Estado de São Paulo. 2009.

\begin{tabular}{|c|c|c|}
\hline $\begin{array}{c}\text { DRS } 14 \text { - São João da } \\
\text { Boa Vista } \\
\end{array}$ & $\begin{array}{c}\text { DRS } 15 \text { - São José } \\
\text { do Rio Preto }\end{array}$ & $\begin{array}{c}\text { DRS } 15 \text { - São José } \\
\text { do Rio Preto }\end{array}$ \\
\hline Мососа & Indiaporã & Pindorama \\
\hline Mogi-Guaçu & Ipiguá & Pirangi \\
\hline Moji Mirim & Irapuã & Planalto \\
\hline Santa Cruz das Palmeiras & Itajobi & Poloni \\
\hline Santo Antonio do Jardim & Jaci & Pontalinda \\
\hline São João da Boa Vista & Jales & Pontes Gestal \\
\hline São José do Rio Pardo & José Bonifácio & Populina \\
\hline São Sebastião da Grama & Macaubal & Potirendaba \\
\hline Tambaú & Macedônia & Riolândia \\
\hline Tapiratiba & Magda & Rubinéia \\
\hline Vargem Grande do Sul & Marapoama & Sales \\
\hline DRS 15 - São José do Rio Preto & Marinópolis & Santa Adélia \\
\hline Adolfo & Meridiano & Santa Clara d'Oeste \\
\hline Álvares Florence & Mesópolis & Santa Fé do Sul \\
\hline Américo de Campos & Mira Estrela & Santa Rita d'Oeste \\
\hline Aparecida d'Oeste & Mirassol & Santa Salete \\
\hline Ariranha & Mirassolândia & Santana da Ponte Pensa \\
\hline Aspásia & Monções & São Francisco \\
\hline Bady Bassitt & Monte Aprazível & São João das Duas Pontes \\
\hline Bálsamo & Neves Paulista & São João de Iracema \\
\hline Cardoso & Nhandeara & São José do Rio Preto \\
\hline Catanduva & Nipoã & Sebastianópolis do Sul \\
\hline Catiguá & Nova Aliança & Tabapuã \\
\hline Cedral & Nova Canaã Paulista & Tanabi \\
\hline Cosmorama & Nova Granada & Três Fronteiras \\
\hline Dirce Reis & Novais & Turmalina \\
\hline Dolcinópolis & Novo Horizonte & Ubarana \\
\hline Elisiário & Onda Verde & Uchôa \\
\hline Estrela d'Oeste & Orindiúva & União Paulista \\
\hline Fernando Prestes & Ouroeste & Urânia \\
\hline Fernandópolis & Palestina & Urupês \\
\hline Floreal & Palmares Paulista & Valentim Gentil \\
\hline Gastão Vidigal & Palmeira d'Oeste & Vitória Brasil \\
\hline General Salgado & Paraíso & Votuporanga \\
\hline Guapiaçu & Paranapuã & Zacarias \\
\hline Guarani d'Oeste & Parisi & \\
\hline Ibirá & Paulo de Faria & \\
\hline Icém & Pedranópolis & \\
\hline
\end{tabular}


Quadro 1 - Municípios pertencentes aos Departamentos Regionais de Saúde. Estado de São Paulo. 2009.

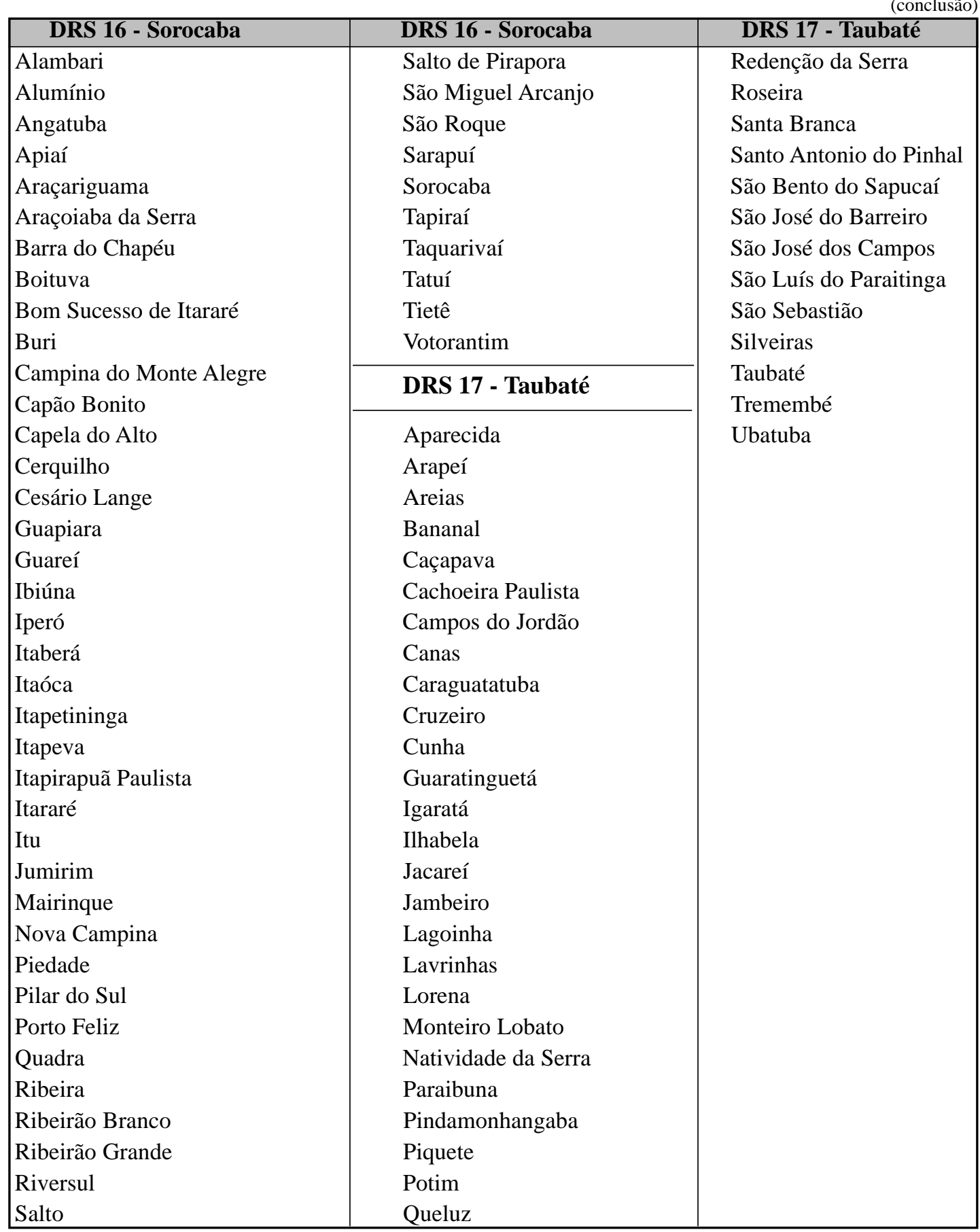

FONTE: Estado de São Paulo. Diário Oficial - Poder Executivo (Retificação do D.O. de 21/09/07); elaboração do autor. 


\section{ANEXO 2 - Distribuição da amostra de Pesquisa de Condições de Vida - PCV nos Departamentos Regionais de Saúde - DRS}

A Pesquisa de Condições de Vida - PCV 2006 foi realizada por meio de um levantamento domiciliar por amostragem no Estado de São Paulo, que abrangeu somente os domicílios localizados nas áreas urbanas do Estado, que concentram, em 2006, 93,7\% da população total (cerca de 40,5 milhões de pessoas). As exceções foram a Região Metropolitana de São Paulo e a Região Administrativa em que todos os domicílios foram alvo do levantamento.

Os domínios amostrais da pesquisa, definidos a partir de um estudo sobre a distribuição das regiões administrativas segundo o Índice Paulista de Vulnerabilidade Social - IPVS,1 são os seguintes: Região Metropolitana de São Paulo; Região Metropolitana da Baixada Santista; Região Administrativa de Campinas; Região Administrativa de Sorocaba; Região Administrativa de São José dos Campos; Região Administrativa de Registro; Aglomerado Central Norte (composto pelas regiões administrativas Central de Bauru, Ribeirão Preto e Franca) e Aglomerado Noroeste (composto pelas regiões administrativas de Barretos, São José do Rio Preto, Araçatuba, Marília e Presidente Prudente).

A amostra também foi planejada para contemplar a Região Metropolitana de Campinas, e desse modo é possível analisar as informações da pesquisa para as três regiões metropolitanas do Estado. 
Em cada domínio, selecionou-se uma amostra probablísitca de domicílios. Foram sorteados cerca de 5.200 domicílios para a Região Metropolitana de São Paulo, 3 mil domicílios em cada uma das Regiões Metropolitanas da Baixada Santista e Campinas, e para complementar a Região Administrativa de Campinas mais 800 domicílios. Já, para cada um dos demais domínios foram selecionados cerca de 1.600 domicílios, totalizando assim 20 mil domicílios no Estado.

O planejamento da amostra de cada domínio baseou-se na utilização de:

- amostragem por conglomerados em dois estágios, sendo a unidade de primeiro estágio o setor censitário do Censo Demográfico 2000 e a de segundo, o domicílio particular permanente;

- técnica de oversampling, com o objetivo de maximizar a participação de famílias de baixa renda na amostra. 
Tabela 1 - Número de conglomerados, domicílios e pessoas com 15 anos e mais na amostra da PCV, segundo os Departamentos Regionais de Saúde. Estado de São Paulo. 2006.

\begin{tabular}{|c|c|c|c|c|}
\hline \multirow[b]{2}{*}{$\begin{array}{l}\text { Departamento Regional } \\
\text { de Saúde - DRS }\end{array}$} & \multicolumn{4}{|c|}{ Tamanho da Amostra } \\
\hline & $\begin{array}{c}\text { Número de } \\
\text { conglomerados }\end{array}$ & $\begin{array}{l}\text { Número de } \\
\text { domicílios }\end{array}$ & $\begin{array}{l}\text { Número de } \\
\text { pessoas de } \\
15 \text { anos } \\
\text { e mais }\end{array}$ & $\begin{array}{c}\text { Número de } \\
\text { pessoas de } 15 \\
\text { anos e mais } \\
\text { utilizados } \\
\text { no estudo }\end{array}$ \\
\hline Total & 1474 & 19934 & 49361 & 41930 \\
\hline DRS 01 - Grande São Paulo & 434 & 5177 & 12728 & 11225 \\
\hline DRS 02 - Araçatuba & 19 & 342 & 788 & 628 \\
\hline DRS 03 - Araraquara & 20 & 356 & 877 & 848 \\
\hline DRS 04 - Baixada Santista & 276 & 3005 & 7368 & 6555 \\
\hline DRS 05 - Barretos & 9 & 162 & 386 & 137 \\
\hline DRS 06 - Bauru & 42 & 755 & 1885 & 1481 \\
\hline DRS 07 - Campinas & 286 & 3184 & 8004 & 6874 \\
\hline DRS 08 - Franca & 16 & 286 & 640 & 616 \\
\hline DRS 09 - Marília & 21 & 378 & 938 & 719 \\
\hline DRS 10 - Piracicaba & 23 & 406 & 1003 & 876 \\
\hline DRS 11 - Presidente Prudente & 10 & 179 & 434 & 258 \\
\hline DRS 12 - Registro & 90 & 1615 & 3907 & 3255 \\
\hline DRS 13 - Ribeirão Preto & 29 & 515 & 1221 & 1102 \\
\hline DRS 14 - São João da Boa Vista & 11 & 198 & 515 & 437 \\
\hline DRS 15 - São José do Rio Preto & 30 & 538 & 1304 & 1033 \\
\hline DRS 16 - Sorocaba & 70 & 1261 & 3241 & 2672 \\
\hline DRS 17 - Taubaté & 88 & 1577 & 4122 & 3214 \\
\hline
\end{tabular}

FONTE: Fundação Seade. Pesquisa de Condições de Vida- PCV; elaboração do autor. 
Tabela 2 - Distribuição porcentual dos indivíduos por condição de informação da renda familiar per capita, segundo os Departamentos Regionais de Saúde. Estado de São Paulo. 2006.

\begin{tabular}{l|cccc}
\hline \multirow{2}{*}{$\begin{array}{l}\text { Departamento Regional } \\
\text { de Saúde - DRS }\end{array}$} & \multicolumn{3}{c}{ Condição de informação da renda familiar per capita } \\
\cline { 2 - 4 } Total & Sem informação & Com informação & Total \\
DRS 01 - Grande São Paulo & 10,4 & $\mathbf{8 6 , 1}$ & $\mathbf{1 0 0 , 0}$ \\
DRS 02 - Araçatuba & 18,1 & 89,6 & 100,0 \\
DRS 03 - Araraquara & 2,9 & 81,9 & 100,0 \\
DRS 04 - Baixada Santista & 10,2 & 97,1 & 100,0 \\
DRS 05 - Barretos & 61,9 & 89,8 & 100,0 \\
DRS 06 - Bauru & 20,7 & 38,1 & 100,0 \\
DRS 07 - Campinas & 13,3 & 79,3 & 100,0 \\
DRS 08 - Franca & 3,0 & 86,7 & 100,0 \\
DRS 09 - Marília & 22,8 & 97,0 & 100,0 \\
DRS 10 - Piracicaba & 11,8 & 77,2 & 100,0 \\
DRS 11 - Presidente Prudente & 40,3 & 88,2 & 100,0 \\
DRS 12 - Registro & 15,0 & 59,7 & 100,0 \\
DRS 13 - Ribeirão Preto & 7,5 & 85,0 & 100,0 \\
DRS 14 - São João da Boa Vista & 15,0 & 92,5 & 100,0 \\
DRS 15 - São José do Rio Preto & 18,9 & 85,0 & 100,0 \\
DRS 16 - Sorocaba & 16,5 & 81,1 & 100,0 \\
DRS 17 - Taubaté & 20,5 & 83,5 & 100,0 \\
\hline FONTE: Fuç, & 79,5 & 100,0 \\
\hline
\end{tabular}

FONTE: Fundação Seade. Pesquisa de Condições de Vida- PCV; elaboração do autor. 
Tabela 3 - Distribuição da população urbana de 15 anos e mais, por Departamento Regional de Saúde - DRS, segundo amostra da PCV e valor projetado. Estado de São Paulo. 2006.

\begin{tabular}{|c|c|c|}
\hline \multirow{2}{*}{$\begin{array}{l}\text { Departamento Regional } \\
\text { de Saúde - DRS }\end{array}$} & \multicolumn{2}{|c|}{ População de 15 anos e mais } \\
\hline & Estimativa PCV & População projetada ${ }^{(1)}$ \\
\hline Total & 29493556 & 29178462 \\
\hline DRS 01 - Grande São Paulo & 14396867 & 14438924 \\
\hline DRS 02 - Araçatuba & 516471 & 500850 \\
\hline DRS 03 - Araraquara & 628766 & 648481 \\
\hline DRS 04 - Baixada Santista & 1259648 & 1226339 \\
\hline DRS 05 - Barretos & 282970 & 290477 \\
\hline DRS 06 - Bauru & 1144186 & 1122532 \\
\hline DRS 07 - Campinas & 2612324 & 2744381 \\
\hline DRS 08 - Franca & 401322 & 456091 \\
\hline DRS 09 - Marília & 638038 & 738788 \\
\hline DRS 10 - Piracicaba & 983623 & 989997 \\
\hline DRS 11 - Presidente Prudente & 393904 & 472793 \\
\hline DRS 12 - Registro & 169993 & 201692 \\
\hline DRS 13 - Ribeirão Preto & 932754 & 916921 \\
\hline DRS 14 - São João da Boa Vista & 863134 & 528048 \\
\hline DRS 15 - São José do Rio Preto & 1245864 & 1014737 \\
\hline DRS 16 - Sorocaba & 1450063 & 1350331 \\
\hline DRS 17 - Taubaté & 1573629 & 1537082 \\
\hline
\end{tabular}

FONTE: Fundação Seade. Pesquisa de Condições de Vida- PCV; elaboração do autor.

(1) Projeção populacional para julho de 2006, corrigidas pela taxa de urbanização obtida por meio do Censo Demográfico 2000. Para os DRS’s da Grande São Paulo e Registro foram utilizadas as projeções para o total da população de 15 anos e mais. 


\section{ANEXO 3 - Glossário de Variáveis}

\subsection{Variáveis derivadas da Pesquisa de Condições de Vida \\ - Conglomerado}

Setor censitário ou parte dele utilizado como referência para sorteio do primeiro estágio da amostra da PCV, segundo o plano amostral desta pesquisa.

\section{- Domicílio}

É o local de moradia, constituído por um ou mais cômodos, com entrada independente e separação. Entende-se por entrada independente o acesso direto à moradia, sem passagem por cômodos destinados à moradia de outras pessoas, e, por separação, o local de moradia que é limitado por paredes, muro, cerca, etc., além de ser coberto por um teto, o que permite às famílias ou às pessoas que o habitam isolarem-se das demais.

\section{- Família}

Conjunto de pessoas residentes em um domicílio ligadas por laços de parentesco (consangüinidade, adoção ou afinidade), assim como a pessoa que vive só. Os pensionistas, empregados domésticos e parentes do empregado doméstico moradores do domicílio não são incluídos como membros da família.A identificação de uma ou mais famílias em um domicílio é obtida a partir da ordenação das relações nucleares (casal), relações primárias (pai, mãe, filho, irmão) e relações secundárias (tio, sobrinho, primo, etc.). 


\section{- Morador}

Todos os indivíduos que residem de forma permanente ou habitual no domicílio pesquisado. Incluem-se, portanto, os moradores habituais que se encontram temporariamente ausentes do domicílio, por um período máximo de seis meses, por motivos de viagem a negócio ou passeio, estudo, tratamento de saúde e detenção sem sentença definitiva.

\section{- Período de Referência}

Para a PCV o período dos últimos 30 dias refere-se aos 30 dias imediatamente anteriores ao dia da entrevista.

\section{- Renda Familiar Total}

Soma dos rendimentos auferidos pelos membros de dez anos ou mais da família no mês anterior ao da pesquisa, provenientes das seguintes fontes: rendimento bruto do trabalho principal; renda do trabalho adicional; renda de aposentadoria, pensões e auxílio previdenciário; outras rendas; renda de aluguéis de imóvel ou terreno urbano, propriedade rural, veículo automotivo de uso comercial, máquinas agrícolas e/ou equipamento comercial e a renda proveniente de programas governamentais e não-governamentais de transferência de renda recebida por algum membro da família. Corresponde à renda familiar total acrescida da renda de programas governamentais e não-governamentais de transferência de renda. Este indicador foi calculado utilizando a correção do ICV e do INPC, e também está apresentado em valor nominal e por classe de salário mínimo. O valor do salário mínimo vigente no período da pesquisa (junho a novembro/2006) era de $\mathrm{R} \$ 350,00$. 


\section{- Renda Familiar per Capita}

Quociente entre a renda familiar total ampliada e o número de membros da família. Este indicador foi calculado utilizando a correção do INPC/IBG e está apresentado por classe de salário mínimo. O valor do salário mínimo vigente noperíodo da pesquisa (junho a novembro/2006) era de R\$ 350,00.

\subsubsection{Indicadores relacionados ao acesso aos serviços de saúde \\ - Condição de Atendimento no Dia da Procura}

Expressa o resultado da procura de atendimento, indicando a proporção de indivíduos que, nos 30 dias anteriores ao da entrevista, foram atendidos no mesmo dia em que se deslocaram até um estabelecimento de saúde. Este indicador não considera a procura por atendimento odontológico.

\section{- Condição de Posse de Convênio ou Plano de Saúde}

Indica a disponibilidade de recursos próprios para assistência médica ou odontológica. Considera todo e qualquer convênio ou plano de saúde (médico ou odontológico) por pagamento antecipado, independentemente da personalidade jurídica do prestador de serviços, compreendendo, portanto, empresas de medicina de grupo, cooperativas médicas, instituições de seguro-saúde e planos de autogestão.

• Condição de Procura por Atendimento de Saúde nos Últimos 30 Dias

Expressa pelo deslocamento do indivíduo, nos 30 dias anteriores ao da entrevista, até um estabelecimento de saúde - prédios ou edificações dotadas de equipamentos e 
de pessoal especializado na prestação de serviços de assistência de saúde. No presente estudo não foi considerado a procura por atendimento odontológico.

\section{- Marcou Consulta Previamente - Existência de Agendamento}

Para os indivíduos que foram atendidos no mesmo dia da procura, indica se o atendimento recebido tinha sido marcado com antecedência ou não. Esta categoria não considera a consulta para atendimento odontológico nem os indivíduos que necessitaram de internação que foram atendidos no mesmo dia da procura.

\section{- Tipo de Serviço Utilizado}

Definido a partir da condição de pagamento do serviço de saúde utilizado nos últimos 30 dias anteriores ao da entrevista: pago (medicina privada): consulta, exame, internação ou outro serviço pago integralmente pelo usuário no ato do atendimento; pré-pago (medicina de grupo): consulta, exame, internação ou outro serviço pago pelo convênio médico do qual o usuário é titular ou dependente; gratuito (seguridade social): consulta, exame, internação ou outro serviço pago por instituições governamentais de seguridade social. Este indicador não considera o atendimento odontológico.

\section{2 Índice Paulista de Vulnerabilidade Social - IPVS}

O IPVS consiste em uma tipologia derivada da combinação entre as dimensões socioeconômica e demográfica, gerada a partir dos dados do Censo Demográfico 2000. O primeiro aspecto - socioeconômico - relaciona-se à renda e ao nível de escolaridade do responsável pela família e reflete, além da renda apropriada, o poder de seus membros em gerá-la. A dimensão demográfica expressa o ciclo de vida familiar. A combinação 
desses itens permite classificar o setor censitário em uma das seis categorias que expressam o grau de vulnerabilidade à pobreza da sua população. As principais características dos seis grupos do IPVS podem ser resumidas como:

- Grupo 1 - nenhuma vulnerabilidade: engloba os setores censitários não vulneráveis, isto é, que exibem os maiores níveis de renda e escolaridade entre os responsáveis pelo domicílio e famílias mais velhas, considerando-se seu ciclo de vida.

- Grupo 2 - vulnerabilidade muito baixa: engloba os setores censitários com vulnerabilidade à pobreza muito baixa, sendo o segundo em termos de renda e escolaridade do chefe e, em média, com as famílias mais velhas.

- Grupo 3-vulnerabilidade baixa: incorpora os setores censitários que apresentam baixa vulnerabilidade à pobreza, posicionando-se em terceiro lugar em condições socioeconômicas e com famílias mais jovens ou em nível intermediário em termos do seu ciclo de vida.

- Grupo 4-vulnerabilidade média: um dos três grupos com maior vulnerabilidade à pobreza, apresentando-a em um nível médio, com famílias mais jovens em termos do seu ciclo de vida.

- Grupo 5 - vulnerabilidade alta: o segundo pior grupo tendo-se em conta as condições socioeconômicas, apresentando famílias mais velhas.

- Grupo 6 - vulnerabilidade muito alta: o grupo que apresenta a maior vulnerabilidade à pobreza, com responsáveis por domicílios jovens, com baixa renda e pouca escolaridade. 


\section{3 Índice Paulista de Responsabilidade Social - IPRS}

Os indicadores do IPRS sintetizam a situação de cada município no que diz respeito à riqueza, escolaridade e longevidade, e quando combinados geram uma tipologia que classifica os 645 municípios do Estado de São Paulo em cinco grupos, cada um com características específicas de riqueza municipal, longevidade e escolaridade. Essa tipologia permite a identificação da situação de cada um dos municípios paulistas nas três dimensões consideradas.

O IPRS é formado por quatro indicadores: três setoriais, que expressam as três dimensões do indicador; e uma tipologia de municípios. Os indicadores sintéticos de riqueza, longevidade e escolaridade são expressos em uma escala de 0 a 100, na qual o valor 100 representa a melhor situação e zero, a pior. Os componentes dos indicadores sintéticos setoriais estão apresentados no Quadro 1.

Os grupos de municípios consistem no cruzamento dos três indicadores sintéticos setoriais em cinco grupos, cada um agregando municípios com características similares em termos de riqueza, longevidade e escolaridade (Quadro 2). 
Quadro 1 - Componentes dos Indicadores Sintéticos Setoriais e seus respectivos pesos

\begin{tabular}{|c|c|c|}
\hline Indicador & Componentes & Pesos (\%) \\
\hline Riqueza & $\begin{array}{l}\text { Consumo residencial de energia elétrica por ligação } \\
\text { Consumo de energia elétrica na agricultura, no comércio e } \\
\text { nos serviços por ligação } \\
\text { Remuneração média dos empregados com carteira assinada e } \\
\text { do setor público } \\
\text { Valor adicionado fiscal per capita }\end{array}$ & $\begin{array}{l}23,0 \\
19,0 \\
14,0\end{array}$ \\
\hline Longevidade & $\begin{array}{l}\text { Taxa de Mortalidade perinatal } \\
\text { Taxa de Mortalidade infantil } \\
\text { Taxa de Mortalidade de adultos de } 15 \text { a } 39 \text { anos } \\
\text { Taxa de Mortalidade de adultos de } 60 \text { anos e mais }\end{array}$ & $\begin{array}{l}30,0 \\
30,0 \\
20,0 \\
20,0\end{array}$ \\
\hline Escolaridade & $\begin{array}{l}\text { Porcentagem de jovens de } 15 \text { a } 17 \text { anos que concluíram } \\
\text { o ensino fundamental } \\
\text { Porcentagem de jovens de } 15 \text { a } 17 \text { anos com pelo menos quatro } \\
\text { anos de escolaridade } \\
\text { Porcentagem de jovens de } 18 \text { a } 19 \text { anos que concluíram } \\
\text { o ensino médio } \\
\text { Porcentagem de crianças de } 5 \text { a } 6 \text { anos que freqüentam a pré-escola }\end{array}$ & $\begin{array}{l}36,0 \\
8,0 \\
36,0 \\
20,0\end{array}$ \\
\hline
\end{tabular}

FONTE: Transcrito de Fundação Seade. Índice Paulista de Responsabilidade Social - IPRS. (www.seade.gov.br).

Quadro 2 - Critérios de Formação dos Grupos do IPRS

\begin{tabular}{|l|l|}
\hline Grupos do IPRS & \multicolumn{1}{|c|}{ Critérios de Formação dos Grupos do IPRS } \\
\hline Grupo 1 & $\begin{array}{l}\text { Alta riqueza, média longevidade e média escolaridade } \\
\text { Alta riqueza, média longevidade e alta escolaridade } \\
\text { Alta riqueza, alta longevidade e média escolaridade } \\
\text { Alta riqueza, alta longevidade e alta escolaridade }\end{array}$ \\
\hline Grupo 2 & $\begin{array}{l}\text { Alta riqueza, baixa longevidade e baixa escolaridade } \\
\text { Alta riqueza, baixa longevidade e média escolaridade } \\
\text { Alta riqueza, baixa longevidade e alta escolaridade } \\
\text { Alta riqueza, média longevidade e baixa escolaridade } \\
\text { Alta riqueza, alta longevidade e baixa escolaridade }\end{array}$ \\
\hline Grupo 3 & $\begin{array}{l}\text { Baixa riqueza, média longevidade e média escolaridade } \\
\text { Baixa riqueza, média longevidade e alta escolaridade } \\
\text { Baixa riqueza, alta longevidade e média escolaridade } \\
\text { Baixa riqueza, alta longevidade e alta escolaridade }\end{array}$ \\
\hline Grupo 4 & $\begin{array}{l}\text { Baixa riqueza, baixa longevidade e média escolaridade } \\
\text { Baixa riqueza, baixa longevidade e alta escolaridade } \\
\text { Baixa riqueza, média longevidade e baixa escolaridade } \\
\text { Baixa riqueza, alta longevidade e baixa escolaridade }\end{array}$ \\
& Baixa riqueza, baixa longevidade e baixa escolaridade \\
\hline
\end{tabular}

FONTE: Adaptado de Fundação Seade. Índice Paulista de Responsabilidade Social - IPRS. (www.seade.gov.br). 


\section{ANEXO 4 - Medidas de ajuste dos modelos de regressão logística em efeitos aleatórios}

A comparação entre o porcentual de pessoas de 15 anos que utilizaram serviços de saúde obtido a partir dos dados da PCV mostra uma grande associação com o valor da mediana da probabilidade predita de se utilizar serviços de saúde, dado as características consideradas no modelo (Gráfico 1).

Gráfico 1- Gráfico de dispersão entre o porcentual de pessoas que utilizaram serviços de saúde e a probabilidade marginal mediana de utilizar serviços de saúde dado o modelo de regressão logística com efeitos aleatórios. Estado de São Paulo. 2006.

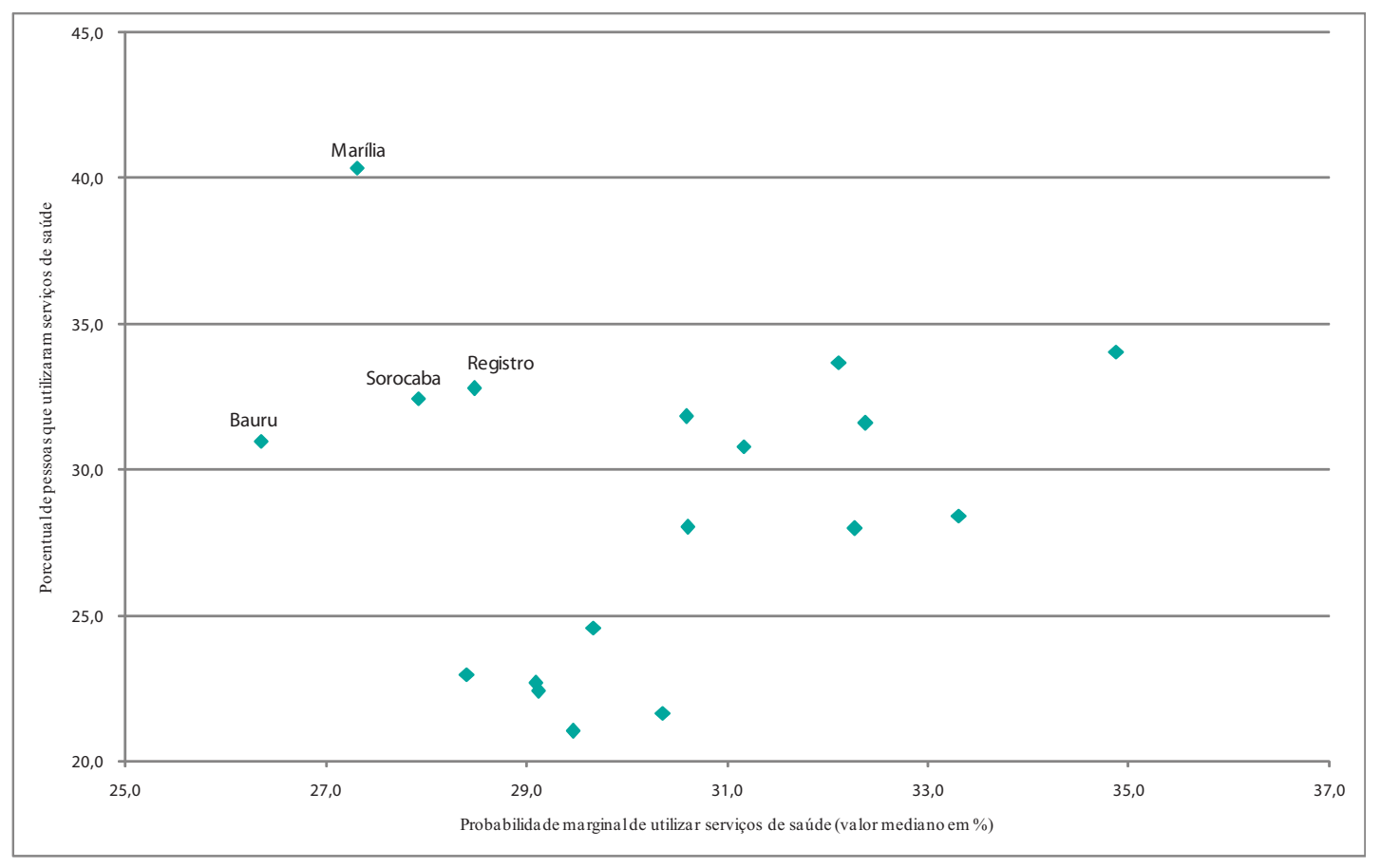

FONTE: Fundação Seade. Pesquisa de Condições de Vida - PCV. Datasus. CRM/SP; elaboração do autor 
O Gráfico 2 apresenta a comparação entre o porcentual de pessoas que utilizaram o SUS e a probabilidade mediana predita de se utilizar o SUS, dado o modelo de regressão logística com efeitos aleatórios.

Gráfico 2 - Gráfico de dispersão entre o porcentual de pessoas que utilizaram o SUS e a probabilidade marginal mediana de utilizar SUS, dado o modelo de regressão logística com efeitos aleatórios. Estado de São Paulo. 2006.

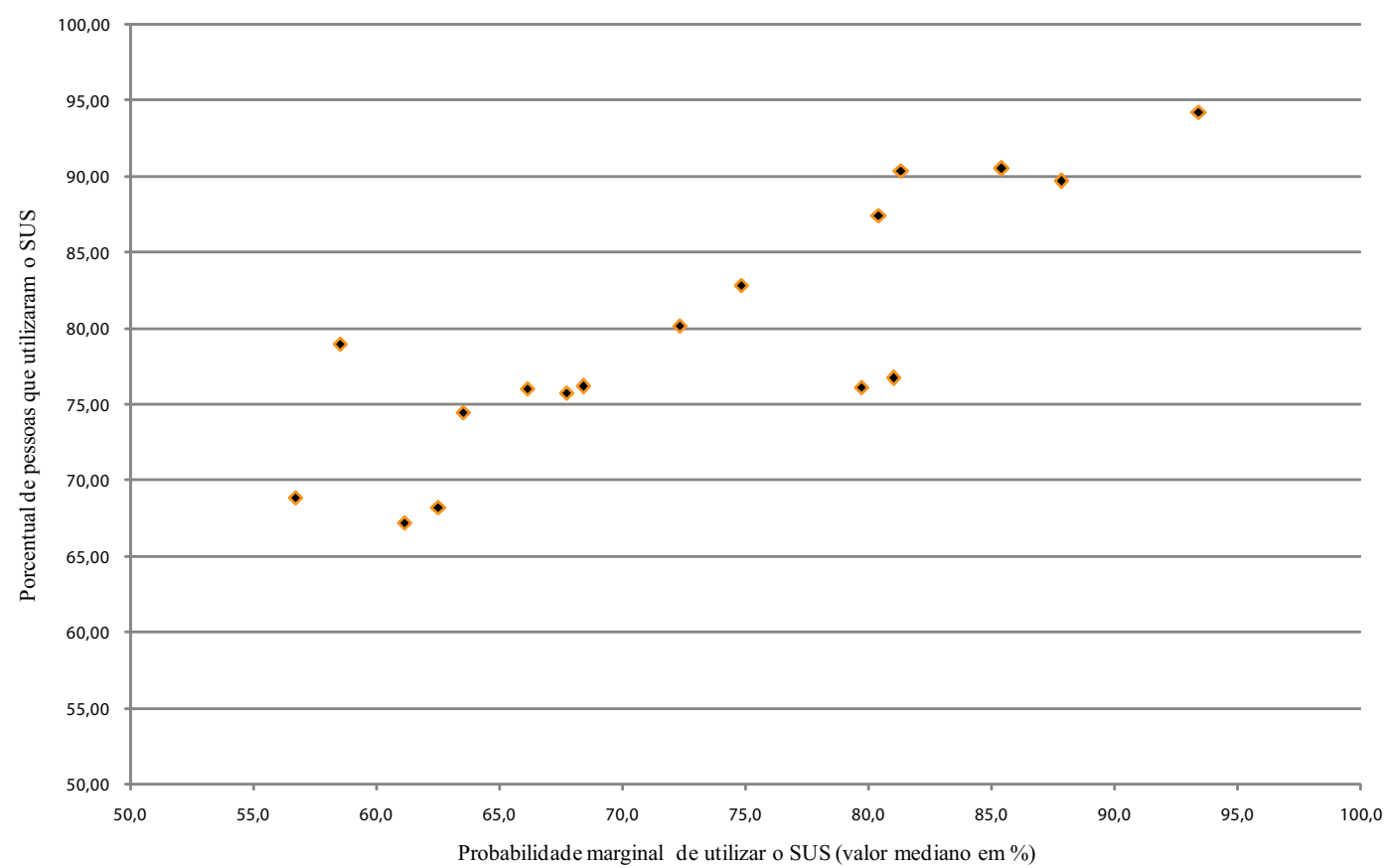

FONTE: Fundação Seade. Pesquisa de Condições de Vida - PCV. Datasus. CRM/SP; elaboração do autor 


\section{REFERÊNCIAS}

Aday LA, Andersen R. A framework for the study of access to medical care. Health Serv Res. 1974; 9:208-220.

Ala-Harja M, Helgason S. Em direção às melhores práticas de avaliação. Revista do Serviço Público. 2000; 51(4):5-60.

Andersen R, Newman JF. Societal and individual determinants of medical care in the United States. Milbank Quartely. 1973; 51:95-124.

Andersen RM. Revisiting the behavioral model and Access to medical care: does it matter? $J$ Health and Soc Behav. 1995; 36:1-10.

Baker J. Evaluating the impact of development projects on poverty: a handbook for practitioners. Word Bank; 2000.

Banco Interamericano de Desenvolvimento - BID. Evaluacion ex-post de lãs operaciones. 2009. Disponível em: http://www.iadb.otg/aboutus/pi/OP_305.cfm? language=Spanish/. [jul. 2009].

Banco Mundial. Business Center - Project Cycle. 2006; Washington. Disponível em: http:// web.worldbank.org/wbsite/external/opportunities/. [jun. 2009].

Banker R, Charnes A, Cooper WW. Some models for estimating technical and scale inefficiencies in data envelopment analysis. Management Science. 1984; 30: 1078-1092.

Bardhan IR, Cooper WW, Kumbhakar SC. A simulation study of joint uses of data envelopment analysis and statistical regressions for production function estimation and efficiency evaluation. Journal of Productivity Analysis. 1998; 9: 249-278.

Brasil. Conselho Nacional de Saúde. 12o Conferência Nacional de Saúde - Conferência Sergio Arouca: manual. Brasília: Ministério da Saúde; 2003. 
Brasil. RIPSA: Fontes de informações: sistemas de informação do Ministério da Saúde. Brasília: 2005. Disponível em: http://tabnet.datasus.gov.br/cgi/idb2005/fontes.pdf.

Brasil. Ministério da Saúde. Pacto pela Saúde. Brasília: 2006.

Cardoso AM, Santos RV, Coimbra CEAJ. Mortalidade infantil segundo raça/cor no Brasil: o que dizem os sistemas nacionais de informação? Cad. Saúde Pública. 2005; 21(5): 16021608.

Carvalheiro JR. Investigação epidemiológica e entrevistas domiciliares. Rev. Saúde Pública. 1981; 15(5): 543-550.

Carvalho JAM, Rodríguez-Wong LL. A transição da estrutura etária da população brasileira na primeira metade do século XXI. Cad. Saúde Pública. 2008; 24(3): 597-605.

Cesar CLG. Morbidade referida e utilização de serviços de saúde na Grande São Paulo. O perfil da desigualdade em saúde [tese de livre-docência]. São Paulo: Faculdade de Saúde Pública, Universidade de São Paulo; 1997.

Cesar CLG, Tanaka OY. Inquérito domiciliar como instrumento de avaliação de serviços de saúde: um estudo de caso na região sudoeste da área metropolitana de São Paulo, 1989-1990. Cad. Saúde Pública. 1996; 12(Supl 2): 59-70.

Donabedian A. Aspects of medical care administration: Specifying requirements for health care. Cambridge (Mass.): Harvard University Press, 1973.

Donabedian A. The seven pillars of quality assessment and assurrance. Arch Pathol Lab Med. 1990; 114: 1115-1118.

Donabedian A, Wheeler JRC, Wyszewianski L. Quality, cost, and health: an integrative model. In: White K L, et al., editores. Health services research: an anthology. Washington: Pan American Health Organization; 1992. p. 735-752.

Draibe, S.M. A política social na América Latina: o que ensinam as experiências recentes de reforma. In: Diniz E, Azevedo S, organizadores. Reforma do Estado e democracia no Brasil. Brasília: UNB/Enap; 1997.

Faria FP, Jannuzzi PM, Silva SJ. Eficiência dos gastos municipais em saúde e educação: uma investigação através da análise envoltória no estado do Rio de Janeiro. RAP. 2008; 42(1): 155-177. 
Felisberto E. Monitoramento e avaliação na atenção básica: novos horizontes. Rev. Bras. Saúde Matern. Infant. 2004; 4(3): 317-321.

Ferlie E, Asburner L; Fitzgerald L; Pettigrew A. A nova administração pública em ação. Brasília: UNB/Enap, 1999.

Ferreira MP, Dini NP, Ferreira SP. Espaços e dimensões da pobreza nos municípios do Estado de São Paulo: índice paulista de vulnerabilidade social - IPVS. São Paulo Perspec. 2006; 20(1): 5-17.

Frenk J. The concept and measurement of accessibility. In: White, K L, et al., editores. Health services research: an anthology. Washington: Pan American Health Organization; 1992. p. 842-855.

Fundação Seade. São Paulo soma em 200540 milhões de habitantes. SP demográfico. São Paulo: 2005; 6(1). Disponível em: http://www.seade.gov.br/produtos/spdemog/ index.php?tip=ma05.

Fundação Seade. Pesquisa de Condições de Vida - PCV2006. São Paulo: 2007. Disponível em: http://www.seade.gov.br/produtos/pcv/.

Furtado JP. Avaliação de programas e serviços. In: Campos GWS, et al., editores. Tratado de Saúde Coletiva. São Paulo: Hucitec; 2006. p. 715-739.

Godard M, Smith P. Equity of access to health care services: theory and evidence from the UK. Social Science \& Medicine. 2001; 53: 1149-1162.

Gonçaves AC, Noronha CP, Lins MPE, Almeida, RMVR. Data envelopment analysis for evaluating public hospitals in Brazilian state capitals. Rev. Saúde Pública. 2007; 41(3).

Hartz ZMA, organizador. Avaliação em saúde: dos modelos conceituais à prática a análise da implantação de programas. Rio de Janeiro: Fiocruz; 1997.

Hartz ZMA. Institucionalizar e qualificar a avaliação: outros desafios para a atenção básica. Ciênc. saúde coletiva. 2002; 7: 419-421.

Heimann LS, Castro IEN, Junqueira V, Ibanhez LC, Luiz OC, Kayano J, et al. Gestão Regional do SUS - São Paulo: rumo ao Pacto de Gestão. São Paulo: Instituto de Saúde; 2007. [Temas em Saúde Coletiva, 5]. 
House ER. Assumptions underlying evaluations models. In: Madaus GF, Scriven M, Stufflebeam DL, editores. Evaluation models: viewpoints on educational and human services evaluation. Boston: Kluwer-Nijhoff; 1983.

Hurst J, Hughes MJ. Perfomance measurement and performance management in OCDE health systems. OECD Health Systems, Labour Market and Social Policy. Occasional Papers. 2001; 47:1-60. Disponível em: http:// www. oecd.org.

Kalton G. Introduction to survey sampling. Newbury Park: Sage Publications; 1983. [Quantitative Applications in the Social Science, 35].

Katzman R. Vulnerabilidad, actives y exclusion social en Argentina y Uruguay. Santiago do Chile: OIT/FORD; 1999.

Kish L. Survey sampling. New York: John Wiley \& Sons; 1965.

Lebrão ML, Carandini L, Magalfi C. Análise das condições de saúde e de vida da população urbana de Botucatu, São Paulo (Brasil). IV - Morbidade referida em entrevistas domiciliares, 1993-1984. Rev. Saúde Pública. 1991; 25(6): 452-460.

Lebrão ML, Duarte YAO, Santos JLF, Laurenti R. Evolução das condições de vida e saúde da população idosa no município de São Paulo. São Paulo Perspec. 2008; 22(2): 30-45.

Marinho A. Avaliação da eficiência técnica nos serviços de saúde nos municípios do Estado do Rio de Janeiro. Rev. Bras. Econ. 2003; 57(2): 515-534.

Marinho A, Cardoso SS, Almeida VV. Brasil e OCDE: avaliação da eficiência em sistemas de saúde. Rio de Janeiro: Ipea; 2009. [Texto para Discussão, 1370].

McCullagh P, Nelder JA. Generalized Linear Models. 2nd ed. London: Chapman \& Hall; 1989.

Neri M, Soares W. Desigualdade social e saúde no Brasil. Cad. Saúde Pública. 2002;

18(Supl): 77-87.

Noronha KVMS, Andrade MV. Desigualdades sociais em saúde: evidências empíricas sobre o caso brasileiro. Revista Econômica do Nordeste. 2001; 32(Especial): 877-897.

Novaes HMD. Avaliação de programas, serviços e tecnologias em saúde. Rev. Saúde Pública. 2000; 34(5): 547-559. 
Oliveira EXG, Travassos C, Carvalho MS. Acesso à internação hospitalar nos municípios brasileiros em 2000: territórios do Sistema Único de Saúde. Cad. Saúde Pública. 2004; 20(Supl 2): S298-S309.

Rabe-Hesketh S, Skrondal A. Multilevel and longitudinal modeling using Stata. 2nd ed. College Station, Texas: Stata Press Publication; 2008.

Ribeiro MCSA, et al. Perfil socioeconômico e padrão de utilização de serviços de saúde para usuários e não usuários do SUS - PNAD 2003. Ciênc. saúde coletiva. 2006; 11(4):10111022.

Rossi PH, Lipsey MW, Freeman HE. Evaluation: a systematic approach. 7th ed. Thousand Oaks, California: Sage Publications Inc; 2004.

Shiell A, Donaldson C, Mitton C, Currie G. Health economic evaluation. J Epidemiol Community Health. 2002; 56(2):85-88. Disponível em: http://www.pubmedcentral.nih.gov/ picrender.fcgi?artid=1732075\&blobtype=pdf.

StataCorp. Stata statistical software: release 10.0 [programa de computador]. College Station, TX: Stata Corp. 2007.

Thiede M. Information and access to health care: is there a role for trust? Social Science \& Medicine. 2005; 61: 1452-1462.

Thiede M, McIntyre D. Information, communication and equitable access to health care: a conceptual note. Cad. Saúde Pública. 2008; 24(5): 1168-1173.

Thoenig JC. A avaliação como conhecimento utilizável para reformas de gestão pública. Revista do Serviço Público. 2000; 51(2): 54-71.

Travassos C, Martins M. Uma revisão sobre os conceitos de acesso e utilização de serviços de saúde. Cad. Saúde Pública. 2004; 20(Supl 2): S190-S198.

Travassos C, Oliveira EXG, Viacava F. Desigualdades geográficas e sociais no acesso aos serviços de saúde no Brasil: 1998 e 2003. Ciênc. saúde coletiva. 2006; 11(4):975-986.

Travassos C, Castro MSM. Determinantes e desigualdades sociais no acesso e na utilização de serviços de saúde. In: Giovanella L, et al., editores. Políticas e sistemas de saúde no Brasil. Rio de Janeiro: Fiocruz; 2008. p. 215-243. 
Ugá MAD, Porto SM. Financiamento e alocação de recursos em saúde no Brasil. In: Giovanella L, et al., editores. Políticas e sistemas de saúde no Brasil. Rio de Janeiro: Fiocruz; 2008. p. 463-505

Viacava F. Informações em saúde: a importância dos inquéritos populacionais. Ciênc. saúde coletiva. 2002; 7(4):607-621.

Viacava F, Almeida C, Caetano R, Fausto M, Macinko J, Martins M, et al. Uma metodologia de avaliação do desempenho do sistema de saúde brasileiro. Ciênc. saúde coletiva. 2004; 9(3): 711-724.

Viana ALd’Á, Ibañez N, Elias PEM, Lima LD, Albuquerque MV, Iozzi FL. Novas perspectivas para a regionalização da saúde. São Paulo Perspec. 2008; 22(1): 92-106.

Worthen BR, Sanders JR, Fitzpatrick JL. Avaliação de programas: concepções e práticas. São Paulo: Gente; 2004. 


\section{BIBLIOGRAFIA CONSULTADA}

Barata RB, Almeida MF, Montero CV, Silva ZP. Health inequalities based on ethnicity in individuals aged 15 to 64, Brazil, 1998. Cad. Saúde Pública. 2007; 23(2): 305-313.

Barata RB. Acesso e uso dos serviços de saúde: considerações sobre os resultados da Pesquisa de Condições de Vida 2006. São Paulo Perspec. 2008; 22(2): 19-29.

Barreto IFJ, Silva, ZP. Reforma do sistema de saúde e as novas atribuições do gestor estadual. São Paulo Perspec. 2004; 18(3): 47-56.

Barreto IFJ, Ferreira MP, Silva ZP. Pesquisa de Condições de Vida 2006: acesso aos serviços de saúde em áreas vulneráveis à pobreza. São Paulo Perspec. 2008; 22(2): 5-18.

Brasil. Ministério da Saúde. Norma operacional básica do sistema único de saúde - NOB SUS 01/96. Brasília (DF): 1997.

Brasil. Ministério da Saúde. Norma operacional básica de assistência à saúde - NOAS SUS 01/2001. Brasília (DF): 2001.

Brasil. Ministério da Saúde. Norma operacional básica de assistência à saúde - NOAS SUS 01/2002. Brasília (DF): 2002.

Consórcio Medicina-USP. Financiamento e gasto com saúde nos municípios paulistas com população superior a 100 mil habitantes (2000-2003). Cadernos de Atenção Básica: estudos descritivos - 2. São Paulo: Centro de Estudos de Cultura Contemporânea/Consórcio Medicina USP; 2006.

Figueiredo MF, Figueiredo AC. Avaliação política e avaliações de políticas: um quadro de referência teórica. Análise e Conjuntura. 1986; 1(3): 107-127.

Guimarães RB. Regiões de saúde e escalas geográficas. Cad. Saúde Pública. 2005; 21(4): 1017-1025.

Hartz ZMA. Avaliação dos programas de saúde: perspectivas teórico metodológicas e políticas institucionais. Ciênc. saúde coletiva. 1999; 4(2): 341-353. 
Ibañez N, Vecina GN. Modelos de gestão e o SUS. Ciênc. saúde coletiva. 2007; 12(Supl): 1831-1840.

Lima, CRA, Carvalho M S, Schramm JMA. Financiamento público em saúde e confiabilidade dos bancos de dados nacionais. Um estudo dos anos de 2001 e 2002. Cad. Saúde Pública. 2006; 22(9): 1855-1864.

Mendes A, Kayano J, Heimann LS, Junqueira V, Castro IEN, Ferreira MRJ, et al. Apuração do Gasto SUS Regionalizado no Estado de São Paulo. São Paulo: Instituto de Saúde; 2007. [Temas em Saúde Coletiva, 6].

Novaes HMD. Pesquisa em, sobre e para os serviços: panorama internacional e questões para a pesquisa em saúde no Brasil. Cad. Saúde Pública. 2004; 20(Supl 2): S147-S173.

Noronha JC, Lima LD, Machado CV. O sistema único de saúde - SUS. In: Giovanella L, et al., editores. Políticas e sistemas de saúde no Brasil. Rio de Janeiro: Fiocruz; 2008. p. 435-472.

Starfield B, Shi L. Policy relevant determinants of health: an international perspective. Health Policy. 2002; 60: 201-218. 